\title{
PERCEPTIONS OF RANGELAND DEGRADATION AND ITS CAUSES IN THE PERUVIAN ALTIPLANO DRY PUNA
}

A Dissertation
presented to
the Faculty of the Graduate School
at the University of Missouri-Columbia
In Partial Fulfillment
of the Requirements for the Degree
Doctor of Philosophy
CECILIA TURIN
br. Jere Gilles, Dissertation Supervisor
July 2019


(C) Copyright by Cecilia Turin 2019

All Rights Reserved 
The undersigned, appointed by the dean of the Graduate School, have examined the dissertation entitled

PERCEPTIONS OF RANGELAND DEGRADATION AND ITS CAUSES IN THE PERUVIAN ALTIPLANO DRY PUNA

presented by Cecilia Turin, a candidate for the degree of doctor of philosophy and hereby certify that, in their opinion, it is worthy of acceptance.

Professor Jere Gilles

Professor J. Sanford Rikoon

Professor Corinne Valdivia

Professor Tola Pearce 
Thanks, my beloved family and friends. 


\section{ACKNOWLEDGEMENTS}

I would like to thank to all professors and colleagues that in different ways made it possible for me to complete this document. My profound gratitude to professor Jere Gilles for all his teachings, thoughtful comments, and wise advice, not only on my research topic but also for my academic and non-academic life. I really appreciate his listening, his academic and family support and believing in my capacity.

My special gratitude to professor Corinne Valdivia, for her valuable friendship and teachings on how the world works from an economic point of view, sharing her knowledge and insights of rural communities in Peru. To professor Sandy Rikoon, for introduced me to integrated frameworks to study complex social and environmental problems. Those frameworks gave me the answers I was looking for long time ago. And to professor Tola Pearce, for her gender and minorities insights.

Infinite thanks to professor Carol Gilles for her wise tips to keep moving when I was getting stuck and for her caring. To my friends Bill McKelvey, Jill Lucht, Keith Jamtgaard and Rafael Esponda, for all their listening, companionship, caring and making me feel at home.

Thank you to the Puno people. To Roberto Valdivia and staff of the Research Center on Natural Resources and Environment (CIRNMA by its acronym in Spanish), for welcoming me in Puno and supporting me. My gratitude to comuneros of Apopata, Chocorasi and Lacotuyo that welcomed me in their homes during fieldwork, for all their wisdom, sharing, and life lessons. Likewise, thanks to all the people at the different universities, research centers, government offices and other institutions that collaborated to provide information. In all the cases they were very interested and eager to contribute. 
Finally, I would like to thank Fulbright Peru, SANREM CRSP, Department of Rural Sociology, MU Graduate School and International Center, for their kind support, either financial or logistic, without which this research would not have been possible. 


\section{TABLE OF CONTENTS}

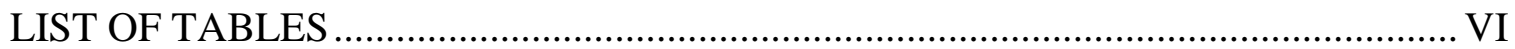

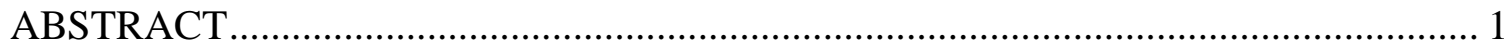

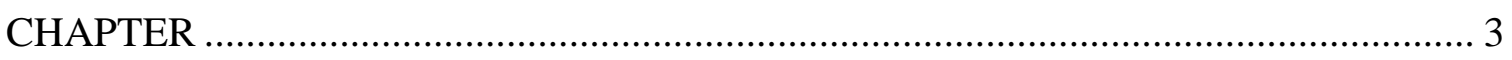

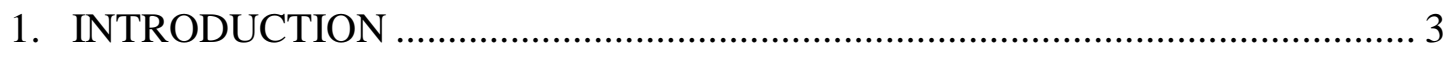

1.1. Andean rangelands and degradation........................................................ 3

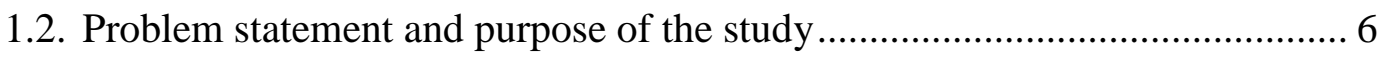

1.3. Objectives and research questions ...................................................... 7

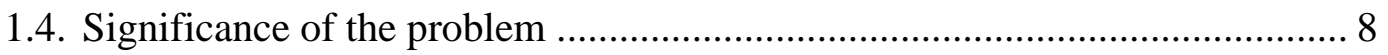

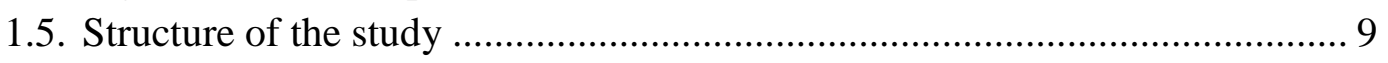

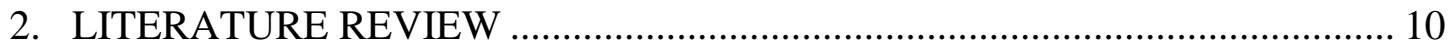

2.1. Rangeland science and rangeland degradation......................................... 10

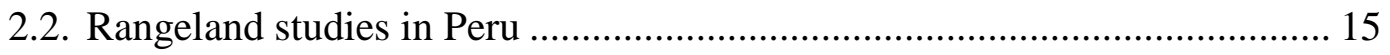

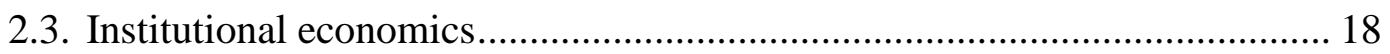

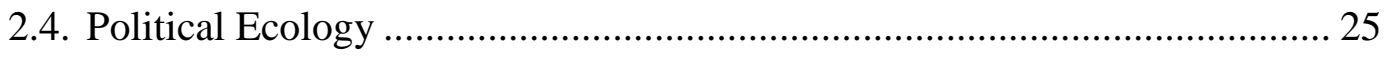

2.5. Actor-oriented interface analysis and life-worlds approach....................... 27

2.6. Pastoralists studies in Peru .................................................................... 29

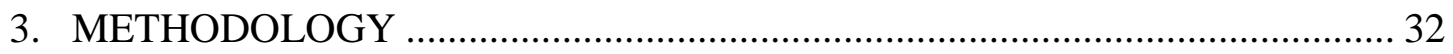

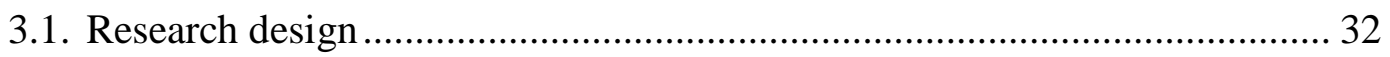

3.2. Selection of research sites and participants ............................................... 33

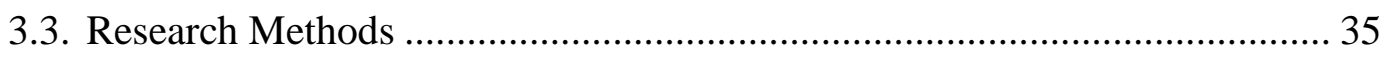

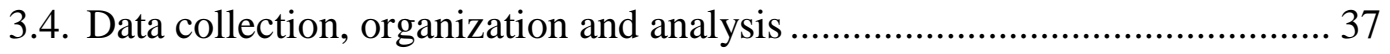

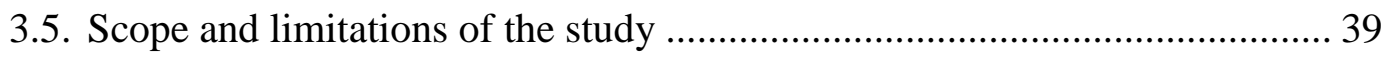

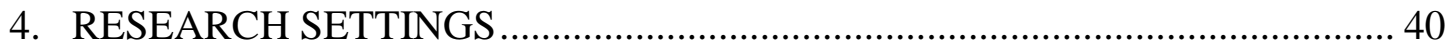

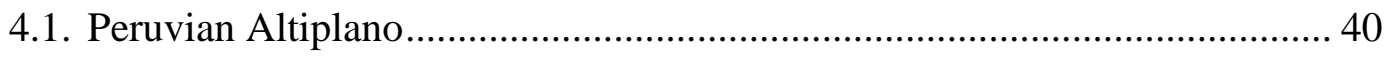

4.2. Peruvian Altiplano southern dry puna ...................................................... 43

4.3. Southern dry puna pastoralist production systems ................................... 47

4.4. Rangeland institutional and management framework ................................ 50

5. PERCEPTIONS OF RANGELAND DEGRADATION ..................................... 53

5.1. Perceptions of Rangeland Degradation by Stakeholders ............................ 53

5.2. Perceptions of rangeland degradation by pastoralists ................................. 64 
5.3. Different perceptions of rangeland degradation ..................................... 71

6. CAUSES OF RANGELAND DEGRADATION ........................................... 75

6.1 Perceptions of Causes of Rangeland Degradation by Stakeholders .............. 75

6.2 Perceptions of Causes of Rangeland Degradation by Pastoralists ............. 100

7. CONCLUSIONS AND RECOMMENDATIONS ........................................ 113

7.1 Perceptions of rangeland degradation .................................................. 114

7.2 Perceptions of causes of rangeland degradation.................................... 122

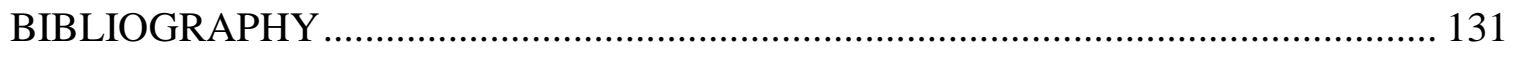

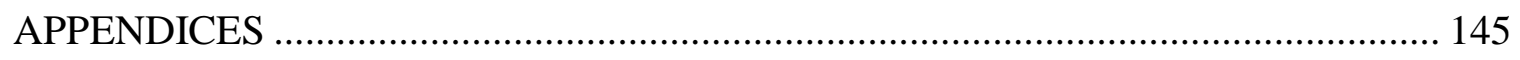

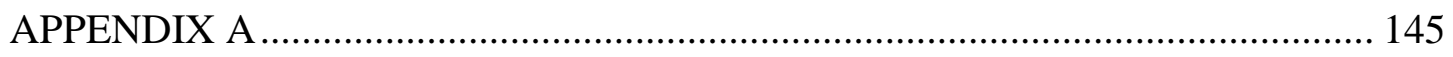

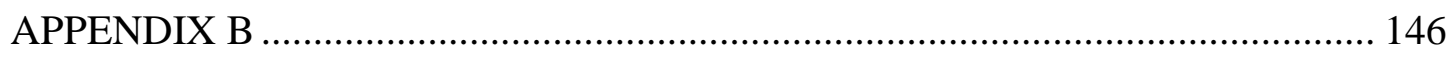

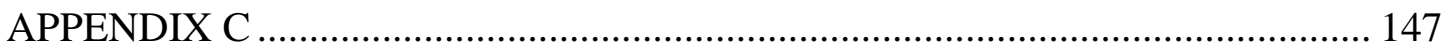

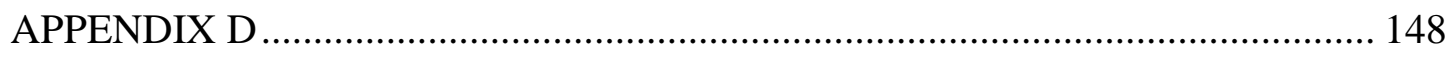

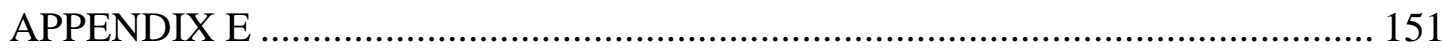

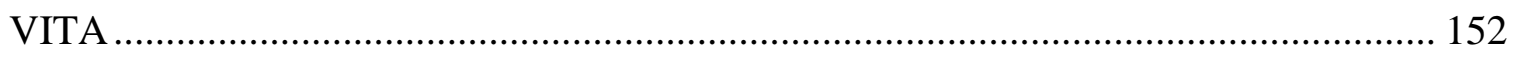




\section{LIST OF TABLES}

Table

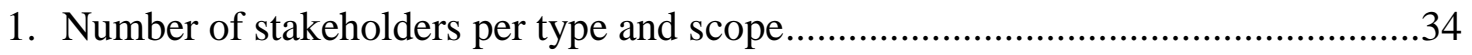

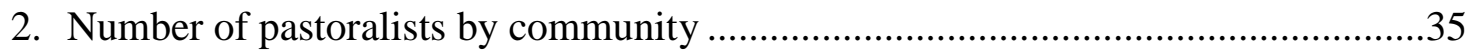

3. Perception of rangeland degradation by type of stakeholder ...............................54

4. Pastoralists' perceptions of rangeland degradation ...........................................65

5. Pastoralists' perceptions of rangeland condition .............................................65

6. Perceptions of main causes of rangeland degradation by stakeholders ..................76

7. Perceptions of main causes of rangeland degradation by scientists .......................77

8. Perceptions of main causes of rangeland degradation by government ...................77

9. Perceptions of main causes of rangeland degradation by NGOs ...........................78

10. Perceptions of other causes of rangeland degradation by stakeholders .................99

11. Perceptions of causes of rangeland productivity decrease by pastoralists .............101

12. Pastoralists climate change perceptions related to rangelands decline .................102 


\title{
PERCEPTIONS OF RANGELAND DEGRADATION AND ITS CAUSES IN THE PERUVIAN ALTIPLANO DRY PUNA
}

\author{
Cecilia Turin
}

\author{
Dr. Jere Gilles, Dissertation Supervisor
}

\begin{abstract}
This qualitative case study investigated rangeland degradation in Peru by better understanding the social component of the Altiplano dry puna rangeland systems. Participants' perceptions of rangeland degradation and its causes were collected from Aymara pastoralists in the Southern altiplano communities of Apopata, Chocorasi and Lacoutyo, and stakeholders consisting of scientists, government officers and NGO's representatives, using structured and semi-structured interviews and participant observation. Findings included that while stakeholders believed that rangeland degradation is severe and widespread, pastoralists believed that degradation is moderate and localized. Likewise, while stakeholders believed that rangeland condition is mostly poor and very poor, pastoralists believed that it is mostly fair. Different participants' perceptions were related to the use of different indicators. While stakeholders focused more on vegetation changes, pastoralists focused more on animal production.

Perceptions of the causes of rangeland degradation were also different. While stakeholders believed that the major cause of degradation was overgrazing through overstocking and inappropriate management, pastoralists believed that the major cause was climate change. Although land fragmentation was a secondary cause for both groups, it was found that was an important driver of degradation. The different participants' perceptions responded to different actors' lifeworlds. Pastoralists' lifeworlds are constructed through their daily experience, while stakeholders' lifeworlds are influenced by the traditional range condition and trend model. The main implication
\end{abstract}


of the research findings is that stakeholders' perceptions lead to inaccurate livestock development and rangeland conservation policies and programs. 


\section{CHAPTER}

\section{INTRODUCTION}

\subsection{Andean rangelands and degradation}

Peru has around 18 million hectares of rangelands, occupying a third of the national territory. Andean rangelands of Peru support $85 \%$ of the national herd population that make up the grazing livestock systems and are therefore the main feeding source for $80 \%$ of cattle, $96 \%$ of sheep, and the totality of camelids (Ministerio de Agricultura y Riego MINAGRI, 2012). Grazing livestock systems of cattle, sheep, or camelids are the primary livelihood for about 4 million Andean highlands inhabitants. Those systems are especially important for the economy of poor subsistence pastoralists living above 3800 meters, locally known as puna region, where agricultural land is not available.

Andean rangelands are distributed in the highlands from north to south. They are lower, narrower, and steeper toward the north and higher, more extensive, and flatter toward the south, covering altitudes between 3500 and 5200 meters above sea level and spanning the agroecological zones suni and puna. (MINAGRI, 2012). Livestock and grazing patterns also vary from north to south. Toward the north, Andean rangelands are grazed by cattle, the main livestock in the lower lands. Toward the south, Andean rangelands are grazed mostly by South American camelids and sheep. About 1.5 million of pastoralists of puna of the central and southern Andean regions of Peru depend exclusively on raising alpacas for a living.

The Peruvian Altiplano, located in the south of the country, has $20 \%$ of the rangelands and almost $50 \%$ of the livestock population of the country; it contains the 
largest population of camelids. Those pastoral systems are small-scale subsistence systems producing mainly wool and meat. This population is among the poorest in the country, lacking access to basic living amenities like electricity, clean water, education, and health.

Andean rangelands are also important because of the ecological and socio-cultural roles they play as a part of Andean ecosystems. Andean rangelands have various uses and provide multiple socio-cultural, economic, and environmental goods and services. This ecosystem provides benefits like soil protection, biodiversity, water retention and infiltration, carbon sequestration, beautiful landscape, wildlife refuge, etc. Rangeland systems are especially important in their functioning as water reservoirs and habitats for biological and cultural diversity. Thus, rangeland systems are key resources in times of climate change, global warming, water scarcity, and desertification threats. Other goods and services associated with rangelands are conservation of plant and animal biodiversity, climate regulation, soil maintenance, nutrient recycling, and erosion control. Rangelands of puna protect the soil from natural erosion and retain water. The soils of those ecosystems store important carbon stocks.

However, experts generally perceive that Andean rangelands are overexploited and have been undergoing degradation for many years. This situation puts at risk not only the livelihood of millions of poor pastoralists, but also future water provision. Experts believe that overgrazing is the main driver of degradation. Rangeland degradation was defined as the decline in the primary and secondary productive capacity of rangelands to support livestock (IFAD, 2007). It is a type of land degradation that can result from the presence of excessive livestock populations and inadequate pasture 
management (FAO, 1994). Hence, overgrazing has always been considered the most pervasive cause of irreversible rangeland and land degradation (United Nation Environment Program UNEP and World Resources Institute, as cited in IFAD, 2007; FAO, 1993).

The study of rangelands degradation in Peru has not been consistent. Rangeland degradation is estimated from measurements of rangeland condition. There is no updated information about rangeland conditions and the degree of degradation at the national level from Peruvian official sources but there are estimations. Estimations conducted in the 80 's and 90 's showed that rangelands condition at the peasant community level was $10 \%$ good, $28 \%$ fair, and $62 \%$ poor, while the conditions estimated for private enterprises were $1 \%$ excellent, $28 \%$ good, $50 \%$ fair, $21 \%$ poor (Florez \& Malpartida, 1988). Range experts at that time concluded that there was serious rangeland degradation process and the worst conditions corresponded to the lowest level of organization and subsistence economies, the peasant communities (Flores, 1996; Lozada, 1991).

Later estimations in the 2000's showed that the amount of rangelands in very poor condition increased and the area in good and fair conditions decreased (12\% good, $24 \%$ fair, $50 \%$ poor, and $14 \%$ very poor) confirming the increasing trend of degradation given previously (Recharte et al., 2002). Lately, the national research institute (Instituto Nacional de Innovacion Agraria INIA, 2012) has estimated that around 50\% of Andean rangelands are undergoing a serious degradation process, presenting a negative tendency to continue deteriorating. Likewise, current range experts' estimations indicate that at least $60 \%$ of Andean rangelands are in poor condition that are found at the peasant community level, and that land used by private enterprises is in better condition. It was 
also estimated that the most severe cases are located in the southern Andes and at the highest altitudes such in the Altiplano. Rangeland degradation in the Altiplano is a serious problem. Range experts indicate that rangelands of the southern Altiplano region present the worst cases of degradation. Experts state that the main cause of Andean rangeland degradation is overgrazing due to mismanagement (Florez \& Malpartida, 1988; Florez \& Bryant, 1990; Lozada, 1991; E. Flores, 1996; Recharte et al., 2002). Range experts base their estimations on evaluations of the ecological component of rangeland systems. Their range models only focus on vegetation. However, rangeland systems also have a social component that has been poorly studied and understood.

The objective of this research is to explore and understand rangeland degradation in the Peruvian Altiplano rangelands; specifically, the situation with the dry puna is the focus of this research. This qualitative case study is based on the perceptions of Altiplano dry puna users and stakeholders of rangeland degradation and its causes. To analyze the rangeland problem, we use more comprehensive and integrated approaches and frameworks like social-ecological systems, institutional economics, political ecology, and actor-oriented analysis.

\subsection{Problem statement and purpose of the study}

According to academic and official sources, the Peruvian Andes are undergoing rangeland degradation processes that are getting worse over time. Most efforts to understand the process come from natural sciences perspectives and propose technical solutions. There has been little attempt to understand the problem using integrated analytical approaches. Efforts done from the social perspective lack integrated 
comprehensive analysis in search of alternative ways to address the problem. There is little information and understanding about the social, political, economic, and even natural processes are related to rangelands degradation.

The purpose of this study is to contribute to a better understanding of the social component of Altiplano rangeland systems, challenge overgrazing and mismanagement as the only causes of degradation, and to consider all possible causes and human drivers, from sociological and institutional perspectives.

\subsection{Objectives and research questions}

To address the purpose of the study, objectives are to:

1. Explore and describe the perceptions of rangeland degradation of pastoralists of Altiplano dry puna, and stakeholders involved in the rangeland arena of the Andes and Altiplano.

2. Explore and describe the perceptions of the causes of rangeland degradation of pastoralists of Altiplano dry puna, and stakeholders involved in rangeland arena of Andes and Altiplano.

3. Based on these perceptions, analyze rangeland degradation from more integrated and comprehensive approaches.

To meet the objectives of this study, the following research questions are asked:

1. What are the perceptions of rangeland degradation of pastoralists and stakeholders and to what degree is degradation a problem? 
2. What are the causes of rangeland degradation in the Peruvian Altiplano and the rest of the Andes according to the different actors involved in rangeland management and governance?

3. What are the implications of perceptions of rangeland degradation and its causes for interventions?

\subsection{Significance of the problem}

Since the major droughts of the 70s, combating rangeland degradation has been on the agenda of the development community (IFAD, 2007). Rangeland degradation became a world concern not only because of its contribution to the global desertification process (United Nations Convention to Combat Desertification UNCCD, 1994; UNCOD, 1977) but also because it is a principal constraint against sustainable development and food security of poor pastoral societies in developing countries (Agenda 21-UNCED, 1992). In this sense, substantial research to understand degradation and interventions to combat desertification have been conducted in African and Asian countries but not with the same intensity in other regions. Rangeland degradation in the Peruvian Andes puts the sustainability of the livelihood of present and future generations of pastoral and agropastoral populations at risk since they depend directly on them. The potential desertification of the Andean ecosystems threatens the availability of water sources coming from the high Andes to the whole country. Eventually, it also threatens the wildlife of the Andes. The scene situation gets worse as climate change has a tremendous impact on the high Andes and the Altiplano. This study will contribute to increased knowledge of rangeland degradation in the Peruvian Andes with important implications 
in other countries of the Andean region. It will highlight the need for the development of mechanisms for conservation direct users and stakeholders contributing alternative solutions. It will provide useful information to enlighten policy makers and governments to improve policies. Lastly, it will also contribute to the literature on natural resources governance.

\subsection{Structure of the study}

The study consists of seven chapters. Chapter One introduces the rangeland degradation problem in the Peruvian Altiplano dry puna and lists the problem statement, purpose, research objectives, and questions, as well as the justification for this research. The second chapter presents the literature consulted for theoretical framework. Chapter Three describes the methodology and Chapter Four the settings for this research. Chapter Five presents the perceptions of rangeland degradation by the different actors. Chapter Six presents the perceptions of causes of rangeland degradation provided by the different actors. Chapter Seven present the conclusions of the study and recommendations for further research. 


\section{LITERATURE REVIEW}

This chapter introduces the theories and approaches used to understand and analyze the problem of rangeland degradation in the Altiplano dry puna. First section presents an overview of rangeland science, and how models to understand rangelands evolved, and so the concepts of rangeland degradation. The next section describes the approaches in social sciences to assess situations of natural resources management and degradation. This includes institutional economics, political ecology, and actor-oriented analysis. The last section presents the state of art of rangeland studies in Peru from both views: ecological and human.

\subsection{Rangeland science and rangeland degradation}

Three models explain rangeland systems: one is based on equilibrium models of nature and the other two are based on non-equilibrium models. The Range Condition and Trend model (RC\&T) proposed by Sampson (1923) emphasizes human activity as the main cause of change in rangeland condition. This is because this model assumes that rangelivestock systems operate in stable environments, minimizing the effect of climate variability. This model, also known as the western or tradition model of range management, derives from the climax concept of the Clementsian theory of succession (1916), developed to explain the dynamics of North American prairies. RC\&T implies that rangelands have a potentially stable state and are under total control of the range manager (Ellis 1992). In this sense, carrying capacity and stocking rate became important concepts that materialized into management practices to keep rangelands in 
good condition or in good health (Ellis, Coughenour, \& Swift, 1993). Likewise, rangeland condition becomes a powerful tool to evaluate rangeland health or degree of degradation, and subsequently, users' management performance.

On the other hand, recognizing that not all rangelands exist under stable conditions Ellis and Swift (1988) proposed the Non-Equilibrium model. This model emphasizes the role of climatic variability in regulating or limiting the animal population through frequent climate perturbations, as well as influencing vegetation production and status by reducing the impact of animals on vegetation. This model has been especially useful in explaining rangelands under conditions of environmental uncertainty like those of arid and semi-arid areas (Ellis, 1992, 1994; Ellis, et al., 1993; Scoones, 1994). This model revealed that some rangeland systems are heavily determined by environmental conditions; user's management has minimal chances to transform the land.

The State and Transition model (S\&T) emphasizes both human activity through grazing pressure and climate variability or other unusual perturbation (Westoby et al., 1989). In this model, rangelands are sets of multiple stable states; transitions result from interactions between grazing and irregular events (e.g. drought or fire) in the short term or changes in management practices (e.g. grazing) in the long run. These changes push rangeland systems over thresholds to new states or into new periods of transition. Here, rangelands do not necessarily return to a higher state of succession or better range conditions if released from grazing (Wessels et al. 2007).

Rangeland models were developed to understand rangeland dynamics under different environments and management circumstances. The RC\&T model was hardly criticized because it was efficient for rangelands in equilibrium, of which there are fewer 
in the world, but inaccurate for non-equilibrium rangeland systems, which are the most common. In this sense, the last two models evolved in response to the limited applicability (both on a practical and theoretical basis) and growing dissatisfaction with the RC\&T model for arid and semiarid rangelands.

Although the non-equilibrium models were developed toward late 80 's, the RC\&T model has continued to be the most influential on range experts, range-livestock development projects, and policies for the last 50 years (Ellis 1992). Briske (2017) explains this happened due to changes in scientific priorities and approaches to range science in the early 90 's. Without funding for further development, research, and training of new generations of range experts, range science declined. In this sense, validation of alternative non-equilibrium models in other world rangeland areas was postponed for two decades, and so their operationalization. Thus, the S\&T model was only considered in 1994 by the Rangeland Health Report ${ }^{1}$ as an alternative rangeland assessment to replace RC\&T model. It was adopted in 1997 by the NRCS ${ }^{2}$, and finally was included in 2010 in the Ecological Site Descriptions Framework for rangeland assessment (Briske 2017). Although the S\&T model has been largely diffused and incorporated in many countries in recent years, in developing countries like Peru, RC\&T continues to be the most influential.

Rangeland models only focus on the ecological component of rangeland systems; however, they also have a social component. Despite rangeland systems are ecological and social systems, generally they have been studied as if they operate independently. Thus, on one hand there are range ecology and management studies, and on the other, there are

\footnotetext{
${ }^{1}$ United States National Research Council

${ }^{2}$ National Resources Conservation Service - NRCS of United States Department of Agriculture - USDA
} 
pastoralists studies. Most research and land management policies are based predominantly on either ecological or social phenomena and problems. Ostrom (2009) argues that independent studies arrive to independent views of a problem and different solutions. Likewise, single-discipline thinking leads to policies which either fail to address the problem or cause unintended consequences. (Huska et al. 2017 in Briske, D. 2017). Environmental problems, like rangeland degradation, arise from failures in social processes as much as from ecological processes, and therefore, a common framework is needed (Ostrom, 2009).

Thereby, there is a crucial need to understanding the social and ecological components, interactions, and processes that shape rangeland conditions including the social, economic, cultural, and political attributes of the people and communities within rangeland system. In response to that, related disciplines contribute with concepts that improve the framework. Thus, from natural resources management models, ecosystem management contributes with adaptive management which included to the framework adaptive management and ecosystem services. Likewise, resilience theory changed the way of thinking and replaced the previous non-equilibrium ecology by more appropriate multiple equilibria states. Socio-Ecological Systems (SES) is a conceptual framework designed to keep both the social and ecological components of a system in focus so that the interactions between them can be scrutinized for drivers of change and causes of specific outcomes (Ostrom 2009). Resilience is a property of Socio-Ecological Systems (SES). A recent model, resilience-based management model recognizes the inevitably of change and seeks to guide change to sustainably provide multiple ecosystem services for 
society. This model embraces ecological and social changes and says that manage should anticipate and guide change rather than minimize (Briske, 2017).

\section{Rangeland condition and degradation}

Rangelands condition is a technical term used by rangeland experts to refer to the present state of vegetation at a determined grazing location in relation to the climax (natural potential) plant community for that site. Rangeland condition expresses a relative degree of the types, proportions, and amount of plants in a plant community compared to the vegetation of the climax plant community for the site. Rangeland condition is not a subjective visual observation, but an objective measurement (Briske, 2017). Rangeland condition is determined through an evaluation of the potential production of vegetation in response to grazing. For this reason, vegetation is classified in three groups: desirable or decreasing plants, increasing plants, and invader plants. Plants of the first group are considered highly palatable and are desired by animals; they grow with proper land management land but decrease with overgrazing. Plants in the second group are less palatable and less desired by animals. This group of plants increases and replaces plants in the first group with overgrazing, but in the case of persistent overgrazing this group of plants could also decrease. Plants in the third group do not belong to the original vegetation community. They are unpalatable to animals and occupy the same ecological niche as plants in the second group. Thus, these plants increase with overgrazing. When overgrazing is persistent, they replace plants in the first and second groups, giving place to a new plant community different from the original. 
Rangeland experts recognize four categories of rangelands condition: excellent, good, fair and poor. Those categories are based on the proportion of type of vegetation present at the site. Thus, rangelands in excellent condition present more plants in the first group of palatable, in fair condition present more plants in the second group of less palatable, and in very poor condition present more plants in the third group of nonpalatable or invader (Florez, 2005). There is a high correlation between good condition and high forage productivity. The condition of rangelands is used to determine the number of animals that can graze in a certain area, making it possible to propose grazing plans. The good condition of rangelands also indicates the good condition of the soil and water infiltration capacity of the land. Thus, improved rangeland condition means that the infiltration capacity of the land has increased, and soil erosion has decreased. Range condition has been used as a powerful tool to determine rangeland health. This tool has been used also to determined degrees of degradation. Thus, it has been assumed that rangelands in poor condition are degraded or in risk of degradation.

\subsection{Rangeland studies in Peru}

In Peru, rangeland degradation of the Andes has been in the scientific discourse and teaching in the academic arena for the past years. It is thought that rangeland degradation in the Peruvian Andes began during the Spanish colonization with changes in land distribution and use and in the type of grazing livestock: from South American camelids to sheep. It is also believed that degradation was intensified in the early republican times with the expropriation of the better lands from indigenous communities and the consolidation of these lands into landgrants (haciendas), leaving indigenous people the 
marginal fragile lands of puna for their grazing (Lozada, 1991; Recharte, Albán, Arévalo, Flores, Huerta, Orellana, Oscanoa, Sánchez, 2002). Andean rangelands in Peru were studied from the 70 's to the 80 's by local and foreign scientists with international support and cooperation. Unfortunately, this work was interrupted by the violent social climate at the end of the 80's (Lozada, 1991).

Rangeland scholars stated that overgrazing happened due to overstocking in the Andes. It was estimated that the current livestock population is double the number the carrying capacity of the Andean rangelands can support (Flores, 1996; Florez \& Bryant, 1990; Recharte et al 2002). They explain this is the result of population growth as new families join the communities (Lozada, 1991; MINAG, 2008). Peasant's mismanagement includes inadequate grazing management practices, lack of protective practices, and changes in land use (Lozada, 1991; E. Flores, 1996).

Other scholars focus on pastoralist's limitations and constraints related to rangelands management. Other causes of rangeland degradation attributed to pastoralists are land tenure type and loss of indigenous knowledge. They also lack organizational capacity, access to technical assistance (provided by the government), capacities for technology adaptation, reinvestment capacities, and norms and rules for range management (MINAG, 2008). Others argue that causes of rangeland degradation in the Andes also include external aspects affecting rangelands management. Although they are recognized as possible drivers connected to degradation, almost no effort has been done to understand them. Thus, external factors contributing to the rangeland degradation are the fragility of the Andean ecosystems, the society and government's insufficient 
knowledge about Andean rangelands, and the lack of legislation to regulate the use and conservation of rangelands (Flores, 1996; Lozada, 1991; Recharte et al., 2002).

Other external drivers of rangelands degradation are related to the interventions of the Peruvian government and non-governmental organizations (NGOs). Their most promoted alternative for improving rangeland conditions and dealing with degradation has been the introduction of cultivated pastures. This technology failed in the Andean highlands due to the socio-economic conditions of pastoralists as well as geographic constraints. However, it has been used extensively as a political tool and is of high interest to pastoralists. Consequently, pastoralists value the cultivated pastures that have been introduced rather than native grasslands. This devaluing of rangelands also has influenced peasants' values, knowledge, and practices and therefore their rules for rangeland management (Gilles \& Jamtgaard, 1988). Although the degradation of rangelands ecosystem has been linked to the ways that pastoralists communities are organized and the land tenure, the relationship between the government actions, policies, and its performance in the sector about rangeland degradation have been little explored (Flores, 1996; Recharte et al., 2002). Thus, rangeland degradation in Peru seems to be a complex social and economic problem for people considered the poorest and most marginalized in the country. The political ecology approach could help to analyze this complex problem. 


\subsection{Institutional economics}

\subsubsection{Tragedy of commons paradigm: The overgrazing theory}

When Hardin (1968) formulated his tragedy of the commons and presented a scenario of grazing commons where a herder, as a rational self-interested actor, in the absence of rules, feels motivated to graze as many animals as he wants for his own benefit because he thinks that other herders will do the same. In this scenario individuals do not cooperate to arrive at sensible outcomes (rules) that maximize the benefits for everybody in the long term. This scenario neither includes external forces driving herders' decisions nor natural process driving degradation. Hardin, influenced by Malthusian population growth theory and equilibrium models of nature, argues the need for external intervention and proposes government, as the central authority, is called to regulate those resources. In absent of government intervention, he forecasted that the future of those grazing commons is one of degradation and depletion. Based on that theory, it was argued that everybody's property is nobody's property so as an external intervention privatization of grazing lands was proposed (Gordon, 1954, cited in E. Ostrom 1990). Hardin's theory centers on overgrazing because it proposes only human factors as drivers of degradation without considering other factors. Gilles and Jamtgaard, (1981) state that it was unfortunate that Hardin used rangelands (a type of grazing commons) to explain his theory because it led to ill-conceived intervention strategies. Many governments influenced by international policies based on Hardin's tragedy of the commons have tried to privatize rangelands and other common property resources around the world. However, most of those interventions have failed to prevent degradation, and often they have contributed to it (Runge, 1992). The grazing commons were used only as an example to describe what 
would happen to natural resources in a situation of no control at all. However, almost no grazing areas in the world are open access resources. Most of them are common, state, or private property, meaning that they have specific user(s) and owner(s), and therefore there are rules or institutions that regulate their use (McKean, 2000). Hardin's theory has influenced rangeland policies worldwide.

Many people think that common property resources are equal to open-access resources because they share many characteristics. Consequently, many people think that common property resources lack institutions for management and are therefore exposed to degradation. Studies about rangelands degradation in different regions of the world have demonstrated that overgrazing and pastoralists' mismanagement are not the only causes of degradation. Other causes reported in eastern Africa were frequent and prolonged droughts (Kassahun et al. 2008; Solomon et al., 2007), decreased mobility (Baars \& Aptidon, 2002), and an increased use of grazing land for cultivation (Solomon, et al., 2007). Moreover, it was found that degradation is a consequence of the implementation of development policies and initiatives emphasizing the commercial aspect of livestock farming and privatization by governments and NGOs.

Those policies, influenced by the tragedy of the commons and modernization concepts, try to avoid free access to rangelands, excess animal numbers, and subsistence modes of production. However, these policies destroyed traditional transhumant patterns because the rules pastoralists have for sustainable rangeland management were misunderstood or ignored. The multi-purpose goals of traditional pastoral systems resulted in the weakening or destruction of local rangeland tenure and management institutions (Forstater, 2002; Ogbaharya, 2007; Rohde et al., 2006). Similarly, studies in 
China indicated that main causes of rangeland degradation were mismanagement and overstocking as a result of a lack of technical management and population growth (Zhaoli, Ning, Dorji, \& Jia, 2005). However, further analyses of the causes of overstocking and overgrazing in China and Mongolia indicate that government interventions with the introduction of inappropriate technologies and changes in politics over time have also contributed to rangeland degradation (Fratkin, 1997; Ho, 2001; Mearns, 1996; Upton, 2005; Zhaoli, et al., 2005).

\subsubsection{Socio Ecological Systems. Natural resources governance institutions}

Ostrom (2009) argues that environmental problems, like rangeland degradation, arise from failures in social processes as much as from ecological processes. Recognizing this, a common framework is needed for understanding and analyzing the drivers that lead to improvement or deterioration of natural resources (Briske 2017). For Ostrom and other scholars, degradation results from institutional mismanagement. Major role of institutions in new economic institutions is to reduce uncertainty and reduce transaction costs. Those rules may be respected, violated, reproduced, broken down, adapted, or evolve according the situation. Every society or community has a set of rules or norms to maintain order and structure human interactions. They may be formal laws or informal conventions that structure human transactions, whether political, social, or economic. They regulate, reward, or sanction certain human behaviors according to their specific purposes (North, 1993). For Ostrom (1986), institutional rules are prescriptive statements that forbid, require, or permit some action or outcome. Thus, any action or outcome that 
is not required or forbidden is permitted. Consequently, the absence of a rule forbidding or requiring an action is logically equivalent to the presence of a rule that permits it.

Similarly, a common pool resource (CRP) situation in which no one is forbidden or required to take any action is logically equivalent to a CPR situation in which everyone is permitted to take any and all actions. The rules governing such situation are all default rules. The cost of changing rules varies substantially from one rule to another, from one political regime to another, and from one level of analysis to another, and they also vary over time as participants and conditions change (Ostrom 1990). Ostrom (1990) conducted an institutional analysis of CRP institutions using game and collective action theories combined with empirical studies. She concluded that common property institutions do not work well in some cases because they are not able to deal with opportunistic behavior or the free rider problem. Based on her conclusions, she proposed a framework she calls "getting the institutions right".

She believes that users, without the need for an external enforcer, collectively organize themselves to create institutions for managing resources. Users are selfmotivated to organize because their interests include the welfare of all appropriators and a sense of community. This is a multilevel form of collective action because it includes decisions at different levels (local, regional, national, international) which implies rules or institutions at different levels.

Ostrom (2009) argues there is no one right model in collective action, there are no formulas to make the institutions function optimally, but based on her experience, she suggests some principles for the getting the right institutions. For her, a good governance of CRP should include: 1) clearly defined boundaries for users and for the resources, 2) 
the right rules for the right place and right time, 3) flexibility for making adjustments, 4) monitoring, 5) graduated sanctions, 6) mechanism to deal with conflicts, 7) autonomy for users to modify rules, and 8) a platform for larger systems. She explains that this process is time-consuming, conflict-provoking, and it involves larger political institutions, culture, and economic environments in which those resources are embedded. Local knowledge must be preserved and passed along from one generation to the next. Thus, she also argues that appropriate institutions include efficiency, sustainability, and equity for the individuals who benefit from them and the environment.

However, some scholars do not share Ostrom's enthusiasm referring to CPR. Some argue that management of the rangelands is more complex than other CPR regimes (Behnke, 1995, cited in Carney \& Farrington, 1998). Particularly in countries where there is no state regulation, pastoralists constantly shift usage rights have mixed tenure regimes. This behavior has proved to be both resilient and successful in managing access, demonstrating that resource boundaries are permeable and ill-defined. Therefore, they do not fulfill the conditions of successful common property regimes as conceptualized in Ostrom's framework (Carney \& Farrington, 1998).

On the other hand, it has been argued that it is incorrect to assume that free rider behavior is dominant in common property resource management. Although there are individuals who do not respect rules and try to take advantage of others, this is not the general behavior. Most try to respect institutional policies but, given the uncertain conditions under which CPR develops, the problem is not the free rider but the lack of incentives to keep institutional arrangements. This is an assurance problem that should be solved with external intervention (Runge, 1992). The presence of institutions for CPR 
management does not ensure they are working properly. Successful cases of CPR management were found in alpine grazing meadows in Switzerland and in an irrigation system in Spain, whereas other cases such as a forest in Japan and an irrigation system in the Philippines were found to be unsuccessful (Ostrom, 1990). Especially in developing countries, like in cases reported from the Sahel and southern Africa, it has been argued that mismanagement of CPR is caused by traditional institutions that fail to address issues (Runge, 1992).

McKean (2000) argues that the problem with privatization is that is unclear to whom property rights should be vested, which rights should be transferred, and which natural resources should be dealt with in this way. In addition, Ostrom (1990) argues that both external ways to regulate CPR imply a cost that increases the transaction cost of common property management and it is not clear who assumes this cost. In the case of alpine grazing meadows in Switzerland, villagers tailor their rules to deal with communal tenure in high mountain meadows and forests as factors in fragile ecosystems. She found that rules vary depending on the abundance or scarcity of resources. Villagers have kept old rules from the 1200's that considered important geographic features. In those rules division of land was prohibited to avoid degradation and so they came up with strict rules to access the resources. Villagers understood that the capacity of the ecosystem and natural resources was limited. Thus, they agree to use according to its capacity, which in this case is low. They understood that the only way to have some benefit from those resources was extracting little and protecting them, to ensure the resource for the future (Netting, 1976, in Ostrom 2000). They dealt with scarcity by sharing fewer resources rather than using resources in ways that are unsustainable. They cooperated because it 
was more advantageous to earn a little than nothing. They could decide not to cooperate and try to take advantage of others, but this was not sustainable because if all users decided to take the same approach, resources would soon be depleted and no one would benefit further.

Ostrom (2000) explains that institutional performance is robust when the rules are fair, fragile when rules are followed inconsistently, and failing when rules are not enforceable. The law does not necessarily prevent depletion of natural resources. Local norms of users are more effective for sustainability. Experience and legacy in tailoring norms are important because a common understanding and use of the norm grew over time and is now widely practiced (Acheson, 2003 in Ostrom, 2007). Ostrom (2000) indicates that institutions should address the following questions at appropriate times: 1) What patterns of interactions and outcomes, such as overuse, conflict, collapse, stability, and increasing returns, are likely to result from using a particular set of rules for the governance, ownership, and use of a resource system and specific resource units in a specific technological, socioeconomic, and political environment 2) What is the likely endogenous development of different governance arrangements, use patterns, and outcomes with or without external financial inducements or imposed rules? 3) How robust and sustainable is a particular configuration of users, resource system, resource units, and governance system to external and internal disturbances? Ostrom (2003) found that users' commitment is important for developing an environment conducive to the selection of norms, rules, and property rights to enhance the performance of communal property-rights systems. Thus, in the case of the Swiss villagers, participants planned to 
live and work in the same area for a long time and in some cases, expected their offspring to live there as well (Grima and Berkes, 1989).

\subsection{Political Ecology}

Political ecology is a way to understand the complex relations between society and nature through a careful analysis of the forms of access and control over resources and their implications for environmental health and sustainable livelihoods (Watts, 2000, in Robbins 2004). It is an interdisciplinary analytical approach that combines the concerns of political economy and cultural ecology to explain in an integrated way conflicts that arise from human and environmental interactions in cultural, political and inherently complex environments (Blaikie \& Brookfield, 1987; Greenberg \& Park, 1994). From the political economy view, scholars working from a political ecology perspective address the need to analyze those conflicts from the perspective of minorities and the less privileged in a social structure. In this sense, political ecologists are interested in understanding the distribution of power between capitalist and production centers and to what extent the uneven development in developing countries is attributed to their historical integration and dependence on capitalism and global market. They are also interested in understanding how modes of production were penetrated, subordinated, transformed, or destroyed when they come in contact with the world economy.

From the cultural ecology perspective, political ecology is influenced by chaos theory adopting a broader vision of environmental relationships to explain the evolution and adaptation of cultural practices and institutions in relation to ecological systems and development through time (Greenberg \& Park, 1994). In this sense, political ecology 
challenges the arguments of traditional ecology utilized to justify conservationist interventions against local/native populations. It also exposes the contradictions of globalization and the consequences of the global ecology (Robbins, 2004). As a mode of research, political ecology provides an integrated and comprehensive analytical framework informed by theories such as common property theory, green materialism, peasant studies, feminist development studies, discourse theory, critical environmental history, and postcolonial theory (Robbins, 2004). This permits the study of a variety of issues such as community collective action, the role of human labor in environmental metabolism, the nature of risk-taking and risk-aversion in human behavior, the diversity of environmental perceptions, the causes and effects of political corruption, and the relationship between knowledge and power (Robbins, 2004). Thus, political ecology has been very useful for explaining social and environmental conflicts in terms of the battles of knowledge, power, practice, politics, justice, and governance (Watts, 2000, in Robbins 2004). Political ecology has also been useful for explaining how environmental change constrains local and regional production choices within global and political economic forces, particularly in developing countries and rural contexts (Blaikie \& Brookfield, 1987).

The analysis includes different actors' perspectives according to their socioeconomic characteristics of class, ethnicity, or gender, within the context of a specific geographic region (Bryant \& Bailey, 1997). Political ecology recognizes the importance of including spatial and temporal scales. Political ecology tries to make political arguments of important human-environmental problems that have been treated in an apolitical way. For example, CPR inherently involves multiple scales of power, diverse 
actors, multiple scales of economic structure, and a broad historical trajectory of socioeconomic change, lack of the political analysis.

The authors of Global Political Ecology (Peet, Robbins, \& Watts 2011) state that farming practices traditionally have been viewed as the cause of soil degradation and as the major environmental problem. They explain that especially farmers in developing countries, lacking political representation, overexploit their soils and resources when production margins are slim, prices are low, labor capacity is low. Household income is limited due to the process of because they sell raw products and do not benefit from value-added commodification of their products. In other words, subsistence-level farmers tend to overexploit their resources to maximize income when entering highly competitive global markets, but when farmers are fairly compensated, they reinvest in their lands. Thus, political ecology shows that environmental degradation is not an unfortunate accident under advanced capitalism; instead, it is a part of the logic of that economic system (Peet et al., 2011).

\subsection{Actor-oriented interface analysis and life-worlds approach}

Long's (2003) in its “Development sociology: actor perspectives" framed the term of “actor-oriented analysis" but Faysse (2018) argues that the interface analysis suits better this approach. Interface is defined as a critical point of view of intersection or linkage between different social systems, fields or levels of social order where structural discontinuities, based upon differences of normative value and social interest, are most likely to be found (Long 1989). 
Long (1989) argues that the concept of "social interface" can serve as a focal point for the development of a new integrated approach. This has profound consequences for the dynamics of interface between the "agents" of scientific knowledge, on the one hand, and the farmers, on the other. Agents of scientific knowledge are categorized as "the experts" who ignore the importance of local knowledge and agricultural practice. As consequence, it is denied to peasants any significant role in rural development. Social interface emphasizes the ways in which the actors' previous experiences and biographies shaped their interaction with each other, leading to differing social constructions of any problem. Although these differences, actors are able to develop bridges between their life-worlds, even when these life-worlds represent major discontinuities within any particular social order. Hence processes of interactions and understanding are not simply defined by the existence of differential relations of power and sources of authority in the society at large, but by the inherent capacity of the actors to process knowledge and to learn from experience, which are the hallmarks of human agency. Important are previous experiences that shaped the social positions and interpretations of the actors where actors' identities and strategies were formed. Previous experiences strongly influence actors' lifeworlds. Consequently, actor's cultural construction of knowledge and experience shapes the contours of specific aggregate social forms like encounters or interactions. Thus, in a peasant or pastoralist community exposed constantly to many changes, their life-worlds are changing. 


\subsection{Pastoralists studies in Peru}

In Peru, rangelands-livestock systems have been studied from perspectives of two disciplines: range science and social science. Studies of range experts focused on vegetation, rangeland ecology, rangeland condition and developing management plans for rangeland use, as it was presented in the first section. On the other hand, social scientists focused on the human dimension of pastoralist systems. They studied pastoralist management and adaptation strategies, cultural ways of labor and land access, control and use, and rangeland management ethnographies. Very few studies integrated both perspectives.

In Peru, studies have reported the existence of institutions for rangeland management on pastoralist and agro-pastoralist communities (Brush, 1985; Fernandez, 1992; Mayer, 2002; McCorkle, 1992; Pinedo, 2000; Postigo, Young \& Crews, 2008). Brush (1985) found that pastoralists communities of the Altiplano implemented governing mechanisms for access to, and management of, rangelands at two levels: supra-household and community. The supra-household level consists of a group of community members elected specifically for this purpose. Both government levels present supervisory mechanisms for the fulfillment of specific behavioral expectations, management principles, time orientation, and social relations. However, antagonistic relationships at household and supra-household levels also occur due to the inherent contradiction between public and private goals (Brush, 1985).

In communities of the central Peruvian Andes, other scholars found that rangeland management includes different organizational levels (supra-household, household and gender). It also involves other associations within the community where decisions 
regarding range management were made. Individuals at each level of organization or association participate in decision-making processes together simultaneously to define, control, and enforce rules for rangeland management (Fernandez, 1992; McCorkle, 1992). The increased demand for resources and continuous social and political structural changes have challenged pastoralist societies to effectively control the exploitation of rangelands. Moreover, the progressive modernization of the pastoralist societies with the introduction of capitalistic economic relations, and outmigration have debilitated the traditional communal bonds and the communal authority and rules that were in place to enforce rules and decisions regarding rangelands (Lozada, 1991).

Mayer (2002) found that rules for rangeland management have become ambiguous over time, responding to changes in the power structures of communities. Pinedo (2000) argues that the rules and norms for rangeland allocation and management have also been challenged lately with different conceptions of equity between old and new communal members, and that they are being adjusted to include both conceptions. Most recently, Postigo et al. (2008) found that few reciprocal relationships remain in some communities, as evidence that rules and norms for range management have not responded very well to population pressures nor to external interventions.

Recharte et al. (2002) argue that there are still some places in the Andes where institutions and local knowledge for range management have survived, especially in the southern Andes, the Altiplano, where domestication of alpacas and llamas and the artificial creation of peatbogs took place before colonization. However, neither the social institutions and structures pastoralists have in place for the governance and management 
of rangelands, nor the relationships those institutions have with rangeland degradation, have received much attention.

The outcome of these situations is mismanagement and overgrazing, which has led some, mostly scientists, to believe that peasant communities have not developed any effective mechanisms for rangeland management and that each family proceeds according to its individual interest. They conclude that this leads inevitably to the destruction of rangelands as illustrated in the tragedy of the commons (Florez \& Malpartida, 1988). However, others claim that peasant communities still have a number of customary mechanisms to regulate the use of the rangeland, but that often times their short-term necessities and the incorporation of new practices prevail over their own rules (Tapia \& Flores, 1984; Lozada, 1991). 


\section{METHODOLOGY}

This chapter describes the research design used in this study, selection of research sites, and participants in the study. It describes the research methods used to collect the primary and secondary data and how they were implemented in the field. Likewise, it explains how data was organized, processed and analyzed. Finally, it addresses the scope of the study and its limitations.

\subsection{Research design}

Rangeland degradation in Peru is a complex problem involving decision makers at multiple decision-making levels and diverse socio-environmental contexts. To understand the degradation problem, this research explores rangeland management indepth and captures the perceptions of pastoralists in three rural communities of the Altiplano dry puna. Thus, the research design used is case study (Creswell, 2007). The study explores in depth the rangeland management, the relationship between management and degradation, and the social and ecological factors shaping pastoralists' management decisions in three pastoralist communities. This case study also encompasses stakeholders' views and influences. Finally, the study also explores perceptions of the rangelands held by stakeholders at regional and national levels. 


\subsection{Selection of research sites and participants}

\subsubsection{Selection of research sites}

The southern Peruvian Altiplano was selected as the research site because it has been identified in previous studies as one of the places with the worst cases of rangeland degradation. Three pastoralists communities of the Altiplano dry puna were selected. Thus, the selection of the research sites was purposive (Patton, 1990; Maxwell, 1997). One community (Apopata) was selected due to previous research experience. The other two (Chocorasi and Lacotuyo) were selected due to proximity and increase the number of cases. These pastoralist communities are non-probabilistic samples, but they are representative communities of Altiplano dry puna pastoralists. These communities are Aymara ${ }^{3}$ and are located in the southern Altiplano in the Santa Rosa de Mazocruz district, El Collao province, Puno region (Appendix A, Appendix B).

\subsubsection{Selection of participants}

Selection of participants was purposive since the researcher has a specific interest in certain groups of people who could inform the study (Creswell, 2007). It is also entailed chain referral because participants belong to a network related to rangelands systems (Bernard, 2006). There are two main groups of participants related to rangeland degradation: stakeholders and pastoralists. In all cases participants were adults (men and women) who participated voluntarily, as they expressed in the consent form they signed.

\footnotetext{
${ }^{3}$ Aymara is one of the two main ethnic groups in the Altiplano. The other is Quechua
} 


\subsubsection{Stakeholders}

Stakeholders are representatives of academia, government offices, and non-governmental organizations (NGOs) (Table 1). Representatives of academia are mainly scientists and professors who study rangeland management at the main national agricultural university, main local university, national research institute, and independent consultant.

Representatives of government are officials of agencies of the Ministry of Agriculture (MINAGRI), Ministry of the Environment (MINAM), Regional Government (GORE), Mazocruz Municipio (local government) that deal with rangelands. Representatives of NGOs are development project coordinators working with pastoralists and rangeland management. Each group of stakeholders has national and local representatives. Those with national scope are based in Lima city (capital of Peru) and those with regional scope are based in Puno city (capital of Puno region), in the Altiplano.

Table 1. Number of stakeholders per type and scope

\begin{tabular}{|l|c|c|c|}
\hline Stakeholder & $\begin{array}{c}\text { Lima } \\
\text { (National) }\end{array}$ & $\begin{array}{c}\text { Puno } \\
\text { (Regional) }\end{array}$ & Total \\
\hline Academic & 4 & 6 & 10 \\
\hline Government & 3 & 6 & 9 \\
\hline NGO & 1 & 3 & 4 \\
\hline Total & 8 & 15 & 23 \\
\hline
\end{tabular}




\subsubsection{Pastoralists}

Pastoralists share many characteristics. Their main livelihood is raising alpaca and they live permanently in the communities of Apopata, Chocorasi, and Lacotuyo (Table 2). Within each community, pastoralists were selected randomly, using a list of community members and a household location map, facilitated by community authorities (Appendix C). Pastoralists are key actors of rangelands management because they are the exclusive users of rangelands and they are also part of the governance since they belong to a community, which is the smallest unit of governance.

Table 2. Number of pastoralists by community

\begin{tabular}{|l|c|c|c|}
\hline Community & Women & Men & Total \\
\hline Apopata & 20 & 17 & 25 \\
\hline Chocorasi & 12 & 13 & 26 \\
\hline Lacotuyo & 9 & 12 & 22 \\
\hline Total & 41 & 42 & 83 \\
\hline
\end{tabular}

\subsection{Research Methods}

A combination of research methods was used to collect primary data. Each method was utilized to collect a specific type of data according to the type of participants (Ary et al., 2006; Bernard, 2006). Thus, methods used with pastoralists were interviews and participant observation. Methods used with stakeholders were semi-structured interviews. 


\subsubsection{Interviews}

\subsubsection{Structured interviews}

Structured interviews were used to collect information of pastoralist's households about their livelihoods, family composition, labor availability, migration, land holdings, access to rangelands, livestock property, and perceptions of rangeland condition and degradation (Appendix D). Thus, 83 structured interviews were conducted: 37 in Apopata, 25 in Chocorasi, and 21 in Lacotuyo; respondents included 41 women (49\% of total) and 42 men $(51 \%$ of total $)$.

\subsubsection{Semi-structured interviews}

Semi-structured interviews were used to collect information from stakeholders. A total of 23 interviews were conducted: 15 with stakeholders based in Puno (4 scientists, 3 government officials and 1 NGO representative) and 8 stakeholders based in Lima (6 scientists, 6 government officials and 3 NGO representative).

\subsubsection{Participant observation}

Participant observation was also used to complement the information obtained in the interviews. This was used to understand pastoralist's daily life regarding rangeland management to identify the environmental and social aspects of interactions within the system. Participant observation was used to observe in situ rangelands condition, strategies and practices for rangeland management, daily and seasonal grazing livestock movements and the main labor in charge. Likewise, it was also used to understand how households organize and coordinate with other members. Participant observation also 
gave participants opportunities to identify who they are connected to, what their priorities are, what their threats are, and how they deal with difficult climate conditions and water shortages. Participant observation was used while conducting interviews, attending monthly communal meetings and traditional festivities in Apopata, Chocorasi, and Lacotuyo and in the town of Mazocruz.

\subsection{Data collection, organization and analysis}

\subsubsection{Data collection process}

The collection of data lasted from February, 2010 to January, 2011. Field data collection with pastoralists lasted from March through October, 2010 encompassing a rainy and dry season in order to be present for two periods of rangeland management. Interpreters were used during the interviews since pastoralists speak Aymara. Interviews with stakeholders lasted from August, 2010 to January, 2011 and took place in the cities of Puno and Lima.

The researcher conducted the study according to a code of ethics, acting with high respect and considering all possibilities to anticipate and avoid causing any harm or discomfort to participants other than those ordinarily encountered in daily life (Bernard, 2006). Thus, the proposal and instruments (consent forms, protocols, and questionnaires) were approved by the University of Missouri's Institutional Review Board prior to their application. The study was approved under the category of exempt due to the minimal risk it represented for participants since it did not include physical or psychological examinations.

Consent forms containing further information about the study, the purpose of the interview, and researcher contacts were administrated by the researcher before initiating 
any interview. In the case of pastoralists, consent forms were translated orally from Spanish into Aymara by the interpreter since this language has no written version. They were asked to keep the form as proof of their willingness to be interviewed. In the case of the other stakeholders of Puno and Lima, the consent form was provided in a printed version.

For security reasons, to avoid any possible risk and to protect participants, the researcher does not reveal participants' identities and will keep safe in a secured location and confidential the information they provided.

\subsubsection{Data organization and analysis}

Information from the structured interviews carried out in pastoralist's households in the communities of Apopata, Chocorasi and Lacotuyo was organized by major themes (demographics, livelihood, labor, land, rangelands, livestock) according to the objectives and research questions (perceptions of degradation and causes of degradation). Matrices with pastoralists' responses in the three communities were compared and contrasted among them to look for patterns and differences.

The information collected from the semi-structured interviews carried out with stakeholders was organized by the type of stakeholder (scientist, government official, NGO representative), by scope (regional-Puno and national-Lima) and by major themes according to the objectives and questions. Matrices with answers by type of stakeholder and by regions were compared and contrasted looking for patterns and differences. Likewise, matrixes with answers of stakeholders and pastoralists were contrasted to look for similarities and differences between them. 
Perceptions of degradation are expressed in percentages because the options of answers were closed: yes or no, severely degraded, moderately degraded, not degraded. Causes of degradation are counted since participants could choose multiple responses. Thus, participants answered as many causes as they considered relevant. The numbers for causes were summed up and organized by group. The highest number for a group of participants is the cause of degradation they consider most important and the lowest number is the cause they consider least significant.

\subsection{Scope and limitations of the study}

Since this is case study research, with cases in a specific region of the country, findings about rangeland degradation cannot be generalized to the entire country, nor for the whole Altiplano region. However, since case studies are representative of the southern Altiplano region, findings could be extrapolated for this specific region. 


\section{RESEARCH SETTINGS}

This chapter describes the geographic, environmental, social, economic, and institutional contexts of the Peruvian Altiplano dry puna where the research took place. It also describes the production systems that are the core of this study. Likewise, it introduces the stakeholders involved in this research and the institutional environment of rangelands in the Altiplano and the country.

\subsection{Peruvian Altiplano}

The Peruvian Altiplano, or high plateau, is the southern Andean region of the country between 3800 and 5200 meters of elevation. It encompasses most of Puno region where rangelands are the dominant landscape. The Peruvian Altiplano shares climate and environmental characteristics with the rest of the Andes but it also has specific ones. Northern Puno, with proximity to Amazonia, is more humid, whereas southern Puno is dryer. Likewise, the influence of Lake Titicaca, combined with different altitudes, soils, and topographies define four differentiated agroecological zones: lakeside, suni, humid puna, and dry puna (Tapia, 1996) (Appendix E). Climate varies among these agroecological zones and defines agriculture options and types of livestock system. Thus, the lakeside zone, moist and warmer, is oriented toward multi-crop and mixed farming, with several diversification opportunities. The humid puna, moist but cold, is oriented toward raising cattle and alpaca. The dry puna zone, the driest and coldest, is exclusively oriented toward raising alpaca (Swinton et al., 2001; Tapia, 2008). With little or almost nonexistent diversification opportunities, puna zones are considered the most vulnerable 
to climate variability and change (IPPC, 2007; Valdivia et al., 2001). Altiplano puna zones have been greatly impacted by extreme climate events during the last few decades (FAO, 2008).

Puno has about 3.5 million hectares of rangelands, covering more than half of the region area, which represents $22 \%$ of the nation's total rangeland (GORE Puno, 2008). They are classified in two main vegetation groups: dry-grasslands, mostly used in the rainy season, and peatbogs, mostly used in the dry season (Tapia \& Flores, 1984; Huisa, 1996; Choque \& Palacios, 1998). In general, the largest peatbog area of the country (112 thousand hectares), is concentrated in Puno. Both vegetation types vary according to agroecological zones. Humid puna has more diverse dry-grasslands, while dry puna has the largest peatbog area (TDPS, 2001; Siguayro, 2008). Rangeland conditions in the 80s were $46 \%$ fair, $54 \%$ poor, and very poor (Choque et al., 1990). In 2010, $60 \%$ were poor and $40 \%$ very poor. Moreover, humid puna rangeland conditions are better than those in dry puna rangelands.

Puno rangelands support $47 \%$ of the country's population of alpaca (1.8 million), $35 \%$ of the llamas ( 450 thousand), $25 \%$ of the sheep ( 2.8 million), and $13 \%$ of the cattle (650 thousand) (Instituto Nacional de Estadistica e Informatica [INEI], 2012). Livestock population changed from 1994 to 2012, alpacas (26\%), llamas (23\%) and cattle (13\%) increased and sheep (33\%) decreased (INEI 2012). However, in equivalent animal units, grazing pressure barely increased. Thus, having the greatest extension of rangeland country and the largest national livestock populations, Puno has always been considered the main livestock center of the country. Livestock systems in Puno are its main livelihood and are extensive rainfed grazing systems. 
Puno also has socio-cultural and historical differences between the north and south. There are two ethnic groups, the Quechuas located mostly north of Puno city (the regional capital), and the Aymaras, mainly toward the south and north east of Lake Titikaka. Northern puna lands have gone through several tenure regimes and production systems since the Spanish encomienda: republican hacienda, land reform large livestock cooperatives, and modern day community and individual holdings. Instead, southern puna lands have always been managed by autonomous indigenous pastoralist communities, either as communities or as individuals. Although they were autonomous, southern puna communities were not free from abusive tax collection under Spanish rule and exploitative relationships with gamonales ${ }^{4}$ until land reform policies were implemented. Due to their historical legacy, inhabitants of Puno are among the poorest in the country; the higher the altitude of rural districts, the poorer they are (INEI 2015). For this reason, since 70s, Puno has been the site of NGOs, international cooperation, government development projects, and poverty alleviation actions. Most of them focused on the northern humid puna while paying little attention to the southern dry puna. The population of Puno has increased throughout the years, with average rates of $1.3 \%$, but the rural population has kept stagnant and even decreased since 1993 due to high rates of out migration (INEI, 2017). The number of agricultural units has increased constantly. Puno has maintained as the second region with the largest number of agrarian units (2012, INEI). Likewise, Puno has the most cases of land fragmentation in the country

\footnotetext{
${ }^{4}$ Gamonalismo was an exploitation system like hacienda that dominated southern Peru, since the early republic to the time of land reform. Gamonales were upstart landowners, lacking colonial caste (hacendado) and refinement, who expanded their lands and socio-political power expropriating and subduing indigenous ayllus by illicit coercive and violent means. They imposed unfair lease and disadvantageous commercial relationships based on clientelist methods. (Alvarez Calderon, 2010).
} 
with more parcels per agricultural unit (INEI, 2013a). The southern dry puna provides the geographic context for the present study.

\subsection{Peruvian Altiplano southern dry puna}

Located along the southwest of Puno region, the dry puna is the largest ecological zone in the Altiplano. The dry puna zone features altitudes from 4000 to 4800 meters, annual precipitation between 440 to $600 \mathrm{~mm}$, temperatures between 16 to $-14{ }^{\circ} \mathrm{C}$ degrees, and frost-free periods between 30 to 60 days (Swinton et al., 2001). The southern district of Santa Rosa in the southern El Collao province, and particularly the town of Mazocruz, the district capital, provided the site for this research (Appendix E). At 4010 meters in altitude, Mazocruz is located at $140 \mathrm{~km}$ to the south of Puno, $87 \mathrm{~km}$ from Ilave, the El Collao capital. Mazocruz is connected to the coastal cities of Ilo, Moquegua, and Tacna on one side, and with the city of Ilave on the other side by a highway called binacional. This town has 23 rural pastoralist communities of Aymara descent.

The climate has two marked seasons: the rainy season from December through March and the dry season from April through November. The climate is permanently cold all year, with warm days and very cold nights $\left(-18.5 \mathrm{C}^{\circ}\right.$ registered in June 1980 and 2005). The climate is highly variable with high chances of frost throughout the year, and only 28 frost-free days per year (Quispe, 1989). Mazocruz is one of the most vulnerable places in the country; it is heavily impacted by climate change and extreme climate events like friajes (long frosts), hailstorms, droughts, snow, strong winds, and thunderstorms (World Food Programme [WFP], 2010). 
The landscape of Mazocruz is dominated by native grasslands and peatbogs, and populated with grazing alpacas and poor Aymara pastoralists. Mazocruz rangelands were studied in the late 80's known locally and classified as chilliwares, irus, canllares, tolares and peatbogs (PAL, 1989). The vegetation is sclerophytic, typical of dryland ecosystems. For this reason, peatbogs are key resources for livestock production (Leon Velarde \& Valdivia, 1992; Siguayro 2008). Because peatbogs are important for camelid production, tenure and size determine herd size and therefore the income from livestock sales (PAL, 1989). The greatest number of peatbogs are concentrated in the Mazocruz area, the largest concentration in Puno (TDPS 2001; Siguayro 2008). Peatbogs are also valued as a source of water or humidity for ecosystem maintenance.

The population of Mazocruz was 7.5 thousand in 2012; $85 \%$ of the population is rural and 90\% do not have electricity, water, or sewer. Access to healthcare and education are limited and poorly provided. It has high rates of illiteracy especially among women, high children malnutrition, $0.251 \mathrm{HDI}$ in almost half of region, and monthly incomes of less than 90 soles (27 U.S. dollars) for a family of five members (United Nations Development Programme [PNUD], 2012). With almost nonexistent diversification options, alpaca raising for fiber and meat production remains the main livelihood and chief economic activity of the area. Pastoralists in this area are small holder farmers. Households typically own between 50 and 300 alpacas, 50 llamas, and 30 sheep in about 10 to 50 hectares of rangelands that they manage privately. Due to limited development opportunities, the government and NGOs have intervened very little in this area. Few chances to increase income through livestock, less access to land, few development opportunities, and few job opportunities push the Mazocruz population to 
migrate to other regions of the country, mainly to coastal areas for agricultural work.

This migration can be circular or permanent (Turin \& Valdivia, 2009).

\subsubsection{Community Apopata}

Apopata has an extension of $11,486.76$ hectares and 70 households. It has three sectors:

Humajalso, Patjocco, and Jachaccoco. It is surrounded by many communities:

Huanacamaya toward the north, 24 de Julio and Chocorasi toward the northwest,

Chunguilluni toward the east, the town of Mazocruz toward the southeast, Orcoyo is

toward the south, with the town of Santa Rosa toward the southwest, Lacapacheta toward

the west, and Huancollo and Ichjasi toward the northwest. It has around 70 households.

Apopata is an old community; during Spanish rule it was an Ayllu, later a parcialidad ${ }^{5}$, and with the land reform it become into a Peasant Community. Apopata was officially registered in 1974 as a peasant community, and count with statutes and bylaws updated in 2009. All households own land and manage it privately; there is no communal land nor communal livestock.

Apopata holds board meetings once per month to deal with internal issues. They count with a Water Users Committee ${ }^{6}$, which also holds communal meetings to deal with water issues. Apopata has served as a research site and development program location with international cooperation and government. In the 80s, a Canadian IDRC (International Development Research Center) project called Proyecto de Investigación de

\footnotetext{
${ }^{5}$ Parcialidad has different meanings according to historical context. During Spanish rule until the early republic, it was a portion of Ayllu or a new community that resulted of separation from the nuclear Ayllu. At present, parcialidad is a group of families owing land that associate and to belong a community. They are not included with communal land or required to registered as a peasant community. However, in practice parcialidades use the same organizational and governmental structure as peasant communities. ${ }^{6}$ Comité de Usuarios de Agua: a mandatory government structure according Water Law.
} 
Sistemas Agropecuarios Andinos- PISA (Farming Systems Research Project) using a farming systems approach (PISA 1991). This project characterized pastoralists systems and rangelands in order to propose development options. In the 90s, the Sierra Verde Project of the government program Programa Nacional de Manejo de Cuencas Hidricas PRONAMCHS initiated installation of infiltration trenches for water harvesting to improve rangeland productivity, however they were not completed. From 2006 to 2009, Apopata was the research location for a Sustainable Natural Resources and Environment Management Collaborative Research Support Program (SANREM CRSP), project of USAID Program to study the adaptations of pastoralists to climate and market changes. This project focused on pastoralists' adaptive strategies, including rangeland management. Apopata peatbogs have been especially studied by the PISA project in the 80s, by the Proyecto Binacional de Conservación de la Biodiversidad en la Cuenca del lago Titicaca - Desaguadero - Poopo - Salar de Coipasa - TDPS project in 2000, by the Andean Agriculture in the Altiplano - ALTAGRO project in 2009, and by the Instituto Nacional de Innovación Agraria -INIA in 2010.

\subsubsection{Community Chocorasi}

Chocorasi extends about seven thousand hectares and has a population of about fifty households. The region (?) has five sectors: Chocorasi, Pecanane, Amchallani, Incacachi, and Jinchomamaya. Chocorasi is surrounded by several communities: 24 de Julio is toward the northwest, the Conduriri district toward the north and east, Chunguilluni toward the south, and Apopata toward the southwest. Chocorasi is an old parcialidad. Different from Apopata, indigenous people purchased Chocorasi land in 1893; it became 
a new parcialidad and land was distributed to families in 1955. Thus, Chocorasi does not have communal land. Chocorasi was register as a parcialidad in 1988 and was legally recognized through ministerial resolution No 007-96-MD-SR_MC. As rural indigenous organization they have an official association called Asociacion de Productiores de Camelidos Sudamercanos Vellon de Oro. They also count with a Water Users Committee $^{7}$ which hold monthly meetings.

\subsubsection{Community Lacotuyo}

Lacotuyo extends four thousand hectares and has about 50 households. Lacotuyo is surrounded by other communities: toward the northwest is Chunguilluni, toward the northeast is Conduriri district, toward the east is Providencia, toward the southeast is Sulcanaca, toward the south is Casana, and toward the southwest is the town of Mazocruz. Lacoutyo is a parcialidad created in the 80s. They hold monthly communal meetings and water users committee meetings. It registers with an association named “Asociación de Criadores de Camélidos Sudamericanos de la Parcialidad de Lacotuyo".

\subsection{Southern dry puna pastoralist production systems}

The main livelihood in the Mazocruz area is raising alpaca; which can be complemented with raising llamas and sheep as a way to diversify production. Thus, the main herd for all pastoralists consist of alpacas (100-150), and for many others, a small herd of llamas (30) and a small herd of sheep (50). Most households have two or three grazing plots within the community and some can have access to one or two grazing plots in a

\footnotetext{
${ }^{7}$ Comité de Usuarios de Agua: a mandatory government structure according to Water Law.
} 
neighboring community. The few better off households have more than three. At least one of the grazing plots is peatbog and the other two can be dry-grasslands. The peatbog plot is typically in the flat pampa (lower area) close to the main house. The other grazing plots are in the cerro (hilltop) or ladera (hillside). The number of available grazing plots determines the sizes of herds. The size of the peatbog area determines the number of animals a household can have. Property and access to land within the community is obtained by inheritance. Land beyond the community is obtained through familiar bonds through marriage or by renting. The majority of pastoralists are owners of the land they use, some of them rent, and few of them have borrowed or allowed to use land of close relatives or neighbors with some type of agreement. Ownership of land can be individually when owned by one family or is called indiviso (undivided) when owned collectively by siblings. There are more cases of land owned by one family, however indiviso land has also become common to avoid more land fragmentation. Undivided land can be managed by turnos (by times) when siblings agree. However, when they do not agree, undivided land can become open range. When plots of land were larger, pastoralists could not use fences, but now that plots of land are smaller, they use fences. The use of fences has become a common practice that facilitates management. Pastoralists with fences now reserve some areas of grazing plots for the dry season. Pastoralists do not know the exact measurement of their land in hectares, although they know their boundaries very well.

Depending on the availability of labor and rangelands, livestock is kept in mixed herds or separated herds. Separated herds consist of a herd of alpaca only, and other herd of llamas and sheep. However, most pastoralists manage only one single herd where all 
animals (alpacas, llamas and sheep) are kept together. On average, pastoralists have 150100 alpacas, 50 sheep, and 30 llamas. Since alpacas are the most important type of animal, wealth is measured by the number of alpacas. Thus, the wealthiest $10 \%$ have around 200-300 alpacas, the middle 60\% have between 50-190 alpacas, and the poorest $30 \%$ have fewer than 50 alpacas. The animals in a family's herd belong to several family members (5 to 10), who are part of the nuclear family (parents and children), and also to extended family (grandparents, aunts, uncles, nieces). Family members are the main laborers. Only one or two members of the nuclear family oversee animals. Most of the animal owners (mostly children) have migrated and visit the community once per year to collect profits. There are several labor styles. In general, women, supported by children and elderly people are the main laborers. There are couples who share tasks and support each other. Some arrangements include mothers and daughters working together. Adult man typically work alone, especially elderly man. Elderly women might have shepherds for support. Turnos (by times), taken by all siblings (man and women). Few households have access to small sheds where do the animals sleep at night. In the majority of cases animals sleep in open corrals. Everyone has access to springs.

The secondary livelihood in this area is migration. Mazocruz communities have high rates of migration, around $40 \%$. Migration is either circular or permanent; it is mostly the men who leave the community to work off-farm. More than $80 \%$ of households have family members living and working in the Puno, Tacna, or Moquegua regions. 


\subsection{Rangeland institutional and management framework}

Stakeholders are differentiated in three sub-groups: academics, government officials, and non-governmental agents. They are in two locations: those based in the capital city of Lima, with a national view of the problem of degradation, and those based in the city of Puno, with a local view of the problem, specifically the Altiplano. All of them deal differently with rangelands and pastoralists and are knowledgeable about the rangeland degradation problem in the Andes of Peru. Likewise, all those participants have experience with rangeland management and governance of the Peruvian Altiplano.

\subsubsection{Academia}

Academics in universities and research centers provide education and research on rangelands. Scientists from Lima and Puno are professors and researchers at the main agrarian university of the country and research centers. In Lima, academics are from Universidad Nacional Agraria La Molina UNALM (National Agrarian Univerisity La Molina). In Puno, stakeholders are professors of the Universidad Nacional del Altiplano UNA (State University of Altiplano), scientists at the National Research Institute INIA of Puno, and scientists and private consultants that had led projects in the Altiplano with international cooperation.

\subsubsection{Government}

Government officials monitor, regulate, and promote improvements in the livestock sector including rangelands. Often, government officials count with the expertise participation of range scientists when formulating policies or programs. In Lima, officials of Ministerio de Agricultura y Riego - MINAGRI (Ministry of Agriculture and Irrigation) 
and Ministerio de Ambiente - MINAM (Ministry of Environment), both represent the central government. The stakeholders interviewed in Lima were the government officials dealing with rangelands from the MINAGRI offices of Programa de Desarrollo Productivo Agrario Rural - AGRO RURAL (Program for Productive and Agricultural Development) and Competitividad Agraria (Agrarian Competitiveness), and from the Ministerial Office of MINAM. In Puno, officials represent the central, regional, and local governments. The stakeholders interviewed in Puno were the government officials dealing with rangelands from regional office of the MINAGRI-Puno. In the case of, Gobierno Regional de Puno - GORE Puno (Regional Government of Puno), officials were of Gerencia de Recursos Naturales y Ambiente (Natural Resources and Environment Management) and development projects called of Proyecto Especial de Camélidos Sudamericanos - PECSA (Special Project of Southamericans Camelids) and Programa de Apoyo al Desarrollo Rural Andino - PRADERA (Andean Rural Development Support Program). Mazocruz Municipio (Municipality of Mazocruz) represented the local government.

\subsubsection{Development agencies}

Many NGOs operating in the Andes promote pastoralists' development through capacity building through training on livestock and rangeland management. They often work close with range scientists and their development proposals are based on scientists' work. NGOs also have active participation in all platform for Andean ecosystems conservation organized by government. In Lima, el Instituto de Montana (The Mountain Institute TMI) is a representative NGO operating in the Peruvian Andes. In Puno, NGOs 
operating locally in the Altiplano were represented by Centro de Investigation para los Recursos Naturales y el Medio Ambiente - CIRNMA (Research Center for Natural Resources and Environment), Centro de Estudios y Promocion del Desarrollo - DESCO (Center for Studies and Development Promotion), and Proyecto Manejo Sostenible de Suelos y Agua en Laderas - MASAL (Project Sustainable Management of Soils and Water of Sidehills). 


\section{PERCEPTIONS OF RANGELAND DEGRADATION}

This chapter is organized into three sections. The first section presents the perceptions of rangeland degradation and rangeland conditions provided by rangeland scientists, government officials, and NGO representatives based in Lima and in Puno. It also describes the indicators used to determine condition. The second section presents the perceptions of pastoralists from the communities of Apopata, Chocorasi, and Lacotuyo about rangeland degradation and condition and the indicators they use to determine condition. The third section compares the perceptions of degradation and condition between stakeholders and pastoralists.

\subsection{Perceptions of Rangeland Degradation by Stakeholders}

Table 3 presents the perception of rangeland degradation of stakeholders, which includes those of academia, government, and non-governmental organizations located in Lima and Puno.

\subsubsection{Academia}

As shown in Table 3, all range scientists believe that rangelands are degraded. Eighty percent consider rangelands to be severely degraded and the other $20 \%$ consider that rangelands moderately degraded. There is no difference in perceptions between scientists based in Lima and Puno regarding the degree of degradation and condition of rangelands. The scientists who believe that degradation is severe and widespread claim that most rangelands are in poor and very poor condition and the trend is worsening. 
Table 3. Perception of rangeland degradation by type of stakeholder

\begin{tabular}{|c|c|c|c|c|c|c|c|c|c|c|c|c|c|c|}
\hline \multirow{3}{*}{$\begin{array}{l}\text { Range } \\
\text { degradation } \\
\text { perception }\end{array}$} & \multicolumn{4}{|c|}{ Scientists } & \multicolumn{4}{|c|}{ Government } & \multicolumn{4}{|c|}{ NGO } & \multirow{2}{*}{\multicolumn{2}{|c|}{ Total }} \\
\hline & \multirow{2}{*}{$\begin{array}{r}\text { Lima } \\
\mathrm{n}=4\end{array}$} & \multirow{2}{*}{$\begin{array}{r}\text { Puno } \\
n=6\end{array}$} & \multicolumn{2}{|c|}{ Total } & \multirow{2}{*}{$\begin{array}{c}\begin{array}{c}\text { Lim } \\
\mathrm{a}\end{array} \\
\mathrm{n}=3\end{array}$} & \multirow{2}{*}{$\begin{array}{r}\text { Puno } \\
n=6\end{array}$} & \multicolumn{2}{|c|}{ Total } & \multirow{2}{*}{$\begin{array}{c}\begin{array}{c}\mathrm{Lim} \\
\mathrm{a}\end{array} \\
\mathrm{n}=1\end{array}$} & \multirow{2}{*}{$\begin{array}{r}\text { Puno } \\
n=3\end{array}$} & \multicolumn{2}{|c|}{ Total } & & \\
\hline & & & $\mathrm{n}=10$ & $\%$ & & & $\mathrm{n}=9$ & $\%$ & & & $\mathrm{n}=4$ & $\%$ & $\mathrm{n}=23$ & $\%$ \\
\hline Severe & 3 & 5 & 8 & $80 \%$ & 3 & 5 & 8 & $89 \%$ & - & 2 & 2 & $50 \%$ & 18 & $78 \%$ \\
\hline Moderate & 1 & 1 & 2 & $20 \%$ & - & 1 & 1 & $11 \%$ & 1 & 1 & 2 & $50 \%$ & 5 & $22 \%$ \\
\hline Total & 4 & 6 & 10 & $100 \%$ & 3 & 6 & 9 & $100 \%$ & 1 & 3 & 4 & $100 \%$ & 23 & $100 \%$ \\
\hline
\end{tabular}


They affirm that the worst cases of degradation are observed in peasant communities and the rangelands are better in large production cooperatives. They emphasize that rangeland degradation is more pronounced in southern Peru than in northern Peru. Puno scientists also feel that rangelands in southern Puno are in worse condition than those of northern Puno.

A Lima professor stated, "Rangelands in Peru are degraded, I have studied rangelands around the country, north, central, and south, and everywhere there are obvious symptoms that there is degradation..... in the most severe cases there are soil erosion processes".

Another Lima professor commented "Rangeland degradation in Peru is severe in most of the Andes but only in the places that have had intervention has the problem of degradation have been controlled or reverted, however those cases are few".

A Puno professor affirmed, "I moved from Cuzco (to Puno) about 30 years ago when I was young....... When I arrived here (Puno), rangelands were beautiful..... presently more than $60 \%$ are in poor and very poor condition, and the other $40 \%$ is in fair condition, rangelands in good condition do not exist anymore...... rangelands are mostly degraded".

Plant composition is an important indicator for those scientists who believe that rangelands are severely degraded. They argue that palatable perennial plants like chilliwas and poas have decreased or disappeared. The less palatable species like stipas and calamagrotis, or unpalatable plants like canlla and toxic plants like astragalus have increased. Likewise, they have noticed that plant vigor has decreased because the tillers of Festuca dolichophyla have decreased. Puno scientists focus on the vegetation preferred by camelids because Puno is where this type of animal is concentrated. Puno scientists also have noticed that indicators plants have lost their vigor and density.

A Puno scientist said, "In the last 4 or 5 years the vegetation has changed very fast, the palatable species for alpacas like poas, ginginia, and layo have disappeared, the less palatable and non-palatable plants have expanded and invaded.... The Festuca 
plants nowadays are not easy to find, and if I find them, they are weak with short tillers and scraggly with few stems".

Another indicator for range scientists is plant cover. A majority of scientists state that the plant cover of rangeland areas has been reduced. Lima scientists observe more bare soil due to reduction of plant density. Other scientists claim that there is evidence of soil erosion. However, for Puno scientists, plant cover has not changed too much. They believe that vegetation has been replaced by other less desired plants, but the soil is still covered.

The two scientists who argue that degradation is not a severe problem believe that degradation is a localized problem. They also assert that rangeland conditions are is poor or fair, and that there are some cases of rangelands in good condition. However, one agrees with the majority of scientists that rangeland conditions are declining. The other thinks that the present condition is their natural state because there is no scientific evidence that rangelands were better in the past.

A Puno professor who believes rangeland degradation is not severe explains his point of view in this way, "The general tendency of rangelands is of deterioration because we can see that plant composition has changed. However not all rangelands are in that situation. I think rangelands degradation is heterogeneous. It is true, there are some cases where rangelands are degraded, but there are other cases in which there is no change at all, even more, there are some rangelands that have even improved. The worst cases are found in peasant communities and the best rangelands are in the ex $S A I S^{8, "}$.

Lima scientists who believe that rangeland degradation in the Peruvian Andes is severe are active researchers conducting studies in different parts of the country. They have worked mostly with large cooperatives or SAIS (holding $10 \%$ of rangelands) and

\footnotetext{
${ }^{8}$ SAIS: Sociedad Andina de Interés Social (Andean Society of Social Interest). A land reform structure that was worked from 1969 to 1995
} 
occasionally with peasant communities (holding $80 \%$ of rangelands). Before the land reform in the $60 \mathrm{~s}$ these cooperatives were haciendas. Haciendas were established on the highest quality lands. Peasant communities, due to historical marginalization and land expropriation in favor of haciendas, were allotted the poorest quality lands. Rangelands of cooperatives are managed in large parcels. Rangelands of peasant communities are managed in small plots. Given this historical context, it is expected that rangelands in better condition is in the cooperatives and the worst cases are in the peasant communities. Scientists have preferred to conduct research in the large production cooperatives due to the facilities they provide for research coordination. Very few have conducted research in peasant communities due to the constraints for research coordination; most estimations of condition and degradation in these communities are projections rather than actual studies.

Most of Lima's scientists have been trained in range science departments in American universities between the 70s and 80s. Consequently, they are highly influenced by the Rangeland Condition and Trend model (RC\&T), that measures rangeland condition and is also used to determine degradation. This model categorizes rangelands in excellent, good, fair and poor condition. Excellent condition is close to the climax vegetation that is possible without grazing. Very poor condition is poorly managed and overgrazed rangeland, at risk of degradation. Lima scientists and their colleagues trained the Puno scientists. Therefore, all scientists are influence by the RC\&T model. The application of this model to the Andean rangelands in the 80s led scientists to classify rangeland condition as $0.1 \%$ excellent, $27.9 \%$ good, $50 \%$ fair, $15 \%$ poor and $7 \%$ very poor (Flores \& Bryant 1989). Later in the 90 s, estimations were $9.5 \%$ 
good, about $30 \%$ fair, and $60 \%$ poor (Flores, 1996). Note that in only a decade, the good and fair conditions decreased, and poor and very poor increased. The projections of rangeland condition and degradation for the Altiplano, especially for the dry puna of southern Altiplano, were more alarming. Scientists at that time affirmed that if no actions were taken, the Altiplano would become a desert in the near future (Tapia, 1984).

Comparing their former estimations of rangeland condition and degradation with their current perceptions, rangeland condition has deteriorated because they now estimate rangelands to mostly be in poor and very poor condition. More than 30 years have passed from the time projections of degradation were conducted; neither the Altiplano nor other regions of Peru have become deserts. Yet, no actions were taken yet to protect rangelands, which suggests that either the projections were too pessimistic or scientists were not using the correct instrument to evaluate Peruvian rangelands.

The scientists in Lima and Puno agree on the type of vegetation they use as indicators to evaluate condition. When they affirm that palatable plants are decreasing and less palatable plants are increasing, the plant species they use as indicators are those of the dry-grasslands. This means that the scientists in Lima and Puno focus primarily on dry-grasslands to evaluate condition. However, as cited in the literature, one important vegetation type in the Altiplano is peatbogs. The fact that scientists in Puno largely ignore peatbogs as indicator of rangeland condition and degradation for the Altiplano, could be explained by the influence of the models used by the scientists in Lima.

The scientists who believe that rangelands are moderately degraded only have worked with cooperatives. Therefore, these scientists only have the view of rangeland 
conditions of the large cooperatives and do not have information on the rangelands in peasant communities, which might explain their perceptions.

\subsubsection{Government}

As shown in table 3, almost all government officials believe that rangelands in the country are severely degraded. Most of them affirm that the average condition of the country's rangelands is poor and the tendency is worsening. Officials of the Ministry of Agriculture (MINAGRI) of Lima affirm that the most severe cases are occurring in the southern Andes.

An official at the MINAGRI in Lima explains, "In general terms, the Andean rangelands in the country are impoverished and degraded and the trend is negative, expected to decrease even more.... In the south of the country, rangelands are more degraded than in the north. In Ancash, rangelands are better preserved than in Huancavelica”.

A high official at the Ministry of Environment (MINAM), a former official at MINAGRI says, "I started working in the Ministry of Agriculture in 1973. Since then, experts talked about rangeland degradation.... This is an old problem the Peruvian state has and was not able to address properly..... So I supposed that rangelands now are in worse shape than then".

An official at MINAGRI Puno claims, "I have been working here for more than 20 years. Since then, rangelands in Puno are totally bad, they are completely degraded".

There is not much difference between perceptions of government officials based in Lima and Puno regarding conditions and degree of degradation. Almost all government officials at MINAGRI Puno, GORE Puno and the Municipality of Mazocruz in the southern Puno also believe the rangelands of the Altiplano are severely degraded. The majority of the government officials in Puno believe the rangelands of the Altiplano are in poor condition, except one local government officer who believes that they are in fair 
condition. Regarding the current condition of Altiplano rangelands, officials at MINAGRI Puno consider the majority of rangelands to be in poor condition. They argue that Altiplano rangelands do not meet the minimal nutritional requirements for livestock. Officials at GORE Puno and Mazocruz Municipio consider rangelands to be between fair and poor condition. Only one official at Mazocruz Municipio affirms that rangelands are moderately degraded, and they are in fair condition. Officers at MINAGRI Puno argue that degradation in the southern Puno corresponding to dry puna is more accentuated than in the northern Puno corresponding to humid puna.

An official at MINAGRI Puno says, "In the few places where institutions operate, rangelands are in better condition. However, in places with no institutional presence, degradation is advanced. The worst cases of degradation are found in the provinces with steep slopes like El Collao. In these places plant cover has been reduced considerably as well. In the dry puna (southern Puno), degradation is more pronounced than in the wet puna (northern Puno).

Government officials at MINAGRI Lima indicate that plant composition has changed negatively with a decrease of palatable plants and the invasion of unpalatable plants. Likewise, they have noticed a decrease in plant vigor and productivity of rangelands. They also affirm that plant cover has reduced showing signs of soil erosion and desertification in the worst cases. Government officials of Puno provide more details. Officials at MINAGRI Puno have noticed that rangelands have lost palatable plants like chilliwa (Festuca dolichophyla) and plant cover has decreased. Officers of GORE Puno also have observed that there is a loss of palatable plants, short grasses preferred by alpacas, an increase of less palatable plants (stipas and ichus) and an invasion of non-palatable plants. Moreover, they have also noticed that peatbogs have decreased in number and in extent and there are some erosion and desertification 
processes in place. In addition, they have also noticed that animals obtain lower weights and lower production (fiber, meat, wool).

One official at MINAGRI Puno states, "There is a noticeable loss of palatable plants like festuca dolichophyla, and other plants that I do not remember now which are indicated in the studies done for the Altiplano. We base our interventions in this information".

One official at GORE Puno claims, "The short grasses preferred by alpacas are disappearing because animals eat more and constantly do not allow it to return because they are eaten from their base. Stipas and ichus that are not desirable for alpacas but maybe for llamas, have increased because they are not consumed that much and because they are resistant to climate change. The plants that have good resistance to climate change are those that have invaded."

Most government officials at Lima and Puno believe rangelands are severely degraded because they base their perceptions on information from rangeland studies from the 80s and 90s. They are not range experts but have enough agricultural academic background to understand the problem of rangeland degradation. Similarly, Puno's government officials base their perceptions on old studies by scientists of the Altiplano region. On the other hand, GORE Puno's officials and those in Mazocruz Municipio base their perceptions on fieldwork information. GORE Officers have fieldwork experience and direct contact with pastoralists. This could explain why they provide more details of indicators of degradation compared with the rest. Besides pointing out changes in dry-grassland vegetation as an indicator of condition and degradation, they only point out the changes in peatbogs as an indicator of rangelands degradation and diminished conditions. They also associate rangeland degradation with loss of animal production in the areas they work. Most of GORE Puno's interventions related to rangelands are conducted in the north of Puno considered the wet puna. Therefore, their perceptions are based more on conditions in the northern rangelands. Mazocruz 
Municipio officials base their perceptions on their daily contact with rangelands and because they come from pastoralist families.

\subsubsection{NGOs}

As shown in table 3, perceptions of rangeland degradation of NGOs representatives are divided. Fifty percent believe that rangelands are severely degraded and the other $50 \%$ believe that are moderately degraded. Those NGO representatives who believe that rangeland degradation is severe, also consider that rangeland condition is poor. Those NGO representatives who believe that rangelands degradation is moderate, also consider that rangeland condition is fair. They affirm that degradation is more pronounced in the highlands compared with intermediate and lower levels.

One NGO representative operating in Puno assert: "the condition of rangelands is critical, if actions are not taken soon, I do not think the resource will survive".

One NGO representative operating in northern and central Andes say "I am not a range expert but visually I can see that Andean rangelands are deteriorated, although this is not homogeneous, there is an incredible variability in the degradation from one site to another. However, in the communities where we are working (northern and central Andes) the situation is changing positively".

All NGO representatives operating in Puno have noticed that there is a loss of palatable plants and an increase of invasive plants like aciachne pulvinata. They emphasize the reduction of areas of peatbogs as indicator of degradation. In addition, they also recognize that key plant species are losing vigor, density and plant cover has reduced. They affirm that finally rangeland degradation reflects in the low animal production.

NGO representatives base their perceptions on the rangelands where they operate. Thus, those who believe that rangelands are severely degraded operate in the southern 
Altiplano dry puna. Those who believe rangelands are moderately degraded operate in the northern altiplano wet puna. NGO representatives who believe that rangelands severe degraded have agricultural training. Those who believe that rangelands are moderately degraded have social science training. Different academic background and field work experience explains the perceptions of NGO representatives.

\subsubsection{Summary stakeholders}

Most of the range scientists, government officials, and NGO representatives, believe that severe degradation of Peruvian rangelands is widespread (78\%). These stakeholders consider most rangelands to be in poor condition. Few of them consider rangeland degradation to be moderate and a localized problem (22\%). These stakeholders consider that rangelands are between fair and poor condition. Scientists and government officials emphasize that rangeland degradation is more pronounced in the southern regions than in the north of the country. NGO representatives argue that rangeland degradation is more prominent in the highlands than in lower mountains. Scientists and NGOs representatives affirm that degradation is more accentuated in peasant communities (holding $80 \%$ of the country's rangelands) than in large production cooperatives (holding $10 \%$ of the country's rangelands). All of them agree that there is a negative trend; rangelands are getting worse.

All stakeholders use the same indicators to determine condition and degradation. Those indicators are plant composition, plant vigor, plant productivity, and plant cover. Scientists provided more details about the indicators of degradation compared to the rest of stakeholders. Most of them focus their evaluations on the dry-grasslands. Thus, they 
argue that palatable plants have decreased, while less palatable plants and unpalatable plants have increased. Plant vigor and plant production have diminished, and plant cover has been reduced. Government officials tend to go further by arguing that in the worst cases, there are signs of soil erosion and desertification. NGO representatives in Puno include the quality of peatbogs in their indicators of degradation. These stakeholders argue that peatbogs are shrinking and disappearing in the worst cases. Stakeholders' perceptions of rangeland degradation echo the results of the studies conducted in the $80 \mathrm{~s}$ and 90s that classify rangelands as severely degraded. Rangeland condition worsened from estimations of good (30\%), fair (50\%), and poor (15\%) (Flores \& Bryant, 1989), to mostly poor (80\%) (INIA 2012).

\subsection{Perceptions of rangeland degradation by pastoralists}

Table 4 presents perceptions of rangeland degradation of pastoralists of the communities Apopata, Chocorasi, and Lacotuyo, located in the southern Peruvian Altiplano, corresponding to the dry puna ecozone. In addition, Table 5 presents their perceptions of rangeland condition. Pastoralists women and men were interviewed, but answers are reported together because there was no difference by sex. 
Table 4. Pastoralists' perceptions of rangeland degradation

\begin{tabular}{|l|c|c|c|c|c|}
\hline Rangeland changes & $\begin{array}{c}\text { Apopata } \\
\mathrm{n}=37\end{array}$ & $\begin{array}{c}\text { Chocorasi } \\
\mathrm{n}=25\end{array}$ & $\begin{array}{c}\text { Lacotuyo } \\
\mathrm{n}=21\end{array}$ & $\begin{array}{c}\text { Total } \\
\mathrm{n}=83\end{array}$ & $\%$ \\
\hline Worse & 27 & 15 & 13 & 55 & $66 \%$ \\
\hline Same & 7 & 5 & 5 & 17 & $20 \%$ \\
\hline Better & 3 & 5 & 3 & 11 & $13 \%$ \\
\hline Total & 37 & 25 & 21 & 83 & $100 \%$ \\
\hline
\end{tabular}

Table 5. Pastoralists' perceptions of rangeland condition

\begin{tabular}{|c|c|c|c|c|c|}
\hline Rangeland condition & $\begin{array}{c}\text { Apopata } \\
n=37\end{array}$ & $\begin{array}{c}\text { Chocorasi } \\
n=25\end{array}$ & $\begin{array}{c}\text { Lacotuyo } \\
n=21\end{array}$ & $\begin{array}{l}\text { Total } \\
n=83\end{array}$ & $\%$ \\
\hline Bad & 8 & 2 & 5 & 15 & $18 \%$ \\
\hline Fair & 26 & 19 & 16 & 61 & $73 \%$ \\
\hline Good & 3 & 4 & - & 7 & $8 \%$ \\
\hline Total & 37 & 25 & 21 & 83 & $100 \%$ \\
\hline
\end{tabular}

\subsubsection{Apopata}

When pastoralists of Apopata were asked about the current condition of their rangelands, the majority of them $(70 \%)$ believe that rangelands are in fair condition, $22 \%$ in poor, and $8 \%$ in good condition (Table 5). When they were asked about changes that they have noticed compared to 30 years ago, most of them (73\%) believe that rangelands have gotten worse, some (19\%) believe that rangelands have stayed the same, and a few (8\%) believe that rangelands have improved (Table 4). In addition, the majority believe that the future of rangelands is not positive. 
Pastoralists were asked what changes they have noticed. Those who believe that rangelands got worse and condition is fair and poor noticed changes in vegetation. They primarily refer to changes on peatbogs. Pastoralists claim that peatbogs got smaller and plant species preferred by alpacas were reduced.

A 49-year-old man from Apopata laments: "The bofedales are getting dry..... every year bofedales are getting smaller... from one year to another they are not returning the same .... some plants that alpacas eat are disappearing.....they were more nutritious... especially "tinha"(Distichia muscoides, plant preferred by alpacas) was more robust... but now they stay short, thin, and chuma (rotten), and when they return the next year, they do not grow as before"

Secondly, pastoralists refer to changes in the dry-grasslands. They claim that chillwares (plant preferred by alpacas) grow shorter and weaker than before. Pastoralists also affirm that chilliwares have been displaced by irus and canllas (plants that alpacas do not eat).

A 70-year-old woman from Apopata describes, "Before chilliwas were better, plants grew taller and thicker.....now they are short.... before you could see chilliwares everywhere in the community, but now there are not too many left .... In the past there was not that much iru ......now you can see a lot of irus and canllares.

Other changes observed by pastoralists who believe that rangelands got worse are those related to the productivity of peatbogs and to animal production. Pastoralists realize that peatbogs are less productive because now they can maintain fewer animals than they could before. Likewise, they also realize that animals hardly gain weight, are sick more often, and can sometimes die.

A 68-year-old woman from Apopata discloses, "Alpacas always lose weight at the end of the dry season because the peatbogs are done, but now they get sick and they can die more than before".

Other negative changes that these pastoralists associate with rangelands getting worse are changes in grazing duration; they recognize that the rainy season grazing 
period has shortened. They also notice that animals cannot get enough food in a normal grazing day and that peatbogs and dry-grasslands lasted longer before.

A 50-year-old woman from Apopata shares, "Before, I grazed the whole day and my animals were full at the end of the day, now I do the same but my alpacas look hungry, I feel sorry for them but I do not know what to do".

A 69-year-old man from Apopata says, "Before, both pastures (peatbogs and drygrasslands) lasted the whole year but now they hardly last until October... in November, animals are so skinny that they die, and pregnant females miscarry".

Pastoralists who believe that rangelands have improved, and that conditions are between fair and good, argue that this is because they worked hard on that. These pastoralists affirm that peatbogs were in bad condition when they started to oversee the system. They water, add manure, and enclose some areas of peatbogs for critical times. Thus, they argue that peatbogs have improved because of their conservation practices. However, these pastoralists do not take action to improve dry-grasslands.

\subsubsection{Chocorasi}

The majority (76\%) of pastoralists from Chocorasi believe that rangelands are in fair condition, some of them (16\%) believe that they are in good condition and only few (8\%) believe that they are in bad condition (Table 5). On the other hand, 60\% believe that rangelands have gotten worse, $20 \%$ believe that they have improved, and the other $20 \%$ think they have not changed (Table 4). Like Apopata's pastoralists, most of Chocorasi's pastoralists believe that the rangelands' future is not positive. Those who think the rangelands got worse have noticed changes mainly in the peatbogs. Chocorasi's pastoralists affirm that peatbogs are smaller and less productive. Like in Apopata, they have observed that plants that alpacas prefer have been reduced in availability, density, size, and vigor. These plants are now less available, shorter, and thinner, and therefore 
less productive. They also associate these changes in peatbogs with the reduced ability to keep big herds and the poor animal productivity. These pastoralists also observed some changes in plant composition of the dry-grasslands.

A 55-year-old woman from Chocorasi says, "Before pastures, irus stayed green more time and now they are always dry, they get dry very fast and are like hay most of the year".

Pastoralists who believe that rangelands have improved, and conditions are mostly fair, similarly to Apopatas' pastoralists, think it is because they take care of them very well.

\subsubsection{Lacotuyo}

The majority $(76 \%)$ of pastoralists from Lacotuyo believe that rangelands are in fair condition, and some of them $(16 \%)$ believe that they are in bad condition. Pastoralists of Lacotuyo do not believe they have any rangelands in good condition (Table 5). On the other hand, $62 \%$ believe that rangelands got worse, $24 \%$ believe that they have stayed the same, and the other 14\% think they have improved (Table 4). Like Apopata and Chocorasi, most of Lacotuyo's pastoralists think that rangelands are going to be more scarce in the future. Likewise, those who think rangelands got worse have noticed changes primarily in the peatbogs. Theses pastoralists believe that areas covered by peatbogs have decreased in number and in extension. In addition, the types of plants in the peatbogs have changed as well. Likewise the other communities, pastoralists of Lacotuyo, noticed peatbogs are less productive and grazing times have been reduced.

A 49-year-old man from Lacoutyo claims, "Before, my peatbog lasted the whole year, now only until October, some pastures disappear from the peatbogs" 
Those pastoralists who believe rangelands have improved argue it is a consequence of proper management and the efforts they make to keep them in good shape. They say it is due to constant watering, expanding peatbogs, preserving fields with ahijaderos (enclosures), introducing cultivated pastures, and grazing fewer animals.

\subsubsection{Summary pastoralists}

Pastoralists of the communities of Apopata, Chocorasi, and Lacotuyo share the same perceptions about the rangelands of the southern district of Mazocruz, Puno. The majority (66\%) believe that in the last 30 years, rangelands have gotten worse, some (20\%) think that rangelands have stayed the same, and a few of them (13\%) believe that rangelands have gotten better. One the other hand, $73 \%$ of pastoralists believe that rangelands are in fair condition, $18 \%$ believe that rangelands are in bad condition, and $8 \%$ believe that rangelands are in good condition. Only the pastoralists of Lacotuyo think that there are no rangelands in good condition in their community. Thus, when pastoralists believe that rangelands have gotten worse, they mean slightly worse because they believe rangelands are mostly in fair condition. However, all of them believe that there is a negative trend for conditions to get even worse. It is important to mention that pastoralists do not use the term degradation to refer to those negative changes. It is also important to remind that pastoralists classify rangelands in two main types: peatbogs and dry-grasslands, and changes they observe in them regarding rangelands maintain these local classifications.

The main important change observed by most of pastoralists as they explain degradation is the reduction of the number and extension of peatbogs. Pastoralists affirm 
that peatbogs are now fewer and smaller than they were 30 years ago and they observe that peatbog plants that alpacas prefer are fewer and shorter. Pastoralists affirm that the reduced availability of peatbogs makes animals lose weight and increases their mortality rates. Consequently, the number of animals has been reduced and animal productivity has decreased. Some pastoralists mention other changes with dry-lands related to rangeland degradation. These pastoralists have noticed that festucas (palatable drygrasslands) have decreased, irus (less palatable dry-grasslands), and canllares (unpalatable dry-grasslands) have increased. Plants that alpacas prefer, like festucas, are weaker and less plentiful than 30 years ago. They also associate rangeland degradation with changes in grazing duration. During their daily rotations, they have observed that animals return hungry to the corral at the end of the day. They have also noticed that seasonal grazing in the dry-grasslands during the rainy season is shorter than 30 years ago because availability of dry-grasslands has been reduced.

Rangeland degradation in pastoralists terms, does not seem to be that severe because the majority of pastoralists believe rangelands are in regular condition. If it was severe, most pastoralists would report more rangelands as being in poor condition. Pastoralists associate the deterioration of rangelands with the reduced availability of peatbogs and to the decline in animal productivity they have observed in the last 30 years. The increase of less preferred plants over more preferred plants on the rangelands does not seem to be a determining factor for pastoralists when evaluating rangeland condition. It seems that the type of vegetation in place is not that important for pastoralists as long as some kind of forage is available. The most serious changes for pastoralists are the declines in peatbogs and animal production. 


\subsection{Different perceptions of rangeland degradation}

Perceptions of stakeholders and pastoralists about rangeland condition and degradation are different. While most stakeholders believe that rangelands are severely degraded, most pastoralists believe that they are slightly degraded. Most stakeholders believe that almost all rangelands are in poor condition. On the contrary, most Altiplano pastoralists believe that rangelands are in fair condition. However, all of them, stakeholders and pastoralists, believe that the trends for rangelands are worsening.

Pastoralists and stakeholders use different indicators to evaluate rangelands.

Pastoralists focus more on peatbogs and less on dry-grasslands. Stakeholders, on the contrary, focus more on dry-grasslands and almost not at all on peatbogs. Pastoralists focus more on peatbogs because in these arid lands, peatbogs are the main food source for alpacas, therefore they are key resources for raising alpaca. Peatbogs are used mostly in the dry season, which is the longer and more critical season of the year. Peatbogs are especially crucial at the end of the dry season, when almost no dry-grasslands are available. Dry-grasslands in these pastoralist systems are used mostly in the rainy season, about a quarter of the year. Thus, peatbogs are used to determine the numbers of animals to keep in the herd, which determines the size of the pastoralists' system. Stakeholders focus their rangeland evaluations on dry-grasslands because they represent $75 \%$ of the country's rangelands. For stakeholders, dry-grasslands largely represent the main reserves of plant diversity, plant cover, prevention from soil erosion, and ecosystem services in the Andes.

Pastoralists and stakeholders measure different aspects of vegetation. Pastoralists care about the number, size, and productivity of peatbogs. In the last 30 years, most 
pastoralists have noticed that peatbogs have been reduced in number; some have shrunken, and others have disappeared. Pastoralists have noticed some changes in plant composition, but they do not care that much as long as they produce forage. Thus, peatbog productivity is important for them because it correlates directly with animal productivity. In this sense, pastoralists have noticed animals that do not eat sufficiently do not gain enough weight, produce less fiber, get sick more often, and die more than in the past.

Stakeholders care about plant composition, vigor, and cover from dry-grasslands. The combination of these measurements meets the Range Condition and Trend model used largely by stakeholders, which classifies rangeland condition in excellent, good, fair and poor. All stakeholders reported that palatable plants have decreased, and that fewer or no palatable plants have increased, as indicators of rangeland degradation. Most stakeholders also reported that the vigor of key species has decreased, that plant cover has been reduced, and even some stakeholders reported signs of soil erosion and desertification. Plant composition is important, especially for scientists, because it is associated with plant diversity and vegetation climax. Vegetation climax is a utopic class of vegetation that would exist if rangelands were not grazed. Excellent condition equivalent to vegetation climax and poor condition is associated with degraded rangelands or those at risk of degradation. In Peru, almost all rangelands are grazed. Plant vigor is associated with rangeland health and production while plant cover is associated with prevention of soil erosion. Based on this model, stakeholders affirm that most rangelands are severely degraded because they believe most rangelands are in poor condition. 
Pastoralists and stakeholders have different management goals and interests. The pastoralists' goal is animal production for income generation to meet family needs., whereas the stakeholders' goal is rangeland conservation to preserve ecosystem services for future generations. Pastoralists focus on peatbogs because they depend on them for a living. Thus, they are interested in the economic role of rangelands for their own benefit. Stakeholders focus on dry-grasslands because they provide multiple ecosystems services. Thus, they are interested in the ecological and environmental role of rangelands for the benefit of the planet and for present and future generations. Both interests are valid and can complement each other. Their scale of view of the problem can be another difference. Pastoralists have a view of the problem that is limited to the land they manage, whereas stakeholders have a countrywide or regional view of the degradation problem.

Both views of rangelands degradation are different but can complement each other. Pastoralists and stakeholders have different perceptions because they have different life-worlds. Thus, pastoralists' perceptions are constructed on the direct use of peatbogs, on their empirical knowledge of rangelands, and on the need to meet family demands. Stakeholders' perceptions are constructed on previous and current research information influenced by the RC\&T model, and on the roles each stakeholder plays. Using life-worlds theory (Arce \& Long, 1992), we can explain that pastoralists and stakeholders, based on their own life circumstances, make subjective constructions from their realities of rangeland degradation. Thus, the constructions of reality of rangelands degradation that pastoralists make are that rangelands are slightly degraded. Stakeholders' constructions of reality of rangelands degradation is that rangelands are severely degraded. Each construction of reality works for each group. 
Different perceptions of rangelands degradation, the use of different indicators to measure condition and degradation, and having different goals and interests on rangelands lead to inaccurate policies or erratic behaviors. Thus, stakeholder aim to reduce the stocking rate and have the government promote land privatization and pastoralists tend to overexploit rangelands to increase animal production. It is important to have an objective view of the rangeland degradation problem to promote a common understanding of users and stakeholders. A realistic view of the degradation problem can be obtained with further research with new models. A common understanding of users and stakeholders can be achieved with the use of more comprehensive and integrated management and monitoring models that include both groups as key actors, using their knowledge and participation. 


\section{CAUSES OF RANGELAND DEGRADATION}

\subsection{Perceptions of causes of rangeland degradation by stakeholders}

Table 6 shows stakeholders' perceptions of the causes of rangeland degradation. In order of importance, the causes of degradation stakeholders claimed are overgrazing due to inappropriate mismanagement, overgrazing due to overstocking, climate change, land fragmentation, peasant culture, failure state to meet its responsibilities, fragile ecosystem and other. Inappropriate management for stakeholders consists of all the unsustainable practices that pastoralists and herders use for rangeland and livestock management that lead to overgrazing. Overstocking refers to grazing excessive number of animals that leads to overgrazing. Overstocking can be part of inappropriate management, but stakeholders reported it as a separate cause. Climate change refers to the erratic weather conditions and warming trend observed by pastoralists and stakeholders during the last 30 years. Land fragmentation refers to the division of land among multiple heirs and to the resulting privatized management of rangelands and animals. Peasant culture refers to the poor organizational capacity, subsistence living conditions, and low investment capacity of poor pastoralists. Failure of the state to meet its responsibilities refers to the failure of Peruvian governments at all levels to effectively address rangeland degradation and their failure to protect key natural resources for agriculture and the environment. Fragile ecosystem refers to the high vulnerability of Andean ecosystems, including fragile soils. 
Table 6. Perceptions of main causes of rangeland degradation by stakeholders

\begin{tabular}{|c|c|c|c|c|c|c|c|c|c|}
\hline \multirow{2}{*}{$\mathrm{N}^{\circ}$} & \multirow{2}{*}{ Main Causes of Rangeland Degradation } & \multicolumn{2}{|c|}{ Scientists } & \multicolumn{2}{|c|}{ Government } & \multicolumn{2}{|c|}{ NGOs } & \multicolumn{2}{|c|}{ Summary } \\
\hline & & $\mathrm{n}=10$ & $\%$ & $\mathrm{n}=9$ & $\%$ & $\mathrm{n}=4$ & $\%$ & $\mathrm{n}=23$ & $\%$ \\
\hline 1 & Overgrazing by inappropriate management & 8 & $80 \%$ & 6 & $67 \%$ & 4 & $100 \%$ & 18 & $78 \%$ \\
\hline 2 & Overgrazing by overstocking & 9 & $90 \%$ & 7 & $78 \%$ & 1 & $25 \%$ & 17 & $74 \%$ \\
\hline 3 & Climate change & 5 & $50 \%$ & 5 & $56 \%$ & 3 & $75 \%$ & 13 & $57 \%$ \\
\hline 4 & Land fragmentation & 5 & $50 \%$ & - & - & 3 & $75 \%$ & 8 & $35 \%$ \\
\hline 5 & Peasant culture & 3 & $30 \%$ & 2 & $22 \%$ & 2 & $50 \%$ & 7 & $30 \%$ \\
\hline
\end{tabular}


Table 7. Perceptions of main causes of rangeland degradation by scientists

\begin{tabular}{|c|l|c|c|c|c|c|c|}
\hline \multirow{2}{*}{$\mathrm{N}^{\circ}$} & \multirow{2}{*}{ Main Causes of Rangeland Degradation } & \multicolumn{2}{|c|}{ Lima Scientists } & \multicolumn{2}{|c|}{ Puno Scientists } & \multicolumn{3}{|c|}{ Total } \\
\cline { 3 - 8 } & & $\mathrm{n}=4$ & $\%$ & $\mathrm{n}=6$ & $\%$ & $\mathrm{n}=10$ & $\%$ \\
\hline 1 & Overgrazing by overstocking & 3 & $75 \%$ & 6 & $100 \%$ & 9 & $90 \%$ \\
\hline 2 & Overgrazing by inappropriate management & 2 & $50 \%$ & 6 & $100 \%$ & 8 & $80 \%$ \\
\hline 3 & Climate change & 1 & $25 \%$ & 4 & $67 \%$ & 5 & $50 \%$ \\
\hline 4 & Land fragmentation & 1 & $25 \%$ & 4 & $67 \%$ & 5 & $50 \%$ \\
\hline 5 & Peasant culture & 1 & $25 \%$ & 2 & $33 \%$ & 3 & $30 \%$ \\
\hline & & & & & & & 3 \\
\hline
\end{tabular}

Table 8. Perceptions of main causes of rangeland degradation by government

\begin{tabular}{|c|l|c|c|c|c|c|c|}
\hline \multirow{2}{*}{$\mathrm{N}^{\circ}$} & \multirow{2}{*}{ Main Causes of Rangeland Degradation } & \multicolumn{2}{|c|}{ Lima Government } & Puno Government & \multicolumn{2}{|c|}{ Total } \\
\cline { 3 - 9 } & & $\mathrm{n}=4$ & $\%$ & $\mathrm{n}=6$ & $\%$ & $\mathrm{n}=10$ & $\%$ \\
\hline 1 & Overgrazing by overstocking & 3 & $100 \%$ & 4 & $67 \%$ & 7 & $78 \%$ \\
\hline 2 & Overgrazing by inappropriate management & 2 & $67 \%$ & 4 & $67 \%$ & 6 & $67 \%$ \\
\hline 3 & Climate change & 1 & $33 \%$ & 4 & $67 \%$ & 5 & $56 \%$ \\
\hline 4 & Land fragmentation & - & - & - & - & - & - \\
\hline 5 & Peasant culture & 2 & $67 \%$ & - & - & 2 & $22 \%$ \\
\hline & & & & & & \\
\hline
\end{tabular}


Table 9. Perceptions of main causes of rangeland degradation by NGOs

\begin{tabular}{|c|l|c|c|c|c|c|c|}
\hline \multirow{2}{*}{$\mathrm{N}^{\circ}$} & \multirow{2}{*}{ Main Causes of Rangeland Degradation } & \multicolumn{2}{|c|}{ Lima NGO } & \multicolumn{2}{|c|}{ Puno NGO } & \multicolumn{2}{c|}{ Total } \\
\cline { 3 - 8 } & & $\mathrm{n}=4$ & $\%$ & $\mathrm{n}=6$ & $\%$ & $\mathrm{n}=10$ & $\%$ \\
\hline 1 & Overgrazing by inappropriate management & 1 & $100 \%$ & 3 & $100 \%$ & 4 & $100 \%$ \\
\hline 2 & Climate change & - & - & 3 & $100 \%$ & 3 & $75 \%$ \\
\hline 3 & Land fragmentation & 1 & $100 \%$ & 2 & $67 \%$ & 3 & $75 \%$ \\
\hline 4 & Peasant culture & - & - & 2 & $67 \%$ & 2 & $50 \%$ \\
\hline 5 & Overgrazing by overstocking & - & - & 1 & $33 \%$ & 1 & $25 \%$ \\
\hline
\end{tabular}


For most scientists, most government officials, and all NGOs representatives, inappropriate management is the main cause of degradation. Similarly, most scientists and government officials believe that overstocking is the second most important cause of rangeland degradation. However, for NGO representatives, overstocking is a secondary factor. Climate change is a more important cause of degradation for NGO representatives than for government officials and scientists, who consider climate change a less important cause of degradation. Land fragmentation is an important cause for scientists and NGO representatives, but not at all for government officials. Peasant culture is a secondary cause of degradation for all stakeholders. State failure and a fragile ecosystem are secondary causes for scientists and government officials but not for NGO representatives. Other minor causes of rangelands degradation that stakeholders mentioned are mining, social and market change conditions, and failure by pastoralists to comply with community agreements.

\subsubsection{Overgrazing by inappropriate management}

Overgrazing due to inappropriate management of rangelands is the most important cause of rangeland degradation for $78 \%$ of stakeholders overall (Table 6 ); $80 \%$ of scientists, $67 \%$ of government officials, and $100 \%$ of NGO representatives believe this.

Inappropriate management is the most important cause for rangeland degradation for NGO representatives while it is the second most important cause for scientists and government officials. Overgrazing by inappropriate management is the most important cause of degradation for Puno scientists and the second most important for Lima scientists (Table 7). It is the most important for Puno government officials and second in 
importance for Lima officials (Table 8). For NGOs, inappropriate management is equally most important for both Lima and Puno NGO officials (Table 9).

By inappropriate management, stakeholders refer to the practices that lead to the intense use of rangelands. Those unsustainable practices are continuous grazing, the reduction or discontinuation of resting periods, and the reduction or cessation of rotations. Puno government officials and Puno NGO representatives emphasize that continuous and intensive grazing is even more accentuated in peatbogs than in drygrasslands in the Altiplano. A Puno scientist explains that rotations are less frequent due to reduced grazing plots in the Altiplano. Stakeholders express these views in the following quotes:

A Puno scientist says, "Presently, there is an increased utilization of rangelands..... rangelands are constantly grazed .... the continuous grazing is very harmful because it does not allow plants to grow enough to seed.... that occurs especially with desired plants"

A GORE Puno officer shares, "The rest periods are not respected as they were in the past, impeding the natural recovery of the plants that animals eat.... On the contrary, undesired plants have opportunities to expand with this intensified use, causing degradation".

Stakeholders include the loss of transhumance patterns and reductions in the use of pircas (stone fences) as inappropriate management. A Puno scientist adds that the seasonal vertical movements are also less practiced contributing to the concentration of livestock in small areas. Another Puno scientist argues that pastoralists have abandoned the use of pircas (stone fences) for rangeland management because they are not maintained anymore. They express these views in the following quotes:

A Puno scientist states, "Before, pastoralists strictly moved up the hill during the rainy season and moved down the hill during the dry season. With this management strategy, grasslands on both sites (up the hill and down the hill) had time to recover from 
grazing. However, the high competition for access to the grazing lands in the community has made this movement less feasible. So pastoralists now concentrate more animals in smaller areas, and there is the overgrazing problem".

A Puno scientist argues, "Pastoralists have abandoned the use of pircas that they have for the proper management of rangelands because those fences are not maintained anymore.... the use of fences is critical for the proper management of rangelands, for rotations. Fencing is the indispensable tool for range management. The care of shepherds is not enough. Only with fences can one take care of rangelands properly. If there are no fences, grazing becomes open, and then we have the tragedy of the commons".

Likewise, stakeholders consider the use of single mixed herds and the use of inadequate animal type as inappropriate management. Puno government officials explain that animals have different grazing patterns and rangelands are mostly specific for one type of animal at a time. A Puno scientist explains that alpacas graze selectively while cattle and sheep graze indiscriminately, so competition over vegetation in a single mixed herd is high and this leads to overgrazing and degradation. On the other hand, some stakeholders explain that grazing cattle and sheep in Andean rangelands drives degradation because their grazing behaviors are harmful. In addition, they are alarmed at the use of cattle and sheep in peatbogs since these are exclusively for grazing alpacas. They express this in the following quotes:

A GORE Puno official complains, "Pastoralists now mix all the animals in only one herd, which they graze together... they put alpacas, llamas and sheep, and sometimes even cattle together!.....They lack technical management..... This type of livestock management harms peatbogs and dry-grasslands."

A Puno scientist asserts, "Rangeland degradation started with the introduction of different grazing animals with different grazing patterns. The change from only alpacas grazing selectively to the incorporation of European livestock, which raze everything indiscriminately, definitely was the main perturbation that rangelands had and it continues. However, vegetation have survived but quality has decreased". 
The abandonment of conservation practices for rangeland maintenance and the increased use of burns are also indicated as inappropriate management. The loss of conservation practices like watering and adding manure that pastoralists performed more frequently in the past also contribute to degradation. On the other hand, it is mostly the Puno stakeholders who have noticed that burns in the Altiplano have increased and they believe that these also cause rangeland degradation. Stakeholders explain themselves in the next few quotes:

A MINAM official claims, "The conservation practices that ensured the recuperation of rangelands like watering and adding manure by peasants has been abandoned".

A Puno scientist explains, "Pastoralists in the past counted on developed watering systems for peatbogs maintenance, conservation, and expansion. However, those communal systems are not in place anymore. Thus, the loss of the practice of watering rangelands has contributed to degradation".

A Puno NGO representative states, "The practice of burns has spread in the region, now you can see more burned areas everywhere... they are more frequently used than before as well and the burning period has extended.... Thus, before they only burned in June but now they burn until November".

Finally, stakeholders address the use of turnos (by times) and insufficient or incompetent labor for grazing are also considered inappropriate management. These stakeholders explain that the "turnos" are a sort of itinerate labor that allow migrants (former comuneros living in lower areas) to help out with the management of rangelands and livestock. They also explain that mostly elderly people, women, and children are in charge of grazing. However, they argue that these laborers cannot perform all the activities the rangeland-livestock system demands. They explain in their own words in the next quotes. 
One NGO representative indicates, "The use of "turnos" for managing rangelands-livestock systems reflects the critical condition of rangeland management.....Those turns are made by migrants who only come for a month or turn.....Making decisions for grazing and rotation require information that is only available with the daily interaction with rangelands, animals and environment.... the use of turns promotes the intensive use of rangelands since turn managers do not have enough information"

Another Puno NGO representative explains, "Many elderly people are in charge of animal grazing ...... however they can't do it properly because their elderly condition impedes them from moving around easily. For this reason, they keep animals in the same grazing site. Even if they have more grazing sites, they do not use them because those are too far for them, they can't take animals there, and prefer to keep grazing the closest one".

For most stakeholders, inappropriate management of rangelands leads to intensive use, impeding their growth and recuperation. This intensive use, in turn, leads to overgrazing and degradation. Many of these stakeholders, mostly Lima scientists and government officials in Lima and Puno, explain that pastoralists do not manage rangelands properly because they lack accurate knowledge about rangelands, they do not understand rangeland dynamics, they do not have the capabilities to manage them well, or they just do not care. Other stakeholders, mostly Puno scientists and NGO representatives, go further in their explanations and associate the inappropriate management to other underlying issues in pastoralists systems, like land fragmentation, which will be described later as another cause of degradation. In addition, only Puno NGO representatives associate inappropriate management to labor shortages due to outmigration.

A Puno NGO representative explains it in this way, "Due to limited development opportunities in the highlands, young people out migrate to look for better possibilities...leaving the most vulnerable members of the household like elderly people, women, and children in charge of rangelands, livestock, and water management... These people are not able to provide the appropriate labor that these systems require". 
Another Puno NGO representative provides more detail, "Southern Altiplano pastoralists have developed an interesting peatbog-dry-grasslands management dynamic that consists of changing and rotating animals among sites....one season they take animals here.... another over there and so on...... But things get complicated with migration .... young people go to Tacna or Moquegua ... so elderly people stay to take care of the animals..... However, they cannot continue practicing this (changing sites and rotation) because their (physical) condition does not allow it.... for this reason they keep animals more sedentary, grazing one single site for longer..... and so the overgrazing problem begins.....even more, despite them having other grazing sites, they do not use them because they cannot reach them and take animals there because they are far away. Therefore, sometimes they rent these sites to others, although they cannot supervise them to know how lessees are using them".

\subsubsection{Overgrazing by overstocking}

For $74 \%$ of stakeholders overall, overgrazing due to overstocking is the second most important cause of rangeland degradation (Table 6). Ninety percent of scientists, $78 \%$ of government officials, and $25 \%$ of NGO representatives believe this. So, for scientists and government officials, overstocking is the most important cause of rangeland degradation, while for NGO representatives it is the fourth most important cause. Among scientists and government officials, overstocking is the most important cause of degradation for those in both Lima and Puno (Table 7, Table 8). On the other hand, in regard to NGOs representatives, overstocking is the third most important cause of degradation for Puno NGO representatives but is not mentioned by Lima NGO representatives (Table 9). By overstocking, stakeholders refer to excess animals per grazing area. They argue that pastoralists regularly graze too many animals for the capacity of the land they have.

Overstocking can be considered inappropriate management. However, stakeholders reported it separately because they consider this by itself an important cause of degradation. They express their views about overstocking in the following statements: 
A Lima scientist says, "Presently, there is increased utilization of rangelands. The animal population has increased but the land remains the same, there are more animals now in smaller grazing plots. Therefore, the natural prairie in the Andes has over exceeded its carrying capacity ${ }^{9}$."

A Puno scientist shares, "The constant and permanent overgrazing with high stocking rates ${ }^{10}$ for a long time causes degradation. This occurs mostly in peasant communities."

Another Puno scientist says, "Peatbogs now receive heavy loads of animals for more prolonged time than before. The high concentration of grazing animals in smaller areas of peatbogs leads to degradation".

Another Puno scientist claims, "The livestock population is increasing .... This requires the rangelands to maintain a greater number of animals...then the utilization of the resource has passed its support capacity threshold, leading to overgrazing"

A Lima MINAGRI government official explains, "You can perceive the overgrazing because you notice that the animal population is increasing and the extent of rangelands remains the same ..... There is an increase in the livestock population ... so it is presumed that the rangelands are increasingly under more pressure...."

A MINAM officer says, "The over exceeded carrying capacity in the Andes is something horrible because the sheep are worth so little and the comunero want to have more to have more money ... therefore they overpopulate the flocks"

For most scientists and government representatives, overstocking is an even more important cause than inappropriate management. They believe that the carrying capacity of rangelands per region has been exceeded in most places in the Andes. Too many animals in one specific area obliterate the vegetation, depriving plants of $30 \%$ of the reserves they require to replenish. Then, overgrazing and degradation occur. These stakeholders assume that livestock increased because of population growth in the Andes.

\footnotetext{
${ }^{9}$ Carrying capacity is defined as the number of grazing animals a piece of land can support long term while maintaining or improving the rangeland resources (vegetation, soils, and water). Cite author, year and add to references

${ }^{10}$ Stocking rate is defined as the number of animals grazing on a given amount of land for a specified time. Stocking rates are often expressed in Animal Unit (AUs) per unit area (AU/Hectare). Optimal stocking rates maintain rangelands in good condition. cite author, year and add to references
} 
They explain that population growth implies the creation of new families and each new family starts at least one new herd. These new families also have to meet their needs and so they increase their herds. They explain that pastoralists regularly keep more animals than rangelands can support because they lack knowledge or concern about natural resources.

Others associate overstocking to some practices like keeping animals with poor genetic quality, old and low productivity animals that they link to the situation to be poor pastoralists. Such practices will be addressed later in another section of this chapter. Few stakeholders, especially NGO representatives, associate overstocking to the low prices and other unfavorable market conditions that pastoralists face. For the most part, NGO representatives and a minority of scientists and government officials do not think that overstocking is occurring, or that it is important. They think this because believe that populations decrease or stay the same due to high migration rates from the highlands to lower lands or cities.

One Puno NGO representative says, "There is no population growth in the Altiplano, I would say that instead, the population is stagnant and even decreasing, because there is also a lot of migration. I do not see that livestock has increased that much. What I see is that animals have become less productive, but the number is the same or slightly more”.

\subsubsection{Climate change}

Climate change is the third most important cause of rangeland degradation for $57 \%$ of stakeholders overall (Table 6). Seventy five percent of NGO representatives, $56 \%$ of government officials, and $50 \%$ of scientist agree. Climate change is the second most important cause of degradation for NGO representatives and the third most important 
cause for scientists and government officials. Among scientists, climate change is the third important cause for Lima scientists while it is the second for Puno scientists (Table 7). For the government, it is the third most important cause for Lima government officials, while it is the most important cause for Puno government officials, equally as important as overstocking and inappropriate management (Table 8). Among NGOs, climate change is the most important cause for Puno NGO representatives, as equally important as inappropriate management, but it was not mentioned by the Lima NGO (Table 9).

Stakeholders explain climate change effects related to rangelands degradation. There is less water due to reduced rainfall, irregular rainfall, increased sunshine, increased runoff, less humidity, and increased dryness. There are changes in seasonality due to a shorter and more concentrated rainy season and a longer dry season. There is an increased frequency of extreme events due to daily temperature variations that are more abrupt, and extreme longer temperature drop periods like friajes ${ }^{11}$. Some stakeholders go further to explain that these events not only affect regular vegetation growth and recovery, but also stress calendar and planning pastoralists have for resource management. The following expressions explain climate change as a cause of degradation.

A Lima scientist explains, "Climate change directly impacts precipitation levels. Therefore, water for the rangeland is less available, directly affecting their productivity. On the other hand, because rainfall becomes less regular, there is a lower predictability capacity for herders to adjust their management".

\footnotetext{
${ }^{11}$ Friaje is an occasional climate event consisting of extreme drops in low temperatures and prolonged snow fall periods occurring in the high puna zone of the Andes (FAO, 2008), primarily affecting inhabitants and causing a high number of alpaca deaths, creating a very bad economic situation for pastoralist communities
} 
A Puno scientist recalls, "Altiplano climate is very dynamic and cyclical. There are regular years and irregular years. There are wetter years and dryer years. Thus, there are years with good rangeland production and years with less production, like the present year (2010) where rainfall is delayed. This means that vegetation will stop growing earlier. Therefore, if pastoralists do not adjust stocking rates, rangelands at some point will be overgrazed due to the effect of climate change.

A Puno government officer says, "Climate change is strongly affecting the Altiplano, especially the high areas where the main livelihood is raising alpaca. So, there is less rainfall and the sunshine is more intense, causing water sources to be reduced and dryness to increase. All this makes dry-grasslands produce less and peatbogs get dry”.

A Puno NGO representative notes, "Due to climate change, there is less water to maintain and take care of peatbogs.

A Puno scientist explains, "Climate change causes the dry season to get longer and the rainy season to get shorter and concentrated to a few weeks. This affects rangeland productivity. Soils increase runoff because they are unable to retain much water during the concentrated rainfall, so soil humidity lasts for a shorter time and produces less vegetation. It generates forage deficits for livestock, which get worse when vegetation does not return the next season at the time they expect.

A Puno scientist says, "The problem with seasonality change is that calendars that pastoralists have for rangeland management no longer work under current climate conditions. In addition, adjustments to these calendars are difficult to make because elderly pastoralists hardly adapt to changes.

A Puno government official states, "We have noticed that reforestation activities in the 80s were planned from December to March. Because the rainy season has shortened, we plan for only January and February. So we have also adjusted to that new routine.

A Puno NGO representative says, "With climate change, rainfall has concentrated in a short time and occurs in heavy amounts. So, because the highlands' soils are already eroded, they cannot retain rain now and so increased runoff offers little chance for recovery"

A Puno scientist says, "Irregular rainfall and abrupt day and night temperature variations due to climate change stress plants, causing loss of vigor, reduced density, and they become less productive". 
A Puno NGO representative explains, "Rangeland degradation is not only caused by bad management, but also due to extreme climatic events. When a severe snow falls or frost occurs, the soil is at the freezing point, affecting the roots of the plants, and as a consequence, they die. This especially affects dry-grasslands that have very superficial and small roots".

\subsubsection{Land fragmentation}

For 35\% of stakeholders overall, land fragmentation is the fourth most important cause of rangeland degradation (Table 6). This is because $75 \%$ of NGO representatives and $50 \%$ of scientists believe that. None of the government officials mentioned it as a cause. Land fragmentation is the second most important cause of degradation for NGO representatives and third most important cause for scientists. Among scientists, land fragmentation is the third most important cause for Lima scientists while it is the second most important cause for Puno scientists, equally important as climate change. In regard to NGOs, land fragmentation is the most important cause for Lima NGO representatives, equally important as inappropriate management, while for Puno NGO representatives it is the second most important.

Stakeholders refer to land fragmentation as the land division, privatization, and rangeland distribution processes occurring in the rural communities. They explain that land fragmentation does not allow for proper rangeland management because it cannot be done with small parcels. Proper rangeland management requires large areas for rotations and rest periods, key practices for rangelands recovery. They provide more details in the following quotes: 
A Puno scientist explains, "Rangeland degradation is also result of land parcelacion 12 and privatization. Parcelation happens due to land division due to human pressure. Privatization occurs because the Peruvian state promotes this as a tool for development. Both parcelacion and privatization have fragmented peasant communities' land. With land fragmentation, the functional rangeland management system that was in place was disintegrated".

A Lima scientist claims, "In most communities, land has been divided into too small parcels that I would say is more of a smallholding process because it has been reduced to its smallest units possible. Now, all the land is privatized, everyone owns a piece of land, no matter the size, and nobody can move them from there. They do not have any more communal land. It seems that herders do not realize how this affects them. Degradation occurs because rangelands are fragmented".

An NGO representative states, "In Puno there is a land division process of communal lands. In theory, according to the law, rural communities have to manage communal areas to be considered peasant communities. But in practice, the only communal areas they have are in hilltops, which are not suitable for grazing, only for conservation. Rangeland degradation got worse when land division started.

Another NGO representative adds, "Because peatbogs are the most valuable resources for alpaqueros, many families have distributed them first. It seems to me that peatbogs are more privatized than dry-grasslands. They can even have titles for peatbogs. I do not think this happens much with dry-grasslands. In any case, if they divided the land into parcels and distribute to family members, each family puts animals on their parcels, so in the end, they put more animals than before division".

\subsubsection{Peasant culture}

For 30\% of stakeholders overall, peasant culture is the fifth most important cause of rangeland degradation (Table 6). Fifty percent of NGO representatives, $30 \%$ of scientists, and $22 \%$ of government officials believe this. Then, peasant culture is the third most important cause for NGO representatives and the fourth most important cause of rangeland degradation for scientists and government officials. Among NGO

\footnotetext{
${ }^{12}$ Parcelacion is a local term used in the Peruvian Andes to refer to land division processes into small parcels.
} 
representatives, peasant culture is the second most important cause of degradation for Puno NGO representatives, equally important as land fragmentation, but is not mentioned by Lima NGO representatives (Table 9). For scientists, peasant culture is the third most important cause of rangeland degradation for Lima and Puno scientists (Table 7). For Lima scientists, peasant culture is as equally important as climate change and land fragmentation. However, for Lima government officials, peasant culture is the second most important cause of rangeland degradation, equally as important as inappropriate management (Table 8).

By peasant culture, stakeholders refer to all socio-cultural practices associated with peasants' lifestyles, mentality, land tenure, natural resources management, and decision-making processes. Many stakeholders, especially scientists evoke the haciendas period, or large production cooperatives, as the time when rangelands were properly managed properly and kept in good condition. They evoke these historic periods to refer to the times when land was in the hands of one or few managers, and contrast that era to the current communal land tenure situation. They explain that peasants are not able to deal with rangeland management properly because they lack knowledge, technology, and a vision because of their situation as poor peasants. They explain their views in the following quotes:

A Lima scientist asserts, "Haciendas were strongly attacked but they managed rangelands very well. I came from a family with a small hacienda, where we rotated the fields strictly using fences. We were aware that we had to take care of rangelands very well, otherwise we did not have good animal production. I would say that the problem is the communal land tenancy because nobody or everybody makes their own decision and so it is like open grazing. Proper rangeland management requires management capacity. Haciendas had management capacity, communities do not. I believe that rangelands are not going to recover because their proper management is incompatible with the land tenure regimes and organization of the communities". 
A Puno scientist explains, "When rangelands passed from large production cooperatives to peasant communities, the technical management that they used for rangeland management got lost. Pastoralists do not continue using fences and paddocks because they often do not know about vegetation behavior. Their weak organization, land tenure regime, poverty, lack of technology, many issues that affect proper rangeland management".

Stakeholders also explain that pastoralists deal with many socio-economic constraints like poverty, subsistence systems, and the logic of the rural poor peasant economic system. Stakeholders claim that all those issues undermine their management capacities, and for this reason, their poor peasant situation is not compatible with good rangeland management. They explain what they mean with peasant culture in the next quotes.

A Puno scientist claims, "Although pastoralists are aware of overgrazing rangelands, they say they cannot not reduce their number of animals. They say they can keep the same number or increase, but reduction is not an option. Pastoralists argue that as their families grow, so do member numbers, so their family needs also grow and therefore livestock must increase. They say they cannot reduce the number because they depend on them for survival . Pastoralists have a subsistence mentality. They are only interested in meeting their daily needs and in exploiting the rangelands to the fullest ".

Another Puno NGO representative adds, "Most cultural practices of pastoralists are in response to their situation of subsistence systems and the logic of peasant economics. Thus, they prioritize quantity over quality, having more low-producing animals than few high-producing animals. For this reason, they continue to raise low genetic quality cattle and sheep. They keep as many and older animals as they can to maximize their income opportunities. Chances for a new born to become an adult and productive are little since mortality rates are high and natality rates are low. This is a survival strategy that leads to overgrazing and degradation".

A Lima government official says, "There are many social factors among comuneros (members of a peasant community) that impede productivity. They are more interested in having more animals because it means higher social status. I see that in the community the people who have more animals are respected authorities. So these sociocultural aspects for me are connected with rangeland degradation".

A Puno NGO representative states, "Peasant communities are centers of poverty where peasants have very few and low productivity and profitable assets, so they are 
protective. For alpaca pastoralists, peatbogs are their most valuable resources because these guarantee food for their animals. So, they only focus on these resources and invest their scarce labor. They do not have time to take care of dry-grasslands on a bare slope or "tolares" (shrubs). This pastoralist attitude of only taking care of the most valuable resources and overexploiting or not protecting the least valuable contributes to degradation".

Stakeholders also point out that some social issues affecting their social structure like weak organizations, the rights of those who have out-migrated, and the vulnerability of pastoralists systems are also incompatible with proper rangelands management. The following are some quotes:

A Puno NGO representative asserts, "There is a social deterioration in peasant communities affecting organization and values. Since land division and privatized management, pastoralists behave more as private owners than communal organizations. Community authorities are less respected and have less power to exert community norms. On the other hand, migrants never lose their right to access over land and animals which makes it difficult to make management decisions. Besides, pastoralists leave the most vulnerable labor like elderly people and women to manage rangeland-livestock systems. This indicates that alpaca pastoralism has become a marginal activity characterized by exploitation. All these behaviors and cultural practices related to rangelands management contribute to degradation".

A Puno NGO representative explains, "Altiplano pastoralist communities are specialized production systems with their own economic and social dynamics. These are highly vulnerable systems because they live under risky climate and market conditions. They are highly impacted by extreme climate events such as friajes and droughts. When these events occur, they can cause severe damage and pastoralists can lose all their animals. At the same time, pastoralists are highly dependent on alpaca fiber and meat markets, which have fluctuating markets with unstable prices. Under these risky and uncertain conditions, adaptation possibilities are few and resilience capacity is low. Thus, they just survive. So chances to avoid overexploitation of their natural resources are low".

Most scientists and government officials, when thinking about peasant culture focus more on their land tenure, little knowledge, and limited access to technology access. NGO representatives focus more on poverty conditions, weak organization, ways 
they access the land and animals, control and usufruct and climate and market vulnerabilities when referring to peasant culture. Scientists and government have a more traditional view of peasant communities (not owning land, only have access to communal land, plenty of family labor available), while NGO representatives have a more modern and updated view of these communities (individual land owners, solely decision maker, scarce labor). Scientists and government officials are hardly influenced by the tragedy of the commons theory, which makes connections between communal property and overgrazing and depletion of the rangelands. NGO representatives are more influenced by their experience of working closely with pastoralists.

\subsubsection{Other}

Causes that stakeholders mentioned with less frequency are grouped in other causes (Table 10). These other causes are state failure, fragile ecosystems, insufficient research, internal armed conflict, failure to comply with community agreements, agricultural encroachment, low prices, mining, and social and market changes.

By state failure, stakeholders refer to the neglectful way different governments have tackled rangelands. Scientists and government officials argue that the absence of a national rangeland program, an extension service, and a lack of rangeland law allows the misuse and overexploitation of rangelands. They argue that the Peruvian state does not implement any legal instrument or state office for rangeland control and monitoring. There have been many attempts to create a rangeland program or to formulate a rangeland law since the $80 \mathrm{~s}$, but due to internal changes in the Ministry of Agriculture, these initiatives never consolidated. Scientists also argue that governments have erroneously promoted technologies generated for improving rangeland management for 
which inaccurate or incomplete utilization can lead to degradation. Cultivated pastures were promoted all over the Andes as a rangeland substitute instead of as supplementary forage to lighten the carrying capacity in irrigated areas. Sierra Verde Project infiltration trenches, proposed to capture water for guaranteeing rangeland availability, were initiated all over the Andes but were left unfinished when a term changed, leading instead to land erosion. On the other hand, a MINAM officer argues that the outdated MINAGRI rangeland view lead to bad policies like promoting cattle and sheep raising, animals that have harmful grazing behaviors for Andean rangelands.

By fragile ecosystems, stakeholders refer to the natural conditions that are typical of high-altitude mountain ecosystems like fragile and thin soils, harsh climate variability, slow regeneration rates, and eolic erosion. They argue that these natural conditions facilitate vegetation loss and therefore, degradation. Puno stakeholders say that Altiplano arid lands are considered vulnerable ecosystems because soils are naturally prone to erosion. The Altiplano climate is harsh, with extreme temperatures, low precipitation, and constant frosts. Scientists believe that natural erosion contributes to degradation in a natural way.

By insufficient research, stakeholders refer to the limited scientific information available regarding Peruvian Andean rangelands. Scientists confirm that they do not know much about rangelands dynamics yet, like the water demands of each species or tolerance to perturbations. They argue that this is the case because there are insufficient funds for research due to the reduction of international cooperation and progressive research funding cuts. In the past, they counted on strong financial support from research 
initiatives like Small Ruminant $\mathrm{CRSP}^{13}$ in the 80 s and networking initiatives like REPAAN $^{14}$ in the 90s. However, both retreated due to internal armed conflict and priority changes in the international research agenda. They also argue there is a lack of new generations of rangeland scientists with updated knowledge; most range scientists are older and their research is outdated. In addition, they argue that most rangeland scientists work on cultivated pastures rather than rangelands. On the other hand, government officials argue that the information on rangelands that they consult to formulate policies is outdated from the $80 \mathrm{~s}$, but they have to use it because there are no other updates. This limited rangeland information misinforms government and NGO interventions, and can therefore contribute to degradation.

By internal armed conflict, stakeholders refer to the violent period that struck the country during the decades of the 80 s and 90 s, resulting in nearly 70 thousand deaths, mainly Andean peasants. They say that this event caused a temporary depopulation of the Andean highlands, which broke down community organizational structures that were in place for rangeland management. Likewise, it caused the retraction of research and development institutions working in the rangelands for at least two decades. These stakeholders also argue that rangeland degradation happens due to changes in the lives of poor pastoralists, social networks, values, and community authority as consequences of this conflict.

\footnotetext{
${ }^{13}$ Small Ruminant Collaborative Research Support Program. United States Agency for International Development.

${ }^{14}$ Red de Pastizales Andinos (Andean Rangelands Network). International Development Research Center, Canada.
} 
By failure in community agreements, stakeholders refer to the disrespectful attitude comuneros have toward community agreements and to the actual loss of community rules for rangelands management. Stakeholders argue that comuneros disrespect community agreements because the leaders have lost the authority to enforce them. They explain this is the result of social and political changes they endured. They highlight the implementation of the decentralization process in the country called regionalizacion, and of the implementation of the Autoridad Nacional del Agua - ANA (National Water Authority). Both negatively impacted community authority structures because they were ignored; instead, these were replaced or overlapped with new structures. Weakened authorities lead to weaker community organizations, resulting in negative consequences for natural resources management.

By agricultural encroachment, stakeholders refer to the changes in land use caused by the vertical expansion of agricultural borders. They explain this happens in some cases for food security due to population growth, but mostly for market purposes. Climate change and global warming made agriculture possible in places that before it was not. Some crops like $\mathrm{maca}^{15}$ in the Peruvian central Andes and quinoa ${ }^{16}$ in the Altiplano have been commoditized and take advantage of new growing conditions. The expansion of agriculture compromises rangeland areas where soils are fragile. The transformation of rangelands into cropland implies increasingly bare soil that leads to soil erosion.

By low prices, government officials refer to the little revenue pastoralists received from fiber and meat sales in local markets. They argue that prices are so low that

\footnotetext{
${ }^{15}$ Maca (Lepidium meyenii) is an Andean root known as Peruvian ginseng due to its energetic properties.

${ }^{16}$ Quinoa (Chenopodium quinoa) is an Andean grain with high protein content.
} 
pastoralists cannot make enough income to cover their families' needs. Therefore, with livestock as their only livelihood, pastoralists increase animal populations and keep them longer to improve their incomes. Stakeholders explain that this behavior leads to overgrazing and subsequently, to rangeland degradation.

By mining, stakeholders refer to the consequences of mining operations in the Andes for water sources affecting rangeland production. They explain that mining in Peru mostly occurs in the high Andes where pastoralists raise animals. Mining activity demands large amounts of water for extracting minerals. Thus, there is competition for water sources since mining and rangelands use the same sources. With fewer water sources, rangeland production is reduced and degrades.

By social and market change, an NGO representative refers to the changes that pastoralists societies have been going through resulting from modernization and market penetration. He explains that, as consequences of new road systems and communication networks, pastoralists changed the previous barter and exchange systems, they had with lowland communities with new markets. So, they endangered their food security and become more dependent on markets that are mostly unfavorable toward their impoverished condition. They explain that these changes alter their view of the rangelands to become more market oriented. Therefore, they tend to overexploit, and, as a result, degrade the land. 
Table 10. Perceptions of other causes of rangeland degradation by stakeholders

\begin{tabular}{|c|c|c|c|c|c|c|c|c|c|c|c|c|c|c|c|c|c|c|c|c|}
\hline \multirow{3}{*}{ Other causes } & \multicolumn{4}{|c|}{ Scientists } & \multirow{2}{*}{\multicolumn{2}{|c|}{ Total }} & \multicolumn{4}{|c|}{ Government } & \multirow{2}{*}{\multicolumn{2}{|c|}{ Total }} & \multicolumn{4}{|c|}{ NGO } & \multirow{2}{*}{\multicolumn{2}{|c|}{ Total }} & \multirow{2}{*}{\multicolumn{2}{|c|}{ Total }} \\
\hline & \multicolumn{2}{|c|}{ Lima } & \multicolumn{2}{|c|}{ Puno } & & & \multicolumn{2}{|c|}{ Lima } & \multicolumn{2}{|c|}{ Puno } & & & \multicolumn{2}{|c|}{ Lima } & \multicolumn{2}{|c|}{ Puno } & & & & \\
\hline & $\mathrm{n}=4$ & $\%$ & $\mathrm{n}=6$ & $\%$ & $\mathrm{n}=10$ & $\%$ & $\mathrm{n}=3$ & $\%$ & $\mathrm{n}=6$ & $\%$ & $\mathrm{n}=9$ & $\%$ & $\mathrm{n}=1$ & $\%$ & $\mathrm{n}=3$ & $\%$ & $\mathrm{n}=4$ & $\%$ & $\mathrm{n}=23$ & $\%$ \\
\hline State failure & 1 & $25 \%$ & 1 & $17 \%$ & 2 & $20 \%$ & 1 & $33 \%$ & - & - & 1 & $11 \%$ & - & - & - & - & - & - & 3 & $13 \%$ \\
\hline Fragile ecosystem & 1 & $25 \%$ & - & - & 1 & $10 \%$ & - & - & 2 & $33 \%$ & 2 & $22 \%$ & - & - & - & - & - & - & 3 & $13 \%$ \\
\hline Insufficient research & 1 & - & - & - & 1 & $10 \%$ & - & - & 1 & $17 \%$ & 1 & $11 \%$ & - & - & - & - & - & - & 2 & $9 \%$ \\
\hline Internal armed conflict & 1 & - & - & - & 1 & $10 \%$ & - & - & - & - & - & - & - & - & 1 & $33 \%$ & 1 & $25 \%$ & 2 & $9 \%$ \\
\hline $\begin{array}{l}\text { Failure to community } \\
\text { agreements }\end{array}$ & - & - & 2 & $33 \%$ & 2 & $20 \%$ & - & - & - & - & - & - & - & - & - & - & - & - & 2 & $9 \%$ \\
\hline Agricultural encroachment & 1 & $25 \%$ & 1 & $17 \%$ & 2 & $20 \%$ & - & - & - & - & - & - & - & - & - & - & - & - & 2 & $9 \%$ \\
\hline Low prices & - & - & - & - & - & - & 1 & $33 \%$ & 1 & $17 \%$ & 2 & $22 \%$ & - & - & - & - & - & - & 2 & $9 \%$ \\
\hline Mining & - & - & - & - & - & - & - & - & 2 & $33 \%$ & 2 & $22 \%$ & - & - & - & - & - & - & 2 & $9 \%$ \\
\hline Social \& market change & - & - & - & - & - & - & - & - & - & - & - & - & 1 & $100 \%$ & - & - & 1 & $25 \%$ & 1 & $4 \%$ \\
\hline
\end{tabular}




\subsection{Perceptions of causes of rangeland degradation by pastoralists}

Table 11 shows the perceptions of causes of decreases in rangeland productivity decrease by pastoralists. It is important to remember that pastoralists refer to decrease in rangeland productivity and do not use the term degradation. It is also important to recall that 55 of 83 pastoralists attest to observing the decline of rangelands. The other 28 pastoralists either think rangelands remain the same or have improved, the reason they are not included in this section. In order of importance, these causes are climate change (93\%), land fragmentation (22\%), overgrazing by inappropriate management (18\%), and overgrazing by overstocking (13\%). Among the other causes are mining activity, environmental pollution, and natural erosion.

\subsubsection{Climate change}

For $93 \%$ of pastoralists overall, climate change is the main cause of declines in rangeland productivity (Table 11); 96\% of Apopata pastoralists, $87 \%$ of Chocorasi pastoralists, and 92\% of Lacotuyo pastoralists believe that changes in climate occurring over the last 30 years have caused rangelands to be in bad shape. By climate change (Table 12), pastoralists refer to less water (88\%), increased heat (29\%), stronger frosts (16\%), and rainfall during the dry season $(8 \%)$. 
Table 11. Perceptions of causes of rangeland productivity decrease by pastoralists

\begin{tabular}{|c|l|c|c|c|c|c|c|c|c|}
\hline \multirow{2}{*}{ Claim } & \multirow{2}{*}{ Causes } & \multicolumn{2}{|c|}{ Apopata } & \multicolumn{2}{c|}{ Chocorasi } & \multicolumn{2}{|c|}{ Lacotuyo } & \multicolumn{3}{|c|}{ Total } \\
\cline { 2 - 10 } & $\mathrm{n}=27$ & $\%$ & $\mathrm{n}=15$ & $\%$ & $\mathrm{n}=13$ & $\%$ & $\mathrm{~N}=55$ & $\%$ \\
\hline 1 & Climate change & 26 & $96 \%$ & 13 & $87 \%$ & 12 & $92 \%$ & 51 & $93 \%$ \\
\hline 2 & Land fragmentation & 8 & $30 \%$ & 3 & $20 \%$ & 1 & $8 \%$ & 12 & $22 \%$ \\
\hline 3 & Inappropriate management & 5 & $19 \%$ & 3 & $20 \%$ & 2 & $15 \%$ & 10 & $18 \%$ \\
\hline 4 & Overstocking & 2 & $7 \%$ & 5 & $33 \%$ & - & - & 7 & $13 \%$ \\
\hline 5 & Other & 2 & $7 \%$ & 2 & $13 \%$ & - & - & 4 & $7 \%$ \\
\hline
\end{tabular}


Table 12. Pastoralists climate change perceptions related to rangelands decline

\begin{tabular}{|l|c|c|c|c|c|c|c|c|}
\hline \multirow{2}{*}{ Climate change } & \multicolumn{2}{|c|}{ Apopata } & \multicolumn{2}{c|}{ Chocorasi } & \multicolumn{2}{c|}{ Lacotuyo } & \multicolumn{2}{c|}{ Total } \\
\cline { 2 - 9 } & $\mathrm{n}=26$ & $\%$ & $\mathrm{n}=13$ & $\%$ & $\mathrm{n}=12$ & $\%$ & $\mathrm{n}=51$ & $\%$ \\
\hline Less water/rainfall & 22 & $81 \%$ & 12 & $92 \%$ & 11 & $92 \%$ & 45 & $88 \%$ \\
\hline Heat increase & 8 & $31 \%$ & 4 & $31 \%$ & 3 & $25 \%$ & 15 & $29 \%$ \\
\hline Stronger frosts & 2 & $8 \%$ & 3 & $23 \%$ & 3 & $25 \%$ & 8 & $16 \%$ \\
\hline Dry season rainfall & 2 & $8 \%$ & 1 & $8 \%$ & 1 & $8 \%$ & 4 & $8 \%$ \\
\hline
\end{tabular}


The majority of pastoralists in the three communities, $81 \%$ of Apopata, $92 \%$ of Chocorasi and $92 \%$ of Lacotuyo, associate climate change with perceptions of less water availability. Pastoralists argue that rangelands get worse because water has become scarce. They associate water scarcity to less rainfall, delayed rainfall, and water conflicts. They argue that because rainfall has decreased and the rainy season has shortened, rangelands do not grow well and become less productive. With limited irrigation capacities they claim that peatbogs shrink. Another consequence of water scarcity is the increase of water conflicts. They argue that the household behavior of retaining water has further reduced their water availability. Likewise, they explain the effects of the lack of water on peatbogs and dry-grasslands. The following are quotes that describe their perceptions.:

A 65-year-old man from Chocorasi explains, "There are no pastures because there is no rain. The climate has changed, it is not favorable now. Before, it rained a lot but now it rains very little and we lack water. Before, pastures were alright, they were big, but now they become depleted. Before, chilliwas (Festuca sp) were big but now they stay little. With a lack of water, some plants do not grow or produce seeds. We now have fewer chilliwas and more iru (Stipa sp) and canlla (Parastrephia sp., which are very resistant. So, we can't keep too many animals. Only when it rains are pastures alright".

A 57-year-old woman from Lacotuyo laments, "There are fewer and smaller pastures because there is no water. Besides just raining a little, it also rains for less time. Before, it rained in due time, from November to about April. Now, the rains are delayed and it only rains for two or three months. It just starts at the end of December and lasts only until February or the beginning of March. Before, when water was plentiful, pastures were good and thick. Now pastures are lower, fewer, and depleted, and they are scarce. Before, iru (Stipa sp) was always green, and now it stays dry. Alpacas only eat iru when it is green. Plants do not regrow the same because there is not enough water at the right time".

A 62-year-old woman from Apopata complains, "Water is scarce because it does not rain enough, since there are more people, there is not enough water. Neighbors have woken up, so those located upstream retain the water and block the canals from those living downstream. Before, canals brought a lot of water and there were more and better 
pastures. Now, everyone retains it and there is no water to irrigate peatbogs. Pastures are only marginal where water is retained. This happens with my neighbor uphill from me; she blocks water and nothing flows to me. I already told her to not do it but she does not care. So, her peatbog is better than mine. Mine is getting dry and smaller".

A third of the pastoralists in the three communities, $31 \%$ of the households of Apopata, $31 \%$ of Chocorasi, and the $25 \%$ of Lacotuyo, associate their climate change perceptions with increased heat. They notice that over the last few years, daytime heat has increased considerably. They argue that in addition to less water due to decreased rainfall, the increased heat diminishes water sources such as springs and snow accumulation. They explain that peatbogs and dry-grasslands are already stressed due to the lack of water; the increased heat has a worsening effect. Likewise, the increased heat causes rangelands to get dry earlier than expected, before the dry season ends, becoming less available for animal feeding. They explain that animals run out of food for a longer time than before. They also associate the increased heat with the increased rate of animal diseases. They explain that animals get sick more frequently due to increased heat caused by climate change. The following quotes describe their perceptions:

A 70-year-old man from Apopata explains, "Before, hills had snow that stayed for a long time. Nowadays, snow falls and it goes fast. Since it is very hot, the snow melts very fast. We have less water. Everything gets drier now: springs and then pastures. Before, springs permanently had water and the heat was not that strong, so the peatbogs stayed wet, but the climate has changed. Now, besides having less rain, the heat is so strong that the springs dry up and so the peatbogs also dry out and become smaller. Some peatbog plants have even disappeared".

A 64-year-old woman from Chocorasi says, "Due to climate change, it is now very hot. Before, pastures lasted long enough for the year and only got dry at the end of dry season. With the intense sun, pastures get worse and dry out earlier. There is a lack of pastures at the start of October. Alpacas do not eat dry pastures, but now that is the only thing left to eat. They do not get full because they look hungry and their bellies look 
empty. Before, I slaughtered to sell meat only at the end of the rainy season, when animals were at a good weight, but now I do it anytime".

A 50-year-old woman from Lacotuyo asserts, "There are more diseases now due to climate change, and animals get sick more often. Before, when alpacas were born, they didn't get sick too much, but now their bellies are swollen and they die more".

For a few pastoralists, $8 \%$ from Apopata, 23\% from Chocorasi, and 25\% from Lacotuyo, climate change perceptions are related to frost increases. They believe that the stronger and more intense frosts occurring during the last few years negatively affects rangelands. They argue that stronger frosts spoil vegetation and reduce grazing hours and chances for animals to get their food. The next quote describes this perception:

A 57-year-old woman from Chocorasi discloses, "There is no water and it is very hot, but it is also too cold because it frosts a lot and is more intense, freezing all the plants. We have to wait for all snow and (?) frost to thaw in order to get the animals out of the corrals, but since it is quite a lot of frost, it takes more time to melt. We take the animals out at about ten in the morning, which is too late. If we take them out before, animals walk and destroy more plants, but if they eat frozen plants, they get sick with diarrhea. So, our days become shorter because animals have less time to eat. I do not think they have enough because they come back hungry".

Likewise, few pastoralists, $8 \%$ from Apopata, $8 \%$ from Chocorasi, and $8 \%$ from Lacotuyo, associate their climate change perceptions to dry season rainfall. They believe that rainfall occurring during the dry season is very harmful for rangelands since they are not in the growing stage, which is ideal for receiving water. They argue that when this type of rain occurred in the past, it was something unusual but now has become more frequent. They say that this type of rain has a devastating effect on rangelands, already stressed by the water scarcity and heat increases. The following quote describes this perception: 
A 68-year-old man from Apopata says, "Sometimes it rains in June, when it should not, then the old plants that are getting dry, the rain rots them. Rain at the wrong time ends up ruining rangelands because the rain must fall when the grasses are beginning to grow, in November. These plants spoil, they get putrid and die... animals do not eat plants in this state".

Thus, most Apotata, Chocorasi, and Lacotuyo pastoralists who believe that climate change is the main cause of degradation point to the lack of water as its most important effect. They argue that decreased rainfall, a shorter rainy season, and increased heat reduce water availability and dry up springs. So, peatbogs and dry-grasslands are then affected. Water scarcity impedes appropriate rangeland growth and recovery. Likewise, they argue that stronger snows and more intense frosts and more frequent dry season rainfall worsen the already weak vegetation.

\subsubsection{Land fragmentation}

Twenty two percent of pastoralists among the three communities overall (30\% from Apopata, 20\% from Chocorasi, and 8\% from Lacotuyo), believe that land fragmentation is the second most important cause of rangeland degradation (Table 11). Among communities, land division is the second most important cause of rangelands degradation for Apopata pastoralists, while it is the third most important cause for Chocorasi and Lacotuyo pastoralists (Table 11). These pastoralists argue that the land division process or parcelacion ${ }^{17}$ affecting Altiplano households, as consequence of family growth, has caused reductions to the extent of grazing fields. They recognize that smaller grazing plots impede proper management causing rangelands to worsen. They notice that

\footnotetext{
${ }^{17}$ Parcelacion is a local term that pastoralists use for referring to land division.
} 
peatbogs have especially gone through this process now that families end up with tiny parcels of peatbogs and use them more intensively. The following is a quote that describes this perception:

An 80-year-old woman from Apopata recounts, "Pastures were good before, when land was whole. Since we divided land, we lack pastures. We have divided the land too much so that it ends up in too small parcels and these are not good for grazing. You can see this happening more with peatbogs. Now we have small squares of peatbogs. This is not convenient. With a small parcel of peatbog, I can only have few animals. I cannot reserve them for the dry season because I do not have more peatbogs. Only those with more can do it".

In addition, pastoralists argue that grazing fields, especially those of the drygrasslands, end up too distant from them as a consequence of their own land distribution tradition. They explain that when distributing land, all types of rangelands at all location levels are considered their heirs'. This has resulted in distant parcels that are difficult to control and supervise, making opportunities for trespassing, and becoming a sort of open range system that can result in the overexploitation of rangelands. The next quote describes this perception:

A 66 years old woman from Apopata recalls, "When we divided land within the family, each one ended up with small portions in different places in the community. This happened because we distributed land to heirs trying to ensure everyone has the same access to all pasture types at all sites, so they can manage livestock well. So, every heir ended up having peatbogs and dry-grasslands at pampa (flat), ladera (hillside) and cerro (hill) levels. But with time, we noticed, especially for dry-grasslands, that this land division has made it difficult to reach and to allow for rotation. It takes a lot of time to take animals for grazing to these faraway parcels, and I am alone and old. Some people reserve those far lands for other seasons, but I rent them out to prevent my neighbors from trespassing on my property, since it is difficult to control from here. I can't see how they are using my land, but at least they are paying something." 
On the other hand, they also explain that as a consequence of too fragmented land, new generations are forced to migrate since land cannot be further divided. The following quote describes this perception:

A 60-year-old man from Chocorasi explains, "Over the years, the land has been divided many times. We now have more families using the same land that before was used by fewer families. The land is too divided now. There is no more land to divide, so children leave home".

Thus, land fragmentation or land division is associated with the intensified use of rangelands, to an informal land market without regulations, and to forced outmigration. All of these together lead to inappropriate management.

\subsubsection{Inappropriate management}

Eighteen percent of pastoralists among the three communities overall, 19\% from Apopata, 20\% from Chocorasi, and 15\% from Lacotuyo, believe that inappropriate management of rangelands-livestock systems is the third most important cause of rangelands getting worse. Among communities, inappropriate management is the third most important cause for Apopata and Chocorasi pastoralists, while it is the second most important cause for Lacotuyo pastoralists (Table 11). By inappropriate management, pastoralists refer to changes in traditional management practices they used 30 years ago for rangelands and livestock management. They argue that grazing changed from being conducted by an extended family to being performed by a nuclear family. Grazing was managed by kinship groups consisting of several families tied by family bonds who coordinated closely to make decisions. Presently, individual families manage the land and make the decisions they consider the best. Livestock management changed from 
separated herds to one single mixed herd. Before, herds were organized into sub-herds according to animal type, sex, and age, which were assigned grazing sites according their biological requirements. Currently, the majority keep one single herd comprised of different animals, sexes, and ages. They explain that those changes in management practices came along with land division. Another change pastoralists notice is the increase in grazing intensity. Pastoralists explain that in the past, rangelands rested about two or three months, but now resting periods have shortened and grazing is continual. Presently, they do not allow enough time for rangelands to rest and recover before the next grazing period. The following quotes describe their perceptions:

A 63-year-old woman from Apopata discloses, "Before we divided the land, we all grazed together. We consisted of many families grazing together and the land was plentiful. Before, we talked more among ourselves and consulted with our neighbors. We managed livestock in separated troops (herds). There were troops of male, female, and young alpacas separated from llamas. Pastures were well-kept. With land division, each family manages their pastures and animals individually, as they want, without consulting anybody. Now, we manage only one single troop.... all the animals are mixed together, alpaca mothers with llamas and sheep, males and females, adults and young, all together. In this way, animals and pastures do not have the same yields. The pastures are not enough, so I have to rent land from a neighbor".

A 58-year-old man from Chocorasi says, "Before, we stayed with our animals the whole day, checking if have eaten enough, or if plants were grazed enough and we needed to rotate. We always knew where to rotate because we checked around a few days before. We only used parcels where plants had already grown. Now, they put animals on any parcel, even if they see some new plants just emerging. They leave them in the same place for a long time. They do not watch to see if they eat or not, or how much the pastures have been grazed. When animals are hungry, they eat it all and raze the plants. So, it is important to watch animals all the time. Otherwise, plants are not allowed to grow or recover".

On the other hand, pastoralists argue that they quit some practices for peatbogs and dry-grasslands maintenance and conservation. They explain that, due to a lack of 
water, they now only irrigate peatbogs and stopped irrigating dry-grasslands. They used to clean and widen peatbogs' canals regularly, however, now they only do it when they can. They used to reserve both types of rangelands, but now they only reserve peatbogs. Pastoralists argue that when reserving dry-grasslands, which are far from their control, they cannot prevent neighbors from trespassing. They explain that neighbors are aware that trespassing is against community agreements, but since pastures are scarce, neighbors do not respect them. They used to spread manure accumulated in corrals, but they do not do it more because they do not have time. The elderly pastoralists explain that currently, younger pastoralists do not properly manage rangelands as they did in the past because they are not interested. The next two quotes describe their perceptions:

A 65-year-old man from Apopata states, "We used to water all the pastures, but now only the peatbogs because water is scarce. Before, we widened canals, cleaned canals, and added clover seeds to improve the peatbogs. Now we only clean peatbog canals when we can. Before, everybody conserved some areas (for the end of the dry season), but now many don't. I used to save a parcel I have in sector Jacchajoco, but now I do not trust my neighbors. When you are not there to control it, neighbors put their animals there little by little. I ask them about it when I notice it is grazed, but nobody seems to know. Now I conserve one parcel (of dry-grasslands) close to me, and have to check it every day. We mostly save peatbogs because you can control that better. We also used to spread out alpaca manure from the corrals onto the dry grasses before rains, but now we don't have time".

A 71-year-old woman from Lacotuyo discloses "Now, people do not take care of pastures and animals like our grandparents did. The pastures are no good now because people do not make improvements to them like we did in the past. Before, we worked hard to improve the pastures and take care of our animals. We always had problems with the climate, but when you try to improve and conserve, you can handle it. Now people complain too much. Before, we consulted and coordinated with everybody when we did something. Now everything is divided and we only depend on ourselves. People are not the same. We have become lazy". 


\subsubsection{Overstocking}

Thirteen percent of pastoralists overall, 7\% from Apopata and 33\% of Chocorasi, believe that overstocking is the fourth most important cause of degradation (Table 11). Those from Lacotuyo do not think overstocking is an issue. Between the two communities, overstocking is the second most important cause of degradation for Chocorasi pastoralists, while it is fourth for Apopata pastoralists. This means that overstocking is a more important issue for Chocorasi than other communities. They recognize they are using the grasslands intensively by putting too many animals onto the reduced grazing lands, and this causes negative changes to the rangelands.

A 57-year-old woman from Chocorasi says, "Before, we had fewer households in the community and each household had a lot more animals. Now, there are more households and each one determines the number of animals needed to survive. With less livestock, the pastures were enough, with some even left over sometimes. Now that there is more livestock on fewer pastures, they always run out of food. So, we have many more animals on the same land that we had fewer on before. Pastures depend on the amount of livestock that is put there. Now, too many animals impede good pastures growth well and seed production. Now, pastures are doing poorly because they are overgrazed."

\subsubsection{Other}

Seven percent of pastoralists overall, $7 \%$ from Apopata and 13\% from Chocorasi, believe that mining activities, environmental pollution, and natural erosion are other causes of rangeland degradation. Lacotuyo pastoralists did not report other cause. Very few pastoralists believe that mining perforations in surrounding areas (Tacna and Moquegua) cause water ground level decreases, and as consequently, their rangelands have less water available. They also believe that polluted air and water cause decreases in rangeland 
productivity. Likewise, they believe that natural erosion with stronger winds and fragile soils is causing rangelands get worse. 


\section{CONCLUSIONS AND RECOMMENDATIONS}

The rangelands of the Peruvian Andean highlands are important resources for the inhabitants of these areas and their livelihoods. About sixteen million hectares of mountain rangelands constitute the main feeding resource for $80 \%$ of the livestock in Peru and provide for the main livelihood for $70 \%$ of rural pastoralist households, mostly indigenous. Above 4000 meters of altitude, families are extremely poor specialized pastoralists who depend almost exclusively on grazing livestock. Organized into about 5000 rural communities, poor pastoralists manage $80 \%$ of these resources. Mountain rangelands are also important because they make possible the provision of numerous ecosystem services that benefit the population living there and in the lower lands. Those benefits related to the provision, conservation, retention, and infiltration of water, are among the most valued. Moreover, rangelands play a crucial role in the sustainability of high mountain ecosystems. For these reasons, Andean rangelands have been recognized as key resources for dealing with climate change and desertification by international agreements. Therefore, their sustainable use and management, and their conservation are of local and global interests.

Rangelands of the Peruvian Andean highlands have been viewed as degraded since the 80 's. They are considered to be in bad condition with trends worsening. Range condition is a technical term that refers to the state of health of the vegetation. The worst cases of degradation have been associated with the rangelands in the hands of rural communities. The first research question addresses whether rangeland degradation is really happening in the Peruvian highlands and to what extent. The second research 
question addresses the perceptions of the causes of rangeland degradation held by pastoralists, academics, government officials, and non-governmental organization (NGO) representatives. Because this is a sociological analysis of rangeland degradation phenomenon rather than an eco-biophysical one, the study concentrates on the perceptions of groups of people related to rangelands rather than biological or ecological measurements.

Two main groups of people related to the rangelands were identified: rangeland users/managers and stakeholders. Users in this specific case were alpaca pastoralists in three rural indigenous communities of the southern Peruvian Altiplano. The stakeholders are differentiated into three sub-groups: academics, governmental officials, and nongovernmental organization staff. There were two locations for stakeholders: those based in Lima city, the capital of Peru, with a national perspective of the problem of degradation, and those based in Puno city, the capital of Puno region, with a local view of the problem in the Altiplano.

\subsection{Perceptions of rangeland degradation}

Most stakeholders based in Lima and Puno think that rangelands of the Peruvian Andean highlands and the Altiplano are severely degraded and that degradation is worsening because of global warming and climate change. They believe that the majority of rangelands are in poor and very poor condition, and the rest are in fair condition. They also assert that rangelands in good condition do not exist. As indicators of rangeland degradation, this diverse group of stakeholders point to the fact that vegetative composition and species diversity have changed dramatically. Desired plant species have 
been reduced considerably, and encroachment by less desirable or undesirable plant species has taken place. The vigor of plant species also has declined, and plant cover has decreased. Only a minority of scientists and NGO representatives in Lima and Puno believe that rangelands are degraded to some degree and that severe degradation is limited to specific areas; they do not believe that severe degradation is a widespread problem. Moreover, this small group of stakeholders also believes that rangelands are in fair condition and that there are still rangelands in good condition.

Most of the alpaca pastoralists in the three rural communities of the Peruvian Altiplano believe that most rangelands in their communities have experienced small negative changes. Some pastoralists think that rangeland condition has not changed and a few of them even believe that rangelands have improved. Generally, pastoralists use neither the term degradation nor the word condition to explain changes to the rangelands. Thus, pastoralists in the study area believe that most rangelands in their communities are slightly degraded, that some are in very bad shape, and that a few might be in good condition. The negative changes that alpaca pastoralists have observed in rangelands are related to bofedales (peatbogs). They have noticed that peatbogs have been reduced in size and consequently, animal production has been negatively affected.

The perceptions of rangeland degradation held by the majority of alpaca pastoralists in the Altiplano, who believe that rangelands have experienced a slight negative change, contrasts with the perceptions of the majority of stakeholders in Lima and Puno who believe that rangelands are severely degraded. A similar contrast exists with perceptions of range conditions. While most pastoralists believe that rangelands in general terms are in fair condition, most stakeholders assert that rangelands are in poor 
and very poor condition. Pastoralists' perceptions do agree with those of a minority of academics and NGO officials who believe that rangelands are degraded to some degree, that degradation is not severe, or that degradation is limited to some areas.

Why do stakeholders and pastoralists have different perceptions of rangeland degradation? Their different perceptions of degradation may be based on the types of indicators each group uses to describe and evaluate degradation. First, pastoralists and stakeholders assign a different order of importance to types of vegetation. Thus, while stakeholders' evaluations focus on dry or pajonales (rain fed grasslands), pastoralists' interests focus on bofedales (peatbogs). Stakeholders focus their attention on drygrasslands because they represent $75 \%$ of the total of the Andean rangelands of Peru. Pajonales are the most dominant and visible vegetation type in the Andes and are the major type of land cover. Alpaca pastoralists of the Altiplano focus their attention on peatbogs because these are critical resources for raising alpaca since they are the limiting factor determining the number of animals they can raise. Peatbogs are mostly used throughout of the year, but especially during the 8-9-month dry season (AprilNovember). This period is more critical than the 3-4-month rainy season (DecemberMarch), when dry grasslands are most heavily used. Since peatbogs are the key resource for Altiplano pastoralists, they focus their attention and interest on them. For this reason, when pastoralists are asked about rangeland condition, they refer mostly to peatbogs. So, their evaluation of range condition and trend depends on the quantity and quality of the peatbogs. On the other hand, stakeholders barely include peatbogs in their grazing plans because of their small area. 
Second, pastoralists and stakeholders have different goals they want to achieve in regard to the rangelands. Thus, while stakeholders focus on plant composition, diversification, and cover of dry-grasslands, pastoralists focus on animal weight, health, and production. The principal feeding source that affects animal production are the peatbogs. Stakeholders associate plant composition and cover with the ecosystem services that rangelands provide. This means that stakeholders are more interested in the ecological and environmental role of the rangelands while pastoralists associate peatbogs condition with animal productivity. This means pastoralists are more interested in the economic value of rangelands. Therefore, the interests in rangelands for pastoralists and stakeholders are different, and often in conflict. This difference has enormous implications for any initiatives for sustainable development based on rangeland systems.

Why are the perceptions of stakeholders and pastoralists so different? Are Andean rangelands severely degraded, as most stakeholders affirm, or are they slightly degraded, as most pastoralists claim? Perceptions are informed on the basis of daily life experiences. Pastoralists build their perceptions on firsthand information of field data based on their direct daily interactions with peatbogs and other types of rangelands. Pastoralists grazing their livestock everyday observe in situ the current situation of peatbogs and livestock production. Their main purpose is animal production for income generation. Thus, pastoralists' incomes and well-being depend largely on the good condition of peatbogs more than on the dry-grasslands.

On the other hand, stakeholders' perceptions are based on occasional field visits when conducting research, or on studies mostly conducted in the 80's and 90's. These studies were conducted under the strong influence of the Range Condition and Trend 
Model (RC\&T). The RC\&T model or the "range model", is an equilibrium model based on the Clementsian vegetation succession theory that has been influential in Peru for about 50 years. The traditional range model assumes that range-livestock systems operate in environments that are generally stable or equilibrial. Therefore, the management of grazing systems consists largely of determining carrying capacity and regulating animal stocking rates to maintain ranges in good condition. This model assumes that range managers have total control of the range-livestock system, and consequently, range conditions are the results of their decisions. It also assumes that only one climax vegetation exists, so any vegetation composition and production below the vegetation climax are understand as degradation or at risk of degradation. However, this model, developed for practical purposes, is not a good fit for arid rangelands with high climate variability, like the Altiplano where climate conditions change every year. For this reason, the carrying capacity cannot be a single or fixed number; it has to be adjusted to varying climate conditions and multiple goals. Using this model, most of the Andean rangelands are overgrazed and severely degraded.

Because the application of the range model is not suitable for arid rangelands like the Altiplano, this model has already been challenged with non-equilibrium models like the State and Transition model (S\&T). Non-equilibrium models only consider that degradation is occurring when the vegetation has crossed critical thresholds, preventing its subsequent return to another productive state. In arid lands, non-equilibrium models assume the possibility of multiple transitions or states of rangelands as well as multiple climaxes rather than to only one. In this sense, the carrying capacity is a number that is adjusted to these multiple conditions. Despite the conceptualization of non-equilibrium 
models in the early 90s, no updated rangeland studies using these newer models have been carried out in the Andes, so stakeholders continue basing their perceptions on outdated information. In fact, the Condition and Trend model is the only range model taught in Peruvian universities. Most stakeholders base their perceptions on this model, which explains much of the difference between the perceptions of stakeholders and pastoralists.

Furthermore, scale also affects the perceptions of pastoralists and stakeholders. Pastoralists' perceptions reflect the current situation in the rangelands for the pastures that they manage directly. For this reason, pastoralists' perceptions can be heterogeneous because conditions vary from one person's pasture to another's. For example, two neighbors may differ in their evaluation of pasture conditions because one peatbog may be improving because of better management while another may be declining because of lack of water. Stakeholders' perceptions of rangeland conditions are based on average conditions at a national or regional level and so there is more agreement among them. Thus, scale also influences the perceptions of both groups.

Finally, we can either conclude that rangeland degradation is a generalized situation or that the problem of degradation does not exist. The range model that stakeholders use is misleading; it tends to overestimate the degradation problem and lead to inaccurate conclusions about degradation. On the other hand, the reduced scope that pastoralists have on rangelands, which focuses on their parcels and communities, tends to result in their underestimation of the degradation problem and lead to inaccurate perceptions of degradation. Rangeland degradation seems to be a localized heterogeneous phenomenon according the different types of vegetation, microclimates, 
soil qualities, management styles, management goals, production orientations, and land tenures. As stated before, perceptions of degradation also depend on the indicators observed, management goals, and interests. The focus on different types of vegetation, stakeholders look at dry-grasslands while pastoralists look at peatbogs, leads to different perceptions. Having different management goals also leads to different perceptions. Stakeholders are oriented toward conservation or sustainable development and pastoralists are production or market-oriented. Having different interests in rangelands leads to different perceptions, as well. Pastoralists and stakeholders have different interests in Andean highlands rangelands. Pastoralists are looking for personal benefits, whereas stakeholders seek benefits for present and future generations. However, while pastoralists' incomes depend on rangelands, stakeholders' incomes do not. These different interests inform different perceptions of rangeland degradation.

Stakeholders are deeply influenced by western developed and adapted theory (RC\&T model) while pastoralists are influenced by local knowledge and daily life experiences, as well as meeting their family needs. Both perceptions are valid and legitimate, and both must be taken into consideration. Different perceptions of the current state of Andean rangelands systems of Peru can lead to inaccurate livestock development and rangeland conservation policies and programs. For example, stakeholders promote reducing stocking rates and constructing enclosures on available dry-grasslands. Pastoralists are unable to reduce herd numbers and are interested in improving the condition of peatbogs. The challenge for rangeland science in Peru is to integrate the goals and interests of pastoralists, scientists, and policy makers. Pastoralists are autonomous decision makers who use and manage rangelands to meet their family 
needs. The Peruvian government does not have any legal mechanism to protect rangelands and prevent their depletion. Therefore, pastoralists' interests and concerns should be the foundation for development and conservation initiatives.

Each group of actors has its own "social construction of the reality" (Long 2001) of range degradation. With these constructions, stakeholders tend to magnify rangeland degradation, perhaps to increase concern for the conservation of such an important natural resource. On other hand, pastoralists tend to minimize rangeland degradation and perhaps even deny their contributions to it. Both social constructions of rangeland degradation may be valid and legitimate, but any attempt to develop appropriate and feasible actions to improve pasture conditions must be based on mutual understanding. Stakeholders and pastoralists need to work together.

One way to integrate pastoralists' and stakeholders' views of reality toward rangeland degradation is the use of comprehensive approaches like adaptive socioecological systems (SES) and resilience-based management. These new approaches include rangeland users as key actors. These approaches start with users' and managers' interests and concerns and include real socio-economic, institutional, and environmental situations in their decision making. Peruvian range experts should include nonequilibrium models or multiple equilibria in their work because these seem to be more appropriate for the context of the Peruvian Andean rangelands, especially for the Altiplano drylands. New studies of Andean rangelands in the highlands of Peru using integrated and comprehensive approaches like the State and Transition model (S\&T) or resilience-based management should be carried out. Policymakers and stakeholders in Lima and in Puno need to develop updated information on rangelands in order to assess 
the current situation. Otherwise, they cannot formulate accurate policies nor propose appropriate actions. Pastoralists' adaptive capacities need to be strengthened to recognize and incorporate elements of their local knowledge and for technologies to be developed for arid lands.

\subsection{Perceptions of causes of rangeland degradation.}

Aligned with their perceptions of rangeland degradation, stakeholders and pastoralists provided different answers about the causes of degradation. For example, scientists, both in Lima and Puno, see overgrazing due to overstocking and to inappropriate use and management as the main causes of rangeland degradation. Overstocking is understood to be an excess number of animals in a determined grazing space put there by pastoralists or herders. For most range scientists, overstocking is the primary cause of degradation. By inappropriate use and management of rangelands, scientists refer to the unsustainable practices that pastoralists or herders employ for the intensive use of rangelands. Among those practices are prolonged grazing with no rotation, the reduction of fallow and rest periods, the loss of transhumance, and the use of rangelands in high altitude watershed protection areas. Other examples of mismanagement include the use of mixed herds or the use of inappropriate kinds of livestock for specific type of rangelands. Range scientists argue that overgrazing is generated by pastoralists' decisions and actions. Pastoralists are the main responsible of degradation because the range model used by Peruvian range scientists overemphasizes the role that users and managers play in determining rangeland condition. 
Range scientists mention land fragmentation as a secondary cause of degradation. The land fragmentation process is a consequence of population growth on one hand, and to the privatization process promoted by the Peruvian government on the other. The last modification to the land law in the 90's allows rural communities to distribute and privatize communal land, which was not previously legal. This law provided an incentive for individual management, and with it, the decomposition of range-livestock systems. Climate change is another secondary cause of rangeland degradation indicated by half of the range scientists, especially those in Puno. These scientists argue that climate change results in water scarcity, which impedes the recuperation of rangelands, contributing to degradation.

For government officials and scientists, especially those in Lima, overstocking is a major cause of rangeland degradation. They indicate that overstocking is a consequence of the incorporation of new households' herds; by tradition, a household starts a new herd when establishing a family. For these stakeholders, the increase of livestock populations is a result of users' decisions to keep more livestock. Likewise, government officials, like scientists, also indicate that the inappropriate use and management of rangelands leads to overgrazing which, in turn, causes degradation. Inappropriate use and management consist of a number of practices like grazing cows or sheep on grazing lands suitable for camelids, herding multiple species together, and not providing extra care for nursing mothers and babies. Climate change is another cause of rangeland degradation that is frequently cited by government officials in Puno. According to them, climate change in the Altiplano is characterized by reduced rainfall and increased insolation, which has made water less available for the maintenance of 
healthy rangelands. Although the old influential range model does not include climate factors, government officials point out climate change because the Andean highlands, like the Peruvian Altiplano, are among the most affected places in the world by climate change. In contrast to range scientists, government officials do not associate land fragmentation as a driver of degradation of the rangelands, not even as a secondary cause. This could be because government officials lack fieldwork experience or direct contact with use, which prevents them from understandings the social constraints that rural communities face when they manage their natural resources.

For NGOs representatives, especially those with operating in, and with experience in, the Altiplano, overgrazing due to inappropriate management is the main cause of rangeland degradation, followed by climate change. Inappropriate use and management for NGOs consist of the practice of keeping single mixed herds, the persistence in using low quality animals, and the increased burning of rangeland. For these stakeholders, climate change has shortened the rainy season, making water less available. Water scarcity impedes the recuperation of rangelands, causing natural degradation. NGO representatives point to land fragmentation and peasant culture as other significant causes of degradation. Land fragmentation here is seen as a consequence of population growth, but it is not associated with increases in livestock numbers. For this reason, overstocking is not a principal cause of degradation for NGO representatives. Peasant culture, especially as described by NGO representatives in Puno, refers to certain individuals' and communities', poor organizational capacities, irrational economic decision making, conditions of living in poverty or extreme poverty, lack of investment capacities, use of marginal labor, asymmetric unfavorable markets, and high rates of 
migration. NGO representatives understand that rangeland degradation is a multifactor phenomenon including natural, ecological, economic, social, and institutional causes of degradation. NGO representatives' perceptions are closer to the realities of people in these communities due to their field experience and proximity to the direct users of the rangelands.

Thus, for most stakeholders of the Peruvian rangelands, the primary causes of rangeland degradation are overgrazing due to inappropriate range use, mismanagement by pastoralists, and overgrazing due to overstocking. Climate change is considered a secondary cause of degradation, especially by stakeholders in Puno like NGO representatives.

For almost all the pastoralists in Mazocruz, climate change is the main cause of negative changes in peatbogs, the type of rangelands most essential for their livelihoods. Pastoralists have noticed that climate events have changed negatively in the last 30 years, resulting in less rainfall, untimely rain, stronger frosts, and more heat. The increased heat due to global warming has reduced snowpack and decreased runoff. With reduced water availability, peatbogs dry out, shrink, and ultimately disappear. Likewise, dry-grasslands become less productive. In arid lands like Mazocruz, peatbogs are key resources for the survival of pastoralists and their herds. For this reason, pastoralists see climate change as the main cause of rangeland degradation. Only a few pastoralists associate land fragmentation and overstocking with negative changes in peatbogs and dry-grasslands. These few pastoralists recognize that they have divided the land to the point that proper management is infeasible. Likewise, they recognize that more households have incorporated into their communities, which means more animals in the community. 
Concisely, pastoralists and stakeholders have different perceptions of what causes rangeland degradation. Thus, while primary causes of rangeland degradation for most of stakeholders are the inappropriate use and management by pastoralists and herders and overstocking, the primary cause of range degradation for most pastoralists is climate change. Only for NGO representatives is climate change, along with inappropriate use and mismanagement, a primary cause of degradation, while overstocking is not. On the other hand, climate change is a secondary cause of rangeland degradation for most scientists and government officials. Land fragmentation is also a secondary cause of rangeland degradation for scientists, NGOs representatives, and pastoralists, but not for government officials. Likewise, overstocking is another secondary cause of rangeland degradation for pastoralists.

The different perceptions of the causes of rangeland degradation between stakeholders and pastoralists, as stated before, reflect the different types of information each uses to evaluate rangelands. In this sense, most stakeholders are biased toward the Range Condition and Trend model, whereas pastoralists are influenced by their local knowledge and daily life experiences. The Range Condition and Trend model overemphasizes the role that users and managers play in determining current rangeland conditions, holding them responsible for degradation. For this reason, most range scientists and government officials assert that overstocking and mismanagement are the primary causes of degradation. They argue that climate change is a secondary cause of degradation because their model minimizes the role that other factors play in affecting range conditions, like climate change. Climate conditions are included when determining carrying capacity, but not as driver of degradation. Moreover, these experts had declared 
that Peruvian rangelands were severely degraded long before climate change was an issue. However, when NGO representatives consider climate change and inappropriate management together as primary causes of degradation, it can be assumed that they are influenced by their interactions with pastoralists and their social science training. The negative impacts of climate change in arid lands like the Peruvian Altiplano are visible and have been scientifically demonstrated. The conclusions of NGO representatives about the causes of degradation are similar to those that non-equilibrium models or multiple equilibria would generate. NGOs have been operating in the Altiplano since the early 80 s, working directly with users, which gives them a better understanding about pastoralist systems.

Pastoralists claim climate change is almost exclusively the cause of range degradation because they live in the field and experience the daily impacts of it. Thus, with less water available, they feel the increased dryness that makes their peatbogs shrink. The ultimate impacts of climate change for pastoralists are the loss of animal weight and health, as well as the reductions in their herds and incomes. Pastoralists emphasize climate change as a major cause of degradation because they are directly affected by the decrease in snow melt and the decline in animal production. Although a few pastoralists recognize that land fragmentation and overstocking could also affect the current condition of peatbogs and dry-grasslands, most of them do not realize these effects. This is because it is difficult to perceive the long-term effects and scale of their own decisions on a daily basis. Pastoralists hardly perceive the short-term effects of dividing the land on their management and their systems. Likewise, the effect of overstocking is only noticeable at the community, not at the household level. 
The different perceptions of the primary causes of range degradation between stakeholders and pastoralists show a lack of common understanding of degradation and rangeland conditions between the two groups. These differences have huge implications for any proposed rangeland policies, sustainable development programs, or any intervention attempts to conserve rangelands. It is important that stakeholders update the models they use to evaluate rangelands and propose interventions. Pastoralists hold important local knowledge that must be included in the range models. No rangeland intervention can succeed without the active participation of pastoralists.

Although most stakeholders and pastoralists disagree on the primary and secondary causes of rangeland degradation, a minority of both agree that land fragmentation is a factor. The implications of land fragmentation on pastoralist systems are underestimated by most range scientists and NGO representatives and are ignored by government officials. The land fragmentation process has broken the ecological, social, and institutional structures that permitted traditional specialized pastoral systems to function efficiently. Traditional pastoralist systems included access to large plots of land managed by kin. With enough land and labor, pastoralists could make an efficient use of all types of rangelands (i.e., dry-grasslands, peatbogs, shrubs) according to the physiological requirements of the different types of animals. These systems also included seasonal vertical mobilizations and daily horizontal rotations. The efficient functioning of these traditional systems suggests that pastoralist had solid organizational and institutional capacities.

All those practices allowed the ecological and economic use of rangelands and livestock to result in integrated landscape management. Population growth and the 
continuous division of land through inheritance practices, resulted in pieces of land too small for proper management using the old methods of the traditional pastoralist system. Arid and semi-arid rangelands must be managed in large pieces to be sustainable. In the few cases where traditional management of rangelands and livestock is possible because of access to sufficient land and labor, rangelands are in fair condition. Rangeland degradation is occurring especially in the places where the pastoralist's system has already collapsed. In this situation, pastoralists systems become economically inefficient and ecologically unsustainable. Camelid production systems in the southern Peruvian Altiplano are ancient, complex systems that have been poorly studied and understood. Further studies need to be done to identify the decision-making processes in successfully and poorly managed systems in order to identify local alternatives.

Land fragmentation together with the lack of development opportunities, have led to the out-migration of youth. Migration from pastoralist communities has not only reduced the availability of labor, but has also led to the absence of key decision makers in the system. Migration has also hindered the transfer of knowledge from one generation to the next. With limited labor and the absence of decision makers, the social organization that supported the system has broken. The reduced capacities of social institutions to organize and adapt to new contexts of land and labor has forced pastoralists to replace old sustainable systems with unsustainable practices. Examples of unsustainable practices include the use of single mixed herds, the reduction of rotations, and the increased use of burns, among others. Specialized pastoral systems, like those of the Altiplano, demand minimal amounts of land and labor to function well. When sufficient land and labor are not available, the system becomes marginal and 
unsustainable in ecological and economic terms. So, the natural resources become overexploited, leading to degradation.

Climate changes have existed in the past. Pastoralists were able to adapt to these changes because they had the technology, community management structures, labor, and land to do so. However, out-migration has led to an absence of decision makers and necessary labor. As a result, their adaptive capacities have been reduced, making them vulnerable. The current climate change may or may not cause range degradation, but it certainly has aggravated the difficult environmental conditions of the dry puna of the southern Altiplano of Peru. The use of unsustainable practices for rangeland management is a desperate attempt by pastoralists to adapt to climate change, outmigration, and land fragmentation. This should also be seen as a consequence of their struggle to survive and make a living under these circumstances, rather than a cause of degradation alone. From an integrated view of the pastoralist system of this area of the Altiplano, rangeland degradation, should be understood as the failure of pastoralists to adapt to social and environmental changes. This as consequence of their diminished adaptive capacity. Degraded rangelands, and especially degraded peatbogs, also contribute to global warming and climate change. Therefore, there is the need to look at the rangeland degradation problem from an integrated perspective, which includes human and natural dimensions. 


\section{BIBLIOGRAPHY}

Abel, N. O. J., \& Blaikie, P. M. (1989). Land degradation, stocking rates and conservation policies in the communal rangelands of Botswana and Zimbabwe. Land Degradation and Rehabilitation, 1, 101-123.

Addison, J., M. Friedel, C. Brown, Davies, J. and Waldron, S. (2012). A critical review of degradation assumptions applied to Mongolia's Gobi Desert. Rangeland Journal, 34, 125-137.

Agenda 21-UNCED. (1992). UN Conference on Environment and Development. Rio de Janeiro.

Aguilar Meza, T. (1996). Los Pastores Inka. (Etnofolklore No 1). Cusco, Peru. Instituto Nacional de Cultura Cusco. Direccion de Produccion para el Desarrollo Cultural. Andinidad.

ALTAGRO (2006). Informe Anual. Proyecto Agricultura Andina en el Altiplano (Altagro). Centro Internacional de la Papa (CIP). Agencia Canadiense para el Desarrollo Internacional (ACDI).

Argüelles, L. \& Estrada, R. D. (1991). Perspectivas de la investigación agropecuaria para el Altiplano. Proyecto de Investigación en Sistemas Agropecuarios Andinos (PISA) Internacional de Investigaciones para el Desarrollo. Montevideo, Uruguay. International Development Research Centre.

Ary, D., Jacobs, L. C., Razavieh, A., \& Sorensen, C. (2006). Introduction to Research in Education (7th ed.). Belmont, CA: Thompson Wadsworth.

Baars, R. M. T., \& Aptidon, S. M. (2002). Pastoralists' perception of rangeland degradation in eastern Ethiopia. Nomadic Peoples, 6(1), 144.

Behnke, R. H., Scoones, I., \& Kerven, C. (Eds.). (1993). Range ecology at disequilibrium. New models of natural variability and pastoral adaptation in African Savannas. London: Overseas Development Institute. International Institute for Environment and Development. 
Bernard, H. R. (2006). Research Methods in Anthropology. Qualitative and quantitative approaches. (4th ed.). Lanham, MD: Altamira Press.

Blaikie, P. M. (1985). The political economy of soil erosion in developing countries. London and New York: Longman.

Blaikie, P. M., \& Brookfield, H. (1987). Land degradation and society. London; New York: Methuen.

Blench, R., \& Sommer, F. (1999). Understanding rangeland biodiveristy. Working paper 121. London: Overseas Development Institute.

Bourdieu, P. (1977). Outline of a Theory of Practice. Cambridge: Cambridge University Press.

Brinton, M. C., \& Nee, V. (Eds.). (1998). New institutionalism in sociology. New York: Russell Sage Foundation.

Briske, D. (2017). Rangelands systems. Processes, management and challenges. Springer Series on Environmental Management, (free access), Switzerland: Springer International Publisher.

Brush, S., \& Guilllet, D. W. (1985). Small-scale agro-pastoral production in the Central Andes. Mountain Research and Development, 5(1), 10-30.

Bryant, R. L., \& Bailey, S. (1997). Third world political ecology. London and New York: Routledge.

Buttolph, L. P., \& Coppock, D. L. (2004). Influence of deferred grazing on vegetation dynamics and livestock productivity in an Andean pastoral system. Journal of Applied Ecology, 41, 664-674.

Carney, D., \& Farrington, J. (1998). Natural resources management and institutional change. New York: Routledge.

Choque, J. Sotomayor, M. Miranda, F. Mamani, W. \& Canahua, F. (1990). Evaluación agrostologica y ganadera de unidades familiares alpaqueras de puna seca del Altiplano. Informe Tecnico No.20. Serie: Pastos.Proyecto Alpacas. INIAA, CORPUNO-COTESU. Puno, Peru. 
Choque, J., Sotomayor, M. and Miranda, F. (1990). Evaluación agrostológica y ganadera de unidades familiares alpaqueras en puna seca del altiplano. Informe técnico Nro. Proyecto alpacas PAL. Serie de pastos. Puno, Perú.

Choque, J. \& Palacios, A. L. (1998). Producción primaria de praderas nativas en el altiplano de Puno. Puno,Perú.

Coppock, L. Fernandez-Gimenez, M., Hiernaux, P., Huber-Sannwald, E., Schloeder, C., Valdivia, C., Turin, C., ... \& Arredondo, J. (2017). Rangelands in developing nations. D. Briske (Ed.). Rangeland systems. processes, management and challenges. Switzerland: Springer.

Coppock, D.L. and C. Valdivia. (2000). Sustaining agropastoralism on the Bolivian altiplano: The case of San José Llanga. Final synthesis presentation for the GLCRSP. GL-CRSP Annual Meeting, Autlan de Navarro, Jalisco, Mexico.

Coppock, D.L., and C. Valdivia (Eds.) (2001). Sustaining agropastoralism on the Bolivian Altiplano: The case of San José Llanga. Logan, Utah: Department of Rangeland Resources, Utah State University.

Coughenour, M. (2004). The Ellis paradigm - humans, herbivores and rangeland systems. African Journal of Range \& Forage Science, 21, 191-200.

Creswell, J. (2007). Qualitative inquiry \& research design: Choosing among five approaches. Thousand Oaks, CA: SAGE.

Davis, D. K. (2009). Historical political ecology: On the importance of looking back to move forward. Geoforum, 40(3), 285-286.

Doolittle, A. (2008). Stories and maps, images and archives: Multimethod approach to the political ecology of native property rights and natural resource management in Sabah, Malaysia. Environmental Management. 45, (1), 67-81.

Ellis, J. E. (1992). Recent advances in arid land ecology. Relevance to agro-pastoral research in the small ruminant CRSP. In: C. Valdivia, (Ed). Sustainable croplivestock systems for the Bolivian highlands. Proceedings of an SR-CRSP Workshop. La Paz, Bolivia.

Ellis, J. E. (1994). Climate variability and complex ecosystem dynamics: Implications for pastoral development. New directions in pastoral development in Africa. In I. 
Scoones (Ed.), Living with uncertainty. London: Intermediate Technology Publications.

Ellis, J. E., Coughenour, M. B., \& Swift, D. M. (1993). Climate variability, Ecosystem stability and the implications for range and livestock management. In R. H. Behnke, I. Scoones \& C. Kerven (Eds.), Range ecology at disequilibrium. London: Overseas Development Institute.

Ellis, J. E., \& Swift, D. M. (1988). Stability of African pastoral ecosystems: Alternate paradigms for development. Journal of Range Management, 41(6), 450-459.

Elllis, E. C., \& Ramankutty, N. (2008). Putting people in the map: Anthropogenic biomes of the world. Frontiers in Ecology and the Environment, 6(8), 439-447.

Encyclopedia Britannica. (2008). Science \& Technology: rangeland. from http://www.britannica.com/EBchecked/topic/491143/rangeland

Escobal J. and Torero M. (2000). Does geography explain differences in economic growth in Peru? Latin American Research Network Working paper \#R-404, Place: Publisher,

Food and Agriculture Organization. (1993). Land degradation in arid, semi-arid and dry sub-humid areas: rainfed and irrigated lands, rangelands and woodlands. from http://www.fao.org/docrep/X5308E/X5308e04.htm

Food and Agriculture Organization. (1994). Land degradation in south Asia: Its severity, causes and effects upon the people. World soil resources reports from http://www.fao.org/docrep/v4360e/V4360E06.htm

Food and Agriculture Organization. (2008). Informe: Análisis del impacto de los eventos fríos (fríaje) del 2008 en la agricultura y ganadería altoandina en el Perú. Lima,

Faysse, N. (2018). Approaches in social sciences to assess situations of natural resources management: an introduction No.8. Montpellier, France. Available from: http://www.g-eau.net/

Fernandez, M. (1992). The social organization of production in community-based agropastoralism in the Andes. In C. M. McCorkle (Ed.), Plants, animals, and people: Agropastoral systems research. Boulder: Westview Press. 
Flores Ochoa, J., and Kobayashi, Y., (2000.) Pastoreo Altoandino. Realidad, sacraliad y posibilidades. Plural. Museo Nacional de Etnografía y Folklore MUSEF. Bolivia.

Flores, E. R. (1996,). Reality, limitations and research needs of the Peruvian livestock sector. Paper presented at the Latin American Regional Livestock Assessment Workshop. Small Ruminant CRSP, Inter-American Institute for Cooperation on Agriculture (IICA). San José, Costa Rica.

Flores, E. R., Cruz, J. A., \& López, M. (2007). Management of sheep genetic resources in the central Andes of Peru. In K. A. Tempelmann \& R. A. Cardellino (Eds.), People and animals: traditional livestock keepers. Guardians of domestic animals' diversity (pp. 47-57). Rome, Italy: FAO.

Florez, A., \& Bryant, F. (1990). Manual de Pastos y Forrajes. Lima: Instituto Nacional de Investigacion Agraria y Agroindustrial - Porgrama Colaborativo a la Investigacion en Rumiantes Menores, Lima.

Florez, A., \& Malpartida, E., (1988). Manejo de praderas nativas y pasturas en la región altoandina del Perú. (Vol. I). Lima: Fondo del Libro. Banco Agrario del Perú.

Florez Martinez, A., (2005). Manual de pastos y forrajes Altoandinos. Lima: ITDG AL, OIKOS.Spell out??

Forstater, M. (2002). Bones for sale: 'Development', environment and food security in East Africa. Review of Political Economy, 14, 47-67.

Fratkin, E. (1997). Pastoralism: Governance and developmental issues. Annual Review of Anthropology, 26, 235.

Galaty, J. G., \& Johnson, D. L. (Eds.). (1990). The World of pastoralism: Herding systems in comparative perspective. New York: Guilford Press.

Gemedo, D., Isselstein, J., \& Maass, B. L. (2006). Indigenous ecological knowledge of Borana pastoralists in southern Ethiopia and current challenges. International Journal for Sustainable Development \& World Ecology, 13, 113-130.

Gibson, D. J. (2009). Grasses and grassland ecology. New York: Oxford University Press.

Gilles, J. L., \& Jamtgaard, K. (1981). Overgrazing in pastoral areas. The commons reconsidered. Sociologia Ruralis, 21, 129. 
Gilles, J. L., \& Jamtgaard, K. (1988). Barriers to range management research in Peru. Pastoral Development Network Paper 26d. London: Overseas Development Institute.

Glave, L. M. (1988). Demografia y Conflicto Social: Historia de las comunidades campesinas en los Andes del Sur. Unpublished Documento de trabajo. Peru: Instituto de Estudios Peruanos.

GORE Puno. 2008. Plan estratégico regional del sector agrario para la región de Puno 2009 - 2015. Where? Ministerio de Agricultura

Greenberg, J. B., \& Park, T. K. (1994). Political Ecology. Journal of Political Ecology, 1, $1-12$.

Grice, A. C., \& Hodgkinson, K. C. (Eds.). (2002). Global rangelands. Progress and prospects. Oxon, UK: Cabi Publishing.

Hardin, G. (1968). The tragedy of the commons. Science, 162, 1243-1247.

Ho, P. (2001). Rangeland degradation in North China Revisited? A preliminary statistical analysis to validate non-equilibrium range ecology. Journal of Development Studies, 37(3), 99.

Ho, R. \& Montero, R. (2016). La adopción y replica de innovaciones tecnológicas en los sistemas de crianza de alpacas en las comunidades del Altiplano: Consideraciones críticas Apuntes de InvestigAcción $N^{\circ} 7$, Soluciones Practicas.

Hruska, T.,Huntsinger, L., Brunson, M., Li, W., Marshall, N.,Oviedo, J. \& Whitcomb H. (2017). Chapter 8. Rangelands as Social-Ecological Systems. In: D. Briske, (Ed), Rangeland systems. Processes, management and challenges. Switzerland: Springer Series on Environmental Management.

International Fund for Agricultural Development. (2007). Livestock and rangelands. Available from: http://www.ifad.org/lrkm/theme/range.htm

International Fund for Agricultural Development. (2008). Livestock and Rangeland Glossary. Available from : $\mathrm{http}: / /$ www.ifad.org/lrkm/glossary.htm\#p

Instituto Nacional de Estadística e Informática (INEI) (1994). Perú en Mapas. Estructura y dinámicas del Espacio Agropecuario. III Censo Nacional Agropecuario 1994. 
Lima, Peru: Institut Francais de Recherche Scietifique pour le Developpement en Cooperation ORSTOM.

Instituto Nacional de Estadística e Informática (INEI) (2013). Resultados definitivos. IV

Censo Nacional Agropecuario CENAGRO 2012. Peru: Instituto Nacional de Estadística e Informática.

Instituto Nacional de Estadística e Informática (INEI) (2013.) El nuevo rostro del campo. IV Censo Nacional Agropecuario CENAGRO 2012. Lima, Peru: Instituto Nacional de Estadística e Informática.

Instituto Nacional de Estadística e Informática (INEI) (2015). Mapa de Pobreza Provincial y Distrital 2013. Instituto Nacional de Estadística e Informática. Lima, Peru.

INEI-UNPF,2010. Mapa de Pobreza Provincial y distrital. El enfoque de la pobreza monetaria. Instituto NEI. Fondo de Población de las naciones unidas UNFPA. Lima)

Jamtgaard, K. (1984). Limits on common pasture use in an agro-pastoral community: The case of Toqra, Peru., Small Ruminant Collaborative Research Support Program. Technical report series No 42. Columbia, MO: Department of Rural Sociology. University of Missouri.

Jarvis, L. S. (1991). Overgrazing and range degradation in Africa: Is there need and scope for government control of livestock numbers? Eastern Africa Economic Review, $7(1), 95-116$.

Jun Li, W., Ali, S. H., \& Zhang, Q. (2007). Property rights and grassland degradation: A study of the Xilingol Pasture, Inner Mongolia, China. Journal of Environmental Management, 85, 461-470.

Kassahun, A., Snyman, H. A., \& Smit, G. N. (2008). Impact of rangeland degradation on the pastoral production systems, livelihoods and perceptions of the Somali pastoralists in Eastern Ethiopia. Journal of Arid Environments, 72, 1265-1281.

Leon-Velarde, C. and Quiroz, R. (2004). The development of livestock production systems in the Andean región: Implications for stallholder producers. WAAP Book of the year 2003, pp. 233-240. World Association for Animal Production. The Netherlands: The Wageningen Academic Publishers. 
Leon-Velarde, C. and Quiroz, R.(1998). La region Andina: Perspectivas de la investigación en sistemas de produccion animal. In: Memoria 1998. Tercera Parte. Actividades Ecorregionales de Condesan durante 1998. Manizales, Colombia.

Long, N. (Ed.) (1989). Encounters at the interface: A perspective on social discontinuities in rural development. Wageningen: The Agricultural University.

Long, N. (2001.) Development sociology: Actor perspectives. New York, NY: Routledge.

Lozada, C. (1991). Overgrazing and range degradation in the Peruvian Andes. Rangelands, 13(2), 64-67.

MacLeod, N. D., \& McIvor, J. G. (2006). Reconciling economic and ecological conflicts for sustained management of grazing lands. Ecological Economics, 56(3), 386401.

Maxwell, J. A. (1997). Designing a qualitative study. In L. Bickman \& D. J. Rog (Eds.), Handbook of applied research methods (pp. 69-100). Thousand Oaks, CA: SAGE.

Mayer, E. (2002). The Articulated peasant. Household economies in the Andes: Westview press.

McCorkle, C. M. (Ed.). (1992). Plants, Animals \& People. Agropastoral System Research. Boulder, CO: Westview Press.

McKean, M. A. (2000). Common property: What is it, What is it good for, and What Mmakes it work? In C. Gibson, M. A. McKean \& E. Ostrom (Eds.), People and forests: Communities, institutions, and governance. Cambridge, Mass.: MIT Press.

Mearns, R. (1996). Community, collective action and common grazing: The case of postsocialist Mongolia. Journal of Development Studies, 32(3), 297.

Ministerio de Agricultura (MINAG). (2008). Los Pastos Naturales Altoandinos. Lima, Peru. Ministerio de Agricultura del Perú.

North, D. C. (1990). Institutions, institutional change and economic performance. Cambridge; New York: Cambridge University Press. 
Ogbaharya, D. (2007). Ecological degradation in Southern Ethiopia. Peace Review, 19(3), 359-363.

Olson, M. (1971). The logic of collective action. Cambridge, MA: Harvard University Press.

Orlove, B. (1980). Pastoralism in the Southern Sierra. Andean peasant economics and pastoralism. Publication 1. (pp. 87-111). Columbia, MO: Small Ruminants Collaborative Research Support Program. Department of Rural Sociology, University of Missouri.

Ostrom, E. (1990). Governing the commons. The evolution of institutions for collective action. New York, NY: Cambridge University Press.

Ostrom, V., \& Ostrom, E. (1977). A theory for institutional analysis of common pool problems. In G. Hardin \& J. Baden (Eds.), Managing the commons. San Francisco: W.H. Freeman Company.

Ostrom, E. (2009). A general framework for analyzing sustainability of social-ecological systems. Science 325: 419-422.

Paulson, S., \& Gezon, L. L. (Eds.). (2005). Political ecology across spaces, scales, and social groups. Piscataway, NJ: Rutgers University Press.

Peet, R., \& Watts, M. (1996). Liberation ecologies. Environment, development, social movements. London and New York: Routledge.

Pinedo, D. (2000). Manejo comunal de pastos, equidad y sostenibilidad en una comunidad de la Cordillera Huayhuash. In I. Hurtado, C. Trivelli \& A. Brack (Eds.), Peru: El Problema Agrario en Debate. SEPIA VIII. (pp. 277-326). Lima: Seminario Permanente de Investigacion Agraria (SEPIA).

United Nations Development Programme (PUND). (2001). Evaluación de las características y distribución de los bofedales en el ámbito peruano del sistema TDPS. Puno, Perú. Proyecto binacional de biodiversidad del sistema lago Titicaca, Desaguadero, Poopo y Salar de Coipasa (TDPS). 
Postigo, J. C., Young, K. R., \& Crews, K. A. (2008). Change and continuity in ap astoralist community in the High Peruvian Andes. Human Ecology, 36(4), 535551.

Powell, W. W., \& DiMaggio, P. J. (Eds.). (1991). The New institutionalism in organizational analysis. Chicago: University of Chicago Press.

Queiroz, J., Coppock, D.L., Alzérreca, H, \& Norton, B., (2001). Ecology and natural resources of San José Llanga Chapter 3. In D.L. Coppock \& C. Valdivia, (Eds.) Sustaining agropastoralism on the Bolivian Altiplano: The case of San José Llanga. pp 59- 115. Department of Rangeland Resources, Utah State University, Logan, Utah.

Quispe, S. (1989). Caracterizacion de los sistemas productivos de las comunidades Alpaqueras: Aspectos metodologicos. Informe Tecnico No. 11. Proyecto Alpacas. INIA. COTESU/IC.

Ragin, C. C. (1987). The comparative method: Moving beyond qualitative and quantitative strategies. Berkeley: University of California Press.

Ramankutty, N., Evan, A. T., Monfreda, C., \& Foley, J. A. (2008). Farming the planet: 1. Geographic distribution of global agricultural lands in the year 2000. Global Biogeochemical Cycles, 22 (GB1003).

Recharte, J.,Albán, L., Arévalo, R., Flores, E., Huerta, L., Orellana, M, ... Sánchez, P. (2002). El Grupo en Páramo/ Jalcas y Punas del Perú: Instituciones y acciones en beneficio de comunidades y ecosistemas Alto Andinos. Paper presented at the Reunión del Grupo Internacional de Páramos, Bogota, Colombia.

Rist, S., Chidambaranathan, M., Escobar, C., Wiesmann, U., \& Zimmermann, A. (2007). Moving from sustainable management to sustainable governance of natural resources: The role of social learning processes in rural India, Bolivia and Mali. Journal of Rural Studies, 23(1), 23-37.

Robbins, P. (2004). Political ecology. Critical introductions to geography. Malden, MA: Blackwell.

Roche, M. (2005). Historical research and archival sources. In I. Hay (Ed.), Qualitative research methods in human geography (2nd ed.). Melbourne, Australia: Oxford University Press. 
Rohde, R. F., Moleele, N. M., Mphale, M., Allsopp, N., Chanda, R., Hoffman, M. T.... Young, E., (2006). Dynamics of grazing policy and practice: environmental and social impacts in three communal areas of southern Africa. Environmental Science \& Policy, 9, 302-316.

Rossman, G. B., \& Rallis, S. F. (2003). Learning in the field. An introduction to qualitative research (Second edition ed.). Thousand Oaks, CA: SAGE publications.

Runge, C. F. (1992). Common property and collective action in economic development In D. W. Bromley (Ed.), Making the commons work : theory, practice, and policy. San Francisco, CA: ICS Press.

Servicio Nacional de Meteorología e Hidrología del Perú (SENAMHI) (2010). Atlas de Heladas del Peru. Lima, Peru: Cooperación de Cooperación Técnica Interinstitucional. Organización de las Naciones Unidas para la Agricultura y Alimentación.

Scoones, I. (Ed.). (1994). Living with uncertainty. London: Intermediate Technology Publications.

Siguayro, R. (2008). Evaluación agrostológica y capacidad receptiva estacional en bofedales de puna seca y húmeda. (Tesis). Universidad Nacional del Altiplano. Facultad de Ciencias Agrarias. Escuela Profesional de Ingeniería Agronómica.

SNV 2012. Estudio de factibilidad para un programa nacional de biogás doméstico en Perú. HIVOS people unlimited. Soluciones Practicas. Lima, Peru: SNV.

Solomon, T. B., Snyman, H. A., \& Smit, G. N. (2007). Cattle-rangeland management practices and perceptions of pastoralists towards rangeland degradation in the Borana zone of southern Ethiopia. Journal of Environmental Management, 82, 481-494.

Sotomayor, M. (1990). Tecnología campesina en el pastoreo Altoandino. Puno Perú: Proyecto Alpacas-INIAA-CORPUNO-COTESU/IC.

SR-CRSP. (1980) Andean peasant economics and pastoralism. Publication 1 Department of Rural Sociology, University of Missouri: Small Ruminants Collaborative Research Support Program. 
Sserunkuuma, D., \& Olson, K. (2001). Private property rights and overgrazing: An empirical assessment of pastoralists in Nyabushozi County, Western Uganda. Economic Development and Cultural Change, 49(4), 769-792.

Swinton, S.M., Quiroz, R.A., Paredes, S., Reinoso, J.R., and Valdivia, R., (2001). Using farm data to validate agroecological zones in the Lake Titicaca basin, Peru Proceedings - The Third International Symposium on Systems Approaches for Agricultural Development. Available from: https://cipotato.org/site/inrm/home/publicat/99oth83.pdf

Swinton, S.M., Quiroz, R, Paredes, S., Reinoso, J.R. and Valdivia, R.(1999). Using farm data to validate agro-ecological zones in the Lake Titicaca Basin, Peru. SAADIII Symposium: Systems Approaches for Agricultural Development, Lima, Peru, International Potato Center.

Swinton, S. M., \& Quiroz, R. (2003). Poverty and the deterioration of natural soil capital in the Peruvian Altiplano. Environment, Development and Sustainability, 5(3), 477-490.

Tapia, M. (1985). Pastors naturales del Altiplano de Peru y Bolivia. Programa de Investigación Zona Andina. Publicacion Miscelanea Nro 85, Quito, Ecuador: Instituto Interamercano de Ciencias Agrícolas -IICA. Editorial Ecuadro.

Tapia, M. E., \& Flores, J. A. (1984). Pastoreo y pastizales de los Andes del Sur del Peru. Lima, Peru: Programa Colaborativo de Apoyo a la Investigacion en Rumiantes Menores.

Tapia, M. (1996). Ecodesarrollo en los Andes Altos. Lima Perú: Fundación Friedrich Ebert.

Tapia, M. (2008). La ganadería en el Altiplano de Puno. Una visión, técnica, económica, social y ambiental. In G. Damonte, B. Fulcrand, \& R. Gomez (Eds). Peru: El problema agrario en debate, SEPIA XII. Tarapoto, Perú: Seminario Permanente de Investigacion Agraria.

Taylor, J. (2006). Grassland policy, Privatisation and new ecology in Inner Mongolia. Paper presented at the Eleventh Conference of the International Association for the Study of Common Property. Survival of the Commons: Mounting Challenges and New Realities, Bali, Indonesia. 
Turin, C. and Valdivia, C. (2012). Off-farm work in the Peruvian Altiplano: Seasonal and geographic considerations for agricultural and development policies. In R. Sabates Wheeler \& S. Devereux, (Eds.), Seasonality, rural livelihoods and development, pp 145-160. Routledge. UK.

UNCOD. (1977). Ecological Change and Desertification (Conference Document A/Conf. 74/7): United Nations Conference on Desertification.

Upton, C. (2005). Institutions in a pastoral society: Processes of formation and transformation in postsocialist Mongolia. Comparative Studies of South Asia, Africa and the Middle East, 25(3) 584-599.

Urday Concha, F. (1989). Uso de la tierra, visión y estrategia campesina del manejo de pastosnaturales campesinas. Crianza de llamas y alpacas. Lima: PRATEC.

Urday Concha, F. \& Sotomayor Berrio, M. (1989). Uso de la tierra, clasificación campesinas y pastoreo en comunidades Aymaras. Informe Tecnico Nro 18. Proyecto Alpacas.. Serie: Pastos. Puno, Peru: INIAA, CORPUNO-COTESU/IC.

Valdivia, C. (1996). Diversification as a risk management strategy in an Andean Agropastoral community. American Journal of Agriculture Economics, 78(5), 1329-1334.

Valdivia, C. (2004). Andean livelihood strategies and the livestock portfolio. Culture \& Agriculture, 26(1\&2), 69-79.

Ventura, O. (2003). Valoración económica de los bienes y servicios ambientales de las Ppraderas Altoandinas en el Perú-Políticas para el manejo sostenible. Paper presented at the III Congreso Latinoamericano de Manejo de Cuencas Hidrográficas.

Wessels, K. J., Prince, S. D., Carroll, M., \& Malherbe, J. (2007). Relevance of rangeland degradation in semiarid northeastern South Africa to the nonequilibrium theory. Ecological Applications, 17, 815-827.

World Food Programme (WFP) (2010). Perú: Mapa de Vulnerabilidad a la Inseguridad Alimentaria .

Williams, D. M. (1996). Grassland enclosures: Catalyst of land degradation in inner Mongolia. Human Organization, 55(3), 307. 
Yin, R. (1994). Case study research. Design and methods, Second Edition. Applied Social Research Methods Series, Volume 5. Los Angeles, CA: Sage.

Zhaoli, Y., Ning, W., Dorji, Y., \& Jia, R. (2005). A review of rangeland privatisation and its implications in the Tibetan plateau, China. Nomadic Peoples, 9, 31-51.

Zimmerer, K. S. (1996). Discourses on soil loss in Bolivia. Sustainability and the search for socioenvironmental "middle ground". In R. Peet \& M. Watts (Eds.), Liberation ecologies. Environment, development, social movements (pp. 110124). London: Routledge.

Zimmerer, K. S., \& Bassett, T. J. (2003). Political ecology. An integrative approach to geography and environment-development studies. New York: The Guilford Press. 


\section{APPENDICES}

\section{APPENDIX A}

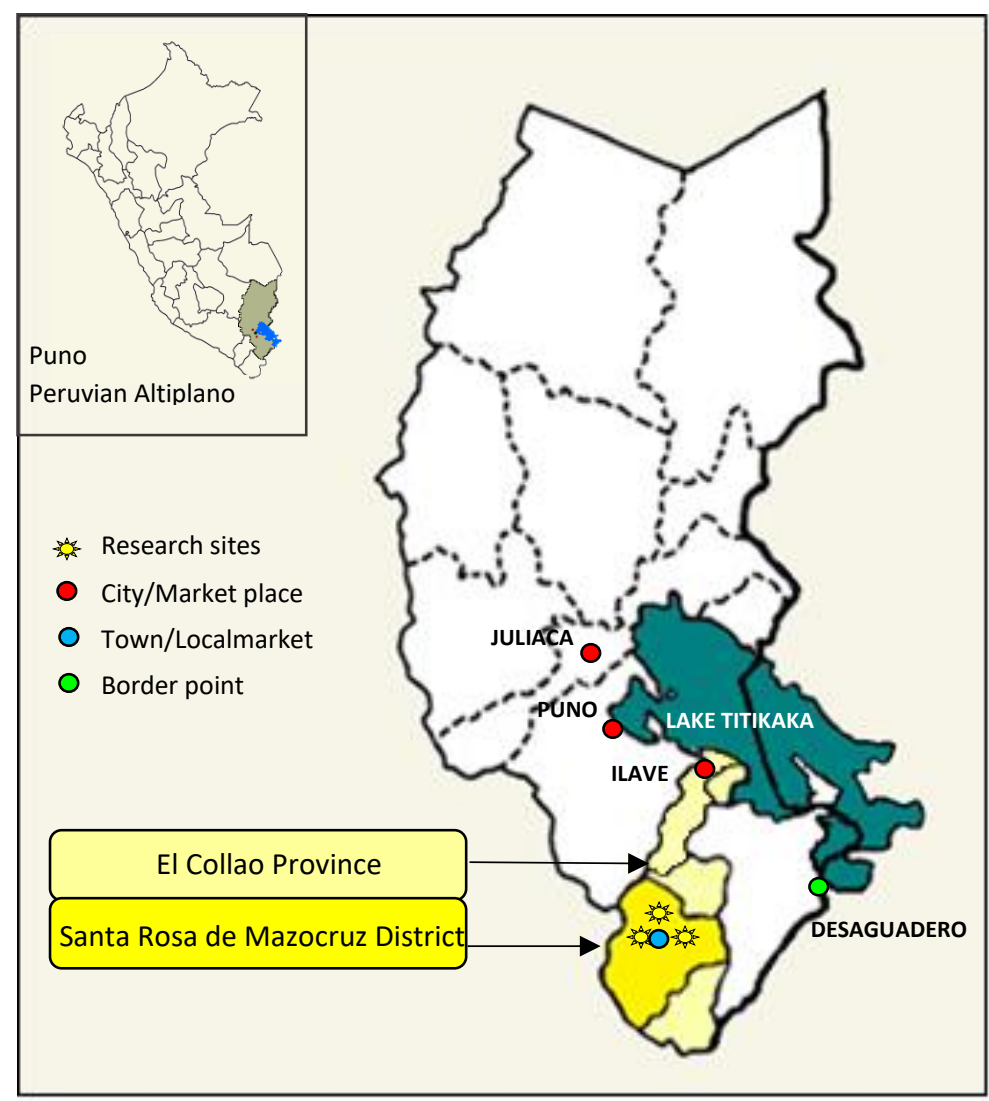

Figure 2. Location of the southern province of El Collao and its southern district of Santa Rosa de Mazocruz 


\section{APPENDIX B}

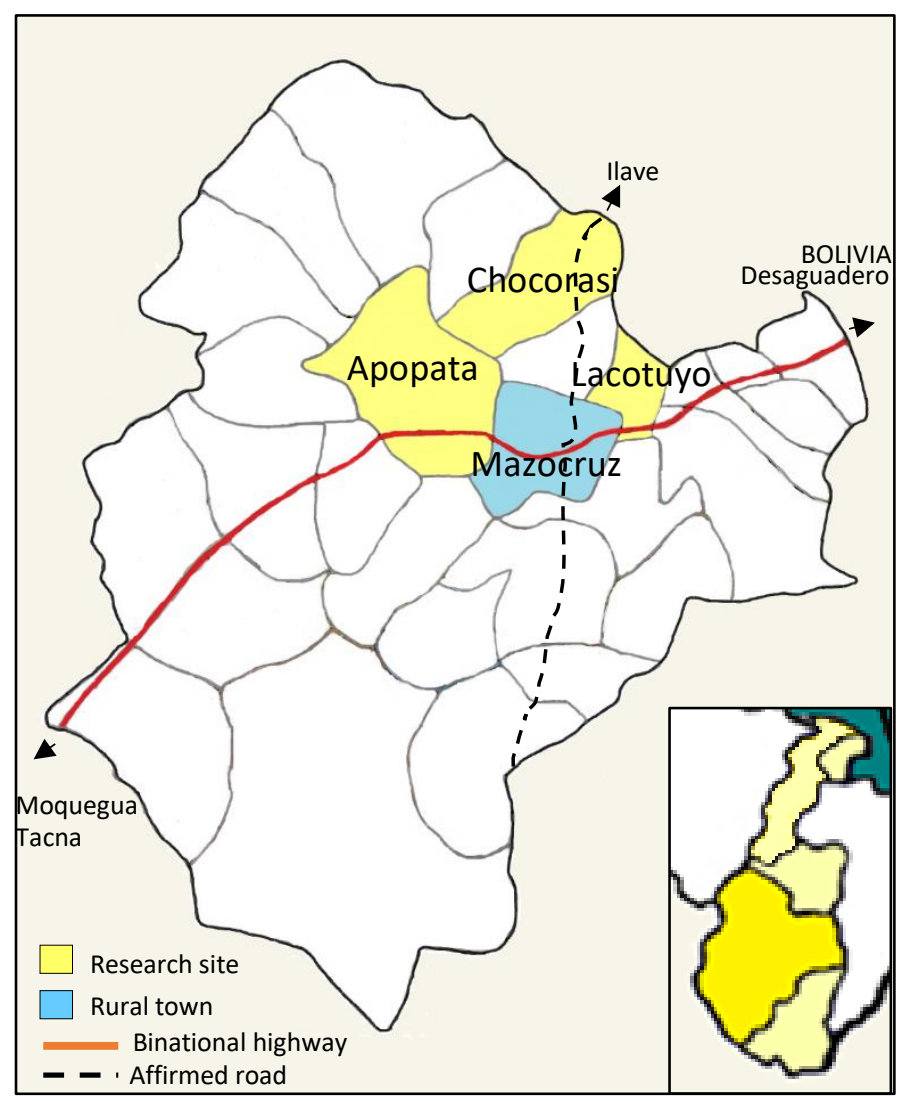

Figure 3. Location of Pastoralist Communities Apopata, Chocorasi and Lacotuyyo in Mazocruz Municipio. 


\section{APPENDIX C}

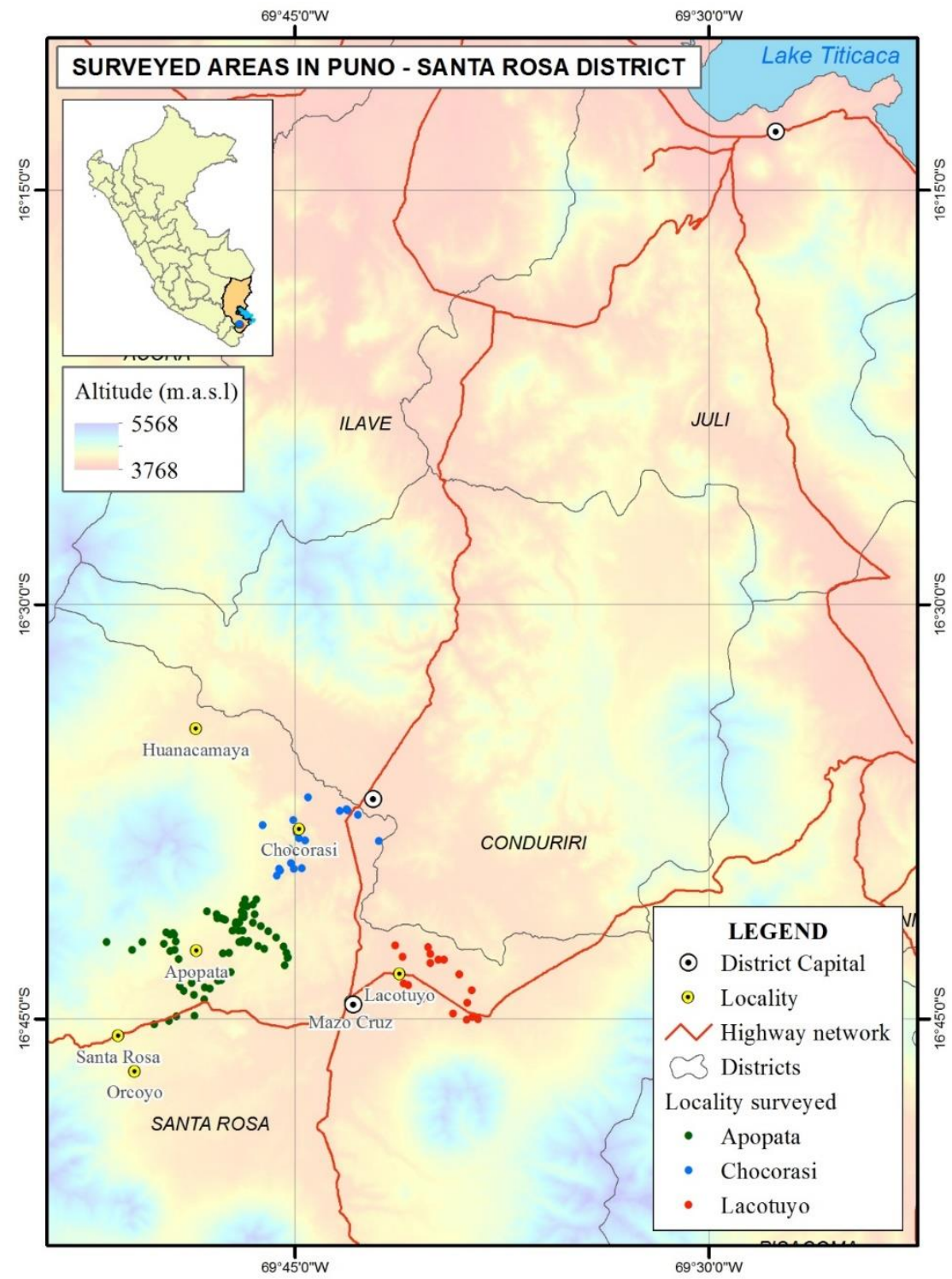

Figure 4. Distribution of household interviewed in Mazocruz Municipio 


\section{APPENDIX D}

Question list to pastoralists (translated from Spanish):

Number. Time

Place: Community of Apopata / Chocorasi / Lacotuyo.

Specific name of the place where we are now within the community:

Household information

1. What is your name, age and place of birth?

2. (If married) What is the name of your spouse, age, place of birth?

3. (If applicable) How many households live here?

4. How many family members live with you here permanently?

5. Do any of them leave the community regularly during the year? If so, how many? For what reason? In which season? For how long do they leave the household and community?

6. How many family members live abroad? Where do they live? What are they doing? Do they depend economically from you in any way? Do they contribute economically with the household? In which way?

7. Who in the family is a registered member in the community?

8. Besides livestock, what other activity do you do to live?

9. In order of importance, which are the main means of living for your household?

Information of grazing sites

10. Where do you graze your herd within the community?

11. (If applicable) Where do you graze your herd out of the community? Why there?

12. Under which condition do you use those grazing sites? Owner/renter/sharing/borrowed/shepherd/other

13. For how long have you been using those grazing sites?

14. Do you know the extension of each grazing site? If so, which is the extension of each one?

15. (If applicable) If you are the owner, do you have documents to demonstrate that you own this land? Which one?

16. As the owner, have you rented or lend this or other property to others anytime? If so, to whom and which is the relationship with this person? When and why?

17. (If applicable) If you are not the owner, who is the owner? And which relationship do you have with the owner? Relative (mother, father, sister brother, etc) /friend/neighbor/anybody/other.

18. If you are not the owner, in which way do you pay the access to the land you use for grazing your herd? Money/animals/grasslands/labor/groceries/favors/other. 
19. As user of these properties, are your borders defined?

20. Do you have any problem with your neighbors?

21. As owner, have you already divided the land for your children as inheritance? If not, when do you think to do it or what other plans do you have for your property?

Herd information

22. How many animals compose your herd per type of animal? How many alpacas, lamas, sheep and cattle?

23. Who are the owners of those animals? Which relationship do you have with the owners? What do you receive in return to take care of other's animals? Money/animals/grasslands/labor/groceries/favors/other.

24. How are the herd organized to be grazed, in one herd or by type/class/age?

25. Which household member is in charge of the grazing of the herd(s) the most part of the year? Do you make use of extra household labor (shepherd) in any case? If so, when?

26. When do the birth, matting, shearing and culling seasons happen?

27. Which household members participate in those activities? Do you make use of extra household labor in any of those seasons? If so, in which?

28. Do your animals get sick regularly? If so, which are the main sicknesses that affect the herd of alpacas, lamas, sheep, and cattle?

29. What do you think is main cause of those sicknesses of your alpacas, lamas, sheep, and cattle?

30. What do you do when an animal get sick?

Knowledge, management practices related to grazing sites

31. According the different type of grasslands: "bofedal" (wetlands of plain), "pampa seca" (grasslands of plain), "ladera" (grasslands of hill), "cerro" (grasslands of steppe), how is composed each grazing site you use?

32. Do you "reserve" any of those types of grasslands to be used at the end of the dry season? When? For how long?

33. Do you water the grasslands? If son? Which ones?

34. Do you add manure to the grasslands?

35. Do you get bigger your bofedales?

36. Do you introduce some pastures? Which ones?

37. If you would evaluate the present condition of your grasslands, which grade would you give them? Excellent, good, fair, poor, or very poor.

38. How were your grasslands when you were a child?

39. Do you think your grasslands have changed over the time? If yes, what have changed? What do you think is causing those changes?

40. Have you changed the way to use the grasslands over the time? 
41. Have you always use fences to limit your land from your neighbors?

42. Have you always use "ahijaderos" (enclosures) to reserve grasslands for the dry season?

43. Does the inclusion of the use of fences and ahijaderos have been favorable or unfavorable for you? Explain your answer.

44. Do you know if the community at the present time has rules to manage grasslands, water and herd? If so, which are they?

45. Do you remember if the community had rules to manage grasslands, water and herd when you were younger? If so, which were they?

46. In your opinion, who (person or institution) should be responsible for the surveillance of the grasslands management?

47. (if applicable) Do you have access to forage? If so which ones (barley, oat, alfalfa, collected ankaria, etc.)?

48. What is the destiny of the forage production (barley, oat, etc): consumption, sale, or barter and exchange?

49. If the main destiny of forage is animal consumption, in order of preference which animals do you feed with the forage? Why this order of preference?

50. (If applicable) If you have access to crop land, where it is?

51. In order of importance, what do you cultivate (potato, quinua, other, etc)?

52. Which is the destiny of the crop production (potato, quinua, corn, canihua, etc): consumption, sale, or barter and exchange?

53. Which is the destiny of the livestock production (alpaca fiber, alpaca meat, lama meat, sheep meat, sheep wool): consumption, sale, or barter and exchange?

54. To what water sources do you have access? Which of them you use to drink, which for the animals, and which to water your grasslands? Are they good or they are polluted? Are they enough or not during the year? 


\section{APPENDIX E}

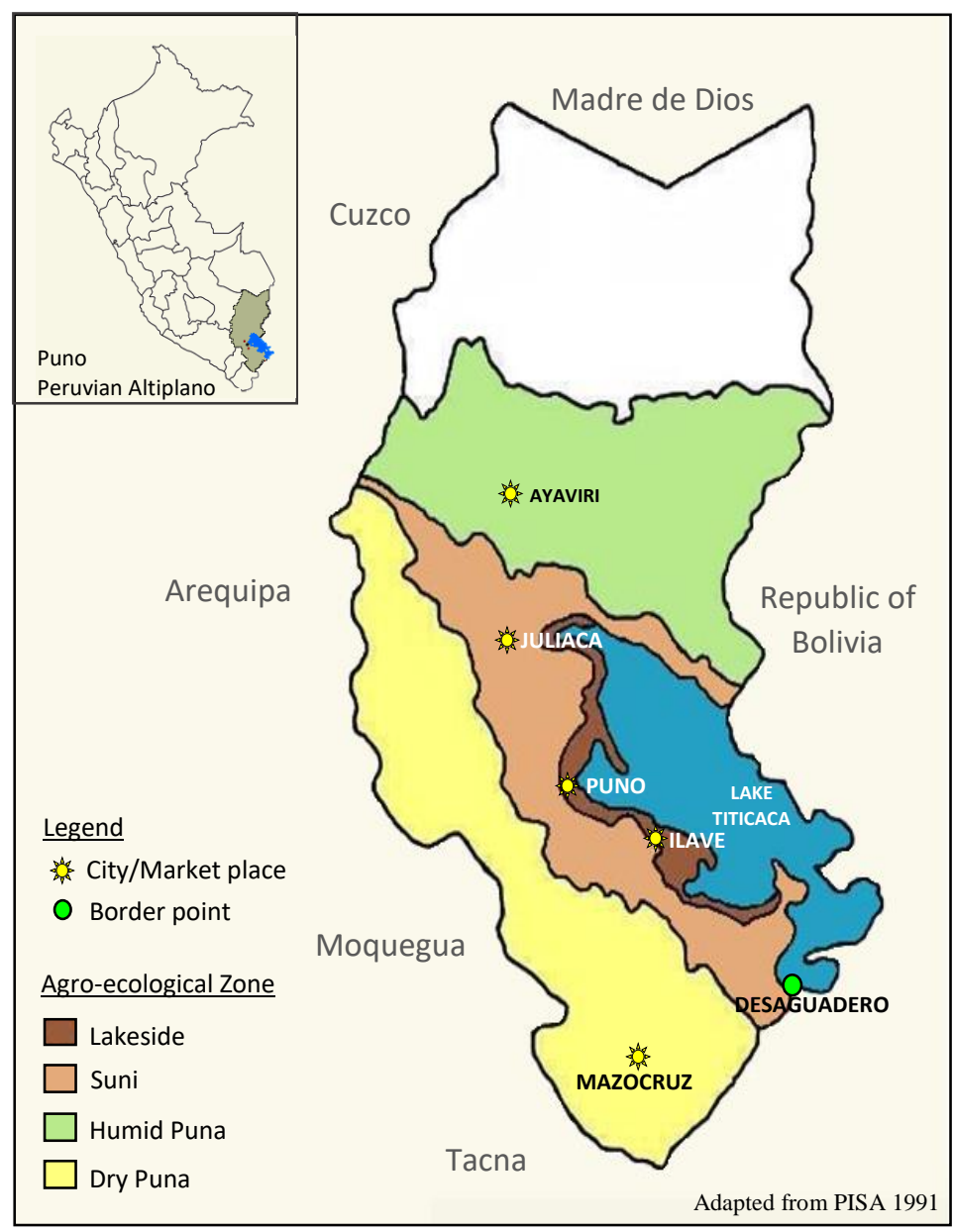

Figure 1. Agro-ecological zones of the Peruvian Altiplano 
VITA

Cecilia Turin was born in Lima, Peru. She is third daughter of a kindergarten teacher and a mining engineer, descendants of Sierra Central migrants who keep alive their family bonds. During her childhood, from her visits to her father in his workplace, she became interested in puna ecoregion and in its inhabitants, poor pastoralists and farmers, natural resources, and rangelands. For this reason, she studied Animal Science in the Agrarian University La Molina (UNALM), where she graduated in 1995.

Since 1996 she was involved in research and extension projects to improve animal production systems in the high Andes. In 2002 she was granted a scholarship by the Dutch Royal Government for her master studies in Agricultural Extension in Larenstein University of the Netherlands. She returned to Peru and started teaching at UNALM in 2004. As a professor she had the opportunity to join a MU research team that conducted a climate change SANREM CRSP project in the Peruvian and Bolivian Altiplano. In 2007 she received a Fulbright scholarship for her doctoral studies and initiated her program the same year. In 2010 she conducted her doctoral research in the Altiplano region until 2011.

She returned to teach at UNALM in 2012 and became Director of an action research institute for the sustainable small holder production systems. From 2013 to 2017 she worked as gender and climate change adaptation expert for the CGIAR International Potato Center. She coordinated, monitored and evaluated gender-oriented climate change research projects in south Asia and Latin America. In 2017 she become international 
consultant on gender and climate change for World Bank and FAO. In 2018 she worked as a M\&E specialist for the Ministry of Agriculture of Peru and Interamerican

Development Bank to enhance capacity building programs tailored for National Agrarian Innovation Institute scientists and extensionists. 